Daniele Ramalho Serra

\title{
Resposta de Gracilariopsis tenuifrons (Gracilariales - Rhodophyta) a estímulos de irradiância in vitro
}

Gracilariopsis tenuifrons (Gracilariales - Rhodophyta) response to irradiance stimuli in vitro 
Daniele Ramalho Serra

\section{Resposta de Gracilariopsis tenuifrons (Gracilariales - Rhodophyta) a estímulos de irradiância in vitro}

Dissertação apresentada ao Instituto de Biociências da Universidade de São Paulo, para obtenção de título de mestrado em ciências na área de Botânica.

Orientadora: Fanly Fungyi Chow Ho

São Paulo 


\section{Ficha Catalográfica}

Serra, D.R.

Resposta de Gracilariopsis tenuifrons (Gracilariales Rhodophyta) a estímulos de irradiância in vitro/ Daniele Ramalho Serra. São Paulo: D.R. Serra, 2013. 97 pp.

Dissertação (Mestrado) - Instituto de Biociências da Universidade de São Paulo. Departamento de Botânica, 2013

1. PAR 2. Óxido nítrico 3. Atividade antioxidante 4.Gracilariopsis tenuifrons. Universidade de São Paulo. Instituto de Biociências. Departamento de Botânica.

\section{Comissão Julgadora:}

Prof (a). Dr(a).

Prof (a). Dr(a).

Prof (a). Dr(a). Fanly Fungyi Chow Ho

(Orientadora) 
O findar de uma longa etapa de persistência e insistência... 


\section{Agradecimentos}

Embora haja uma enorme parcela de solidão na elaboração de um trabalho, ninguém consigue fazer tudo sozinho... Então agradeço:

A Deus causa primária de tudo.

À FAPESP pelo apoio financeiro. E às pessoas da FAPESP, sempre tão solícitas e interessadas em resolver problemas e dúvidas.

À minha orientadora Fungyi Chow, a quem tenho imensa gratidão por ter enfrentado a desconfiança, aceitado o desafio de me orientar e pelo muito aprendido.

Ao pessoal da Fitoquímica laboratório ao qual acabei me associando...

À equipe do Laboratório de Biologia Celular da USP: Júlia Bolanhos, Carminha, Roberta e principalmente às Professoras Eny e Claudete, à Amanda, às Carols, Natália Piscirilo, Sâmila Lopes e André tão atenciosos em ensinar sobre o uso dos equipamentos, a rotina do laboratório e segundo Carol Bueno - "tirarem dúvidas muito boas".

À Adriana e Viviane do Lafieco que foram tão prestativas e atenciosas quando solicitadas.

À Sílvia do laboratório de Biologia Molecular de Plantas por sua correta indicação. E à Tatiana Correa do GATE-LAB pelo desvelo em responder aos meus questionamentos e préstimos relativos à aquisição das placas.

Ao pessoal do Laboratório de Química e Biologia Molecular de Algas, particularmente Cícero e Daniel Andreguetti que muito amistosamente me recebeu e deu início ao entendimento do protocolo de DPPH.

Ao Rosário parte indispensável do LAM-USP, e que não sabe quanto ânimo transmite.

À Carol Franco, À Cíntia Oliveira, Henrique Lauand que junto com Rosário formaram o melhor time de técnicos do LAM, sempre prontos a ajudar.

Ao Iago, pelos toques e conversas, sempre animadas.

Ao Willian pelo auxílio de uma comprida sessão de corte, desvelo sempre que solicitado e por saber transformar sempre o meu humor, me arrancando risadas.

À Priscila, que me ensinou muito e que aos poucos se tornou também parceira e amiga após muitas sessões intermináveis de cortes de ápices, longas viagens pra casa, discussões e conversas presenciais e virtuais, sobretudo lições.

Aos velhos LAMIGOS: Amanda, Bia Torrano, Carol da Valeria, Cíntia Iha, Carlos Amâncio (camuflagem do Lagosta), EEmmaannuueelle(a) Costa (desculpe Manu, não resisti), Fábio Nauer, Fabíola, Henrique Lauand, José Barufi, Lígia Ayres, Marcela 
Amaral, Natália Guimarães, Nelso Navarro, Rafa, Spock e Kauê. A presença de vocês foi muito importante pra mim!!!! E aos novos LAMIGOS: Mário, Carol Azevedo, Janaína, Talita, e Gabriela, novos, mas não menos importantes à minha formação.

À Suzi e D. Maria pelos cumprimentos matinais tão efusivos e revigorantes, além das divertidas conversas.

\section{A todas as pessoas do IB-USP, que conviveram e de alguma forma auxiliaram,} fosse em resoluções, fosse em desvelo, sorriso ou cumprimento.

À Viviane Martins e Alexandre Lucas, meus irmãos de afinidade, que apesar da distância, sempre que puderam estiveram presentes.

À toda minha família, em especial meus pais Francisco e Elba, que mesmo longe, faziam-se presentes, e como dito antes: o princípio de tudo. Aos meus avós maternos Francisco e Nemésia, que sempre ao me falar, incentivam: "nunca deixe de estudar minha filha" e também os paternos Ângelo e Dioclécia (in memorian). Ao meu irmão Fernando e sua companheira Paula, que tantas vezes se dispuseram para mim. Minha irmã Denise que se orgulha sempre. Além deles, o mais novo e não menos importante, Francisco, que tantas vezes provocou lágrimas e risadas: "Titia brigado, de nada, até logo, tchau!"

À família Leati Pelaes, que me acolheu como membro e que tão simplesmente preencheu o vazio, permitindo caminhada mais tranqüila nessa grande e fria cidade. Em especial à D. Cida, Seu Dorva e Patrícia, que além do incentivo, compreensão, atenção e carinho deram grande suporte estrutural na execução do trabalho.

A Marcos, amigo, companheiro, amor... Que acompanhou diretamente e participou em todos os momentos, ajudando de infinitas formas, principalmente quando tudo se encontrava mais difícil...

Todos vocês foram peças importantes no cumprimento deste trabalho, cada palavra, ato, sorriso foi de extrema relevância para que tudo fosse feito, talvez não com a minúcia desejada, mas a conseguida.

\section{Muitíssimo OBRIGADA!}


Índice

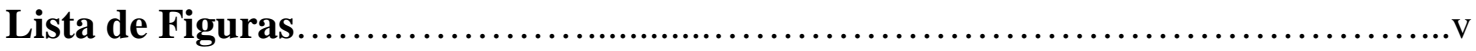

Lista de Abreviaturas: ......................................................

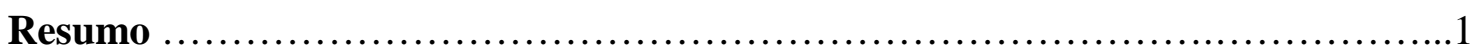

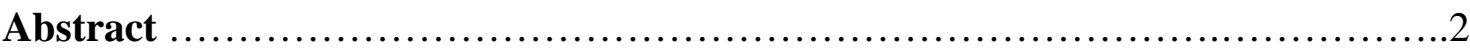

1. Introdução geral

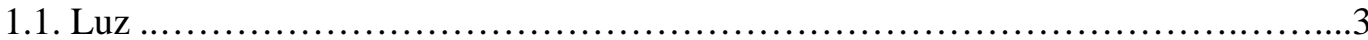

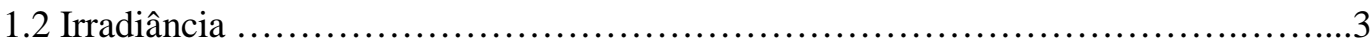

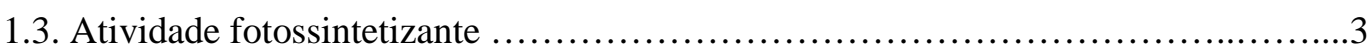

1.4. Pigmentos de Rhodophyta ................................................. 4

1.5. Fotoinibição .......................................................................

1.6. Espécies ativas de oxigênio (ROS) e espécies reativas de nitrogênio (RNS-NO)......8

1.7. Sistemas antioxidantes ...................................................... 10

1.8. Substâncias fenólicas ........................................................11

1.9. Gracilariopsis tenuifons ................................................... 12

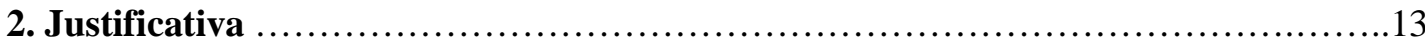

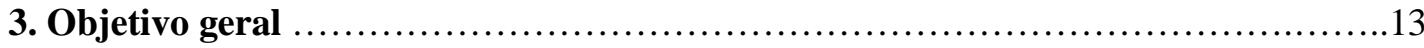

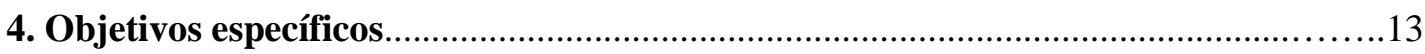

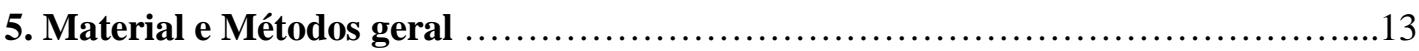

5.1. Material biológico .............................................................

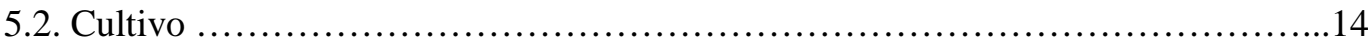

5.3. Delineamento experimental .............................................. 14

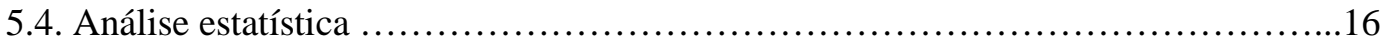

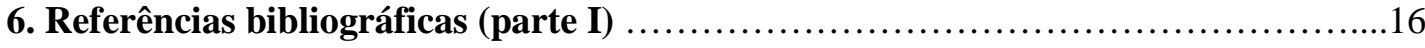

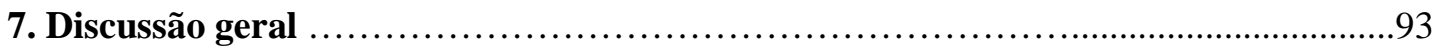

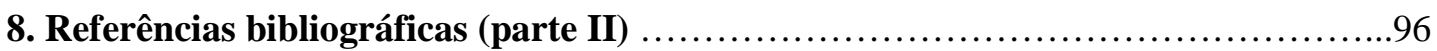


Capítulo I: Efeito da alta irradiância em Gracilariopsis tenuifrons (GracilarialesRhodophyta) sobre a taxa de crescimento, carbono, hidrogênio e nitrogênio tissulares, pigmentos e proteínas solúveis totais em laboratório

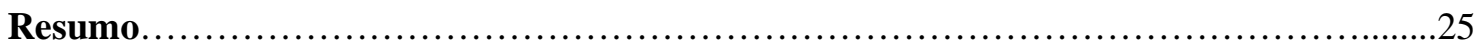

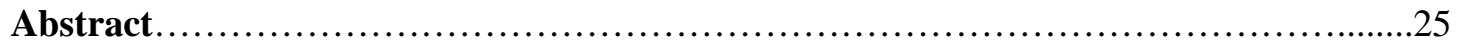

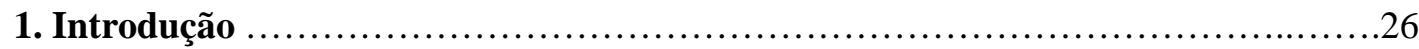

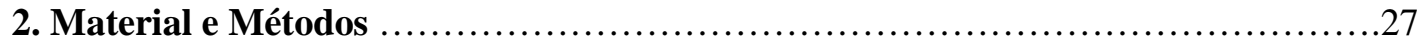

2.1. Delineamento experimental...........................................27

2.2. Taxa de crescimento (TC) e quantificação tecidual de carbono, hidrogênio e

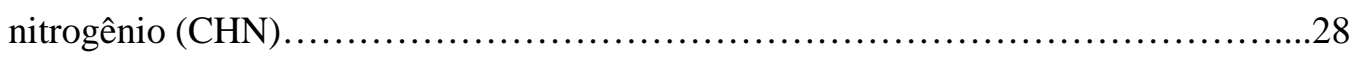

2.3. Pigmentos fotossintetizantes e proteínas solúveis totais (PST)....................29

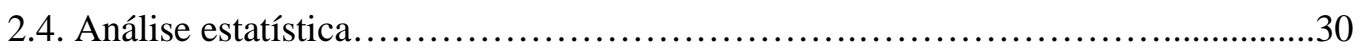

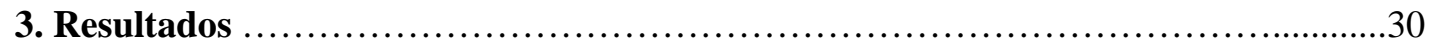

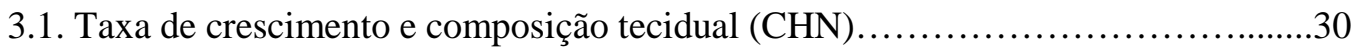

3.2. Composição pigmentar e teor de proteínas solúveis totais............................35

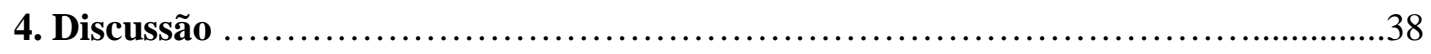

4.1. Taxa de crescimento e composição tecidual .......................................38

4.2. Composição pigmentar e teor de proteínas solúveis totais...........................41

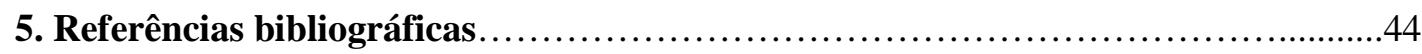


Capítulo II: Substâncias fenólicas e atividade antioxidante total de Gracilariopsis tenuifrons (Gracilariales, Rhodophyta) sob alta PAR em laboratório.

Resumo. .50

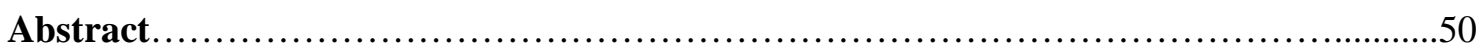

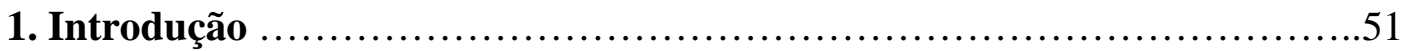

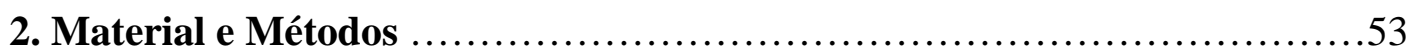

2.1. Delineamento experimental...................................53

2.2. Substâncias fenólicas totais.......................................53

2.3. Atividade antioxidante total.........................................54

2.2.1. Consumo do DPPH.........................................54

2.2.2. Sistema $\beta$-caroteno ácido linoleico.............................55

2.3. Análise estatística.................................................56

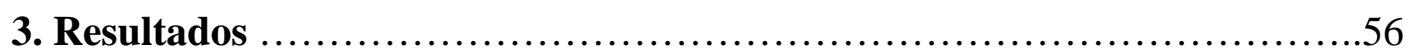

3.1. Substâncias fenólicas totais......................................56

3.2. Atividade antioxidante total....................................57

3.2.1. Consumo do DPPH e $\beta$-caroteno ácido linoleico..................57

3.2.2 Sistema $\beta$-caroteno ácido linoleico..............................57

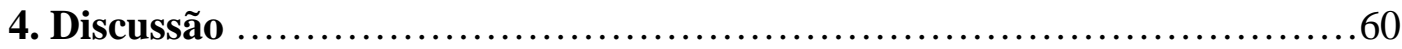

4.1. Substâncias fenólicas totais.........................................60

4.2. Atividade antioxidante total......................................62

4.2.1. Consumo do DPPH..........................................62

4.2.2. Sistema $\beta$-caroteno ácido linoleico...........................64

5. Referências bibliográficas..................................................65 
Capítulo III: Espécies reativas de oxigênio (ROS) e óxido nítrico (NO) em Gracilariopsis tenuifrons (Gracilariales, Rhodophyta) sob estímulo de irradiância em laboratório

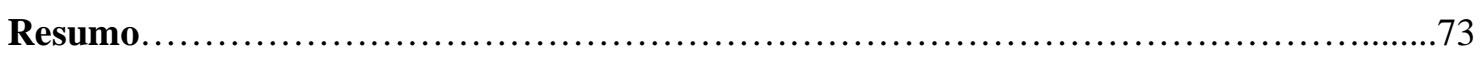

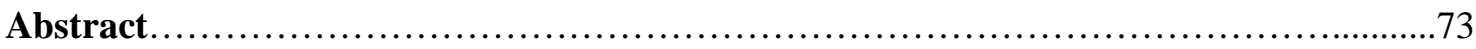

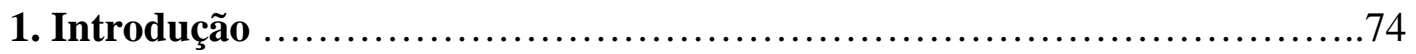

2. Material e Métodos .............................................. 76

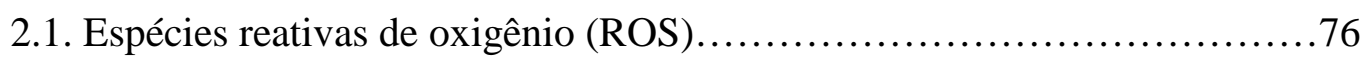

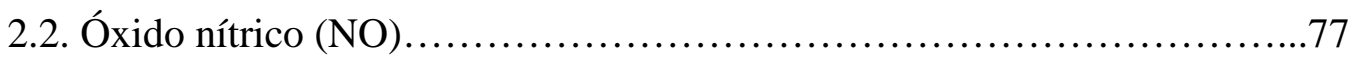

2.3. Análise estatística................................................78

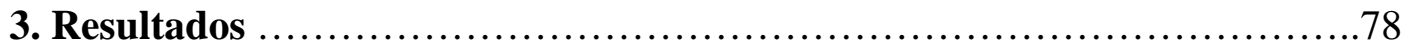

3.1. Espécies reativas de oxigênio (ROS) .............................78

3.2. Óxido Nítrico (NO) ............................................. 79

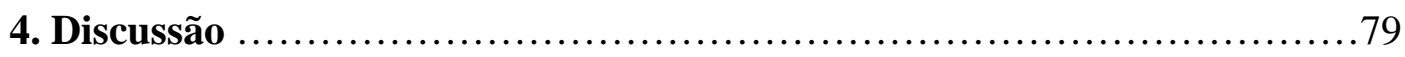

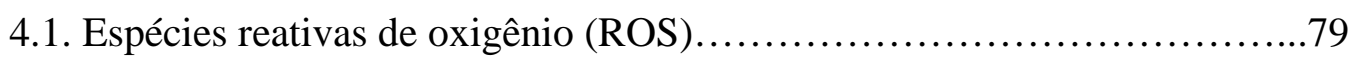

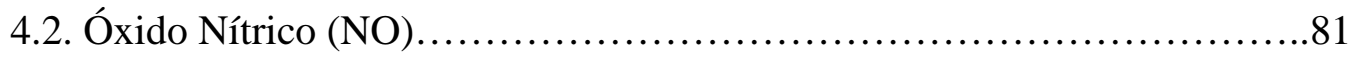

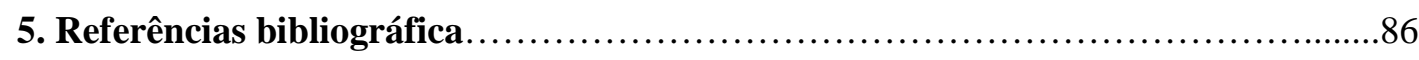


Lista de Figuras:

Figura 1: Esquema das radiações eletromagnéticas de frequências curtas e longas.

Figura 2: Representação simplificada do aparato fotossintetizante e fluxo de elétrons no processo de fotossíntese, enfatizando a captação de luz e transporte de energia.

Figura 3: Esquema representativo dos períodos de coleta durante o fotoperíodo e durante a noite.

Figura 4: Aspecto geral dos ápices de Gracilariopsis tenuifrons após o período experimental

Figura 5: Imagens de Gracilariopsis tenuifrons após o período experimental, detalhando comprimento dos talos e alterações provocadas pela luz.

Figura 6: Imagens de Gracilariopsis tenuifrons após período experimental, em microscópio.

Figura 7: Taxa de crescimento; porcentagem de biomassa seca; e úmida; proporção carbono e nitrogênio; teor tissular de carbono; teor tissular de hidrogênio e teor tissular de nitrogênio de Gracilariopsis tenuifrons submetidas às irradiâncias de $60 \mu \mathrm{mol}$ de fótons. $\mathrm{m}^{-2} \cdot \mathrm{s}^{-1}$ e $600 \mu \mathrm{mol}$ de fótons. $\mathrm{m}^{-2} \cdot \mathrm{s}^{-1}$ por uma semana.

Figura 8: Teor de pigmentos fotossintetizantes e proteínas solúveis totais de amostras de Gracilariopsis tenuifrons submetidas às irradiâncias de $60 \mu \mathrm{mol}$ de fótons. $\mathrm{m}^{-2} \cdot \mathrm{s}^{-1} \mathrm{e} 600 \mu \mathrm{mol}$ de fótons. $\mathrm{m}^{-2} \cdot \mathrm{s}^{-1}$ por uma semana.

Figura 9: Teor de substâncias fenólicas totais de Gracilariopsis tenuifrons submetidas a uma semana a $60 \mu \mathrm{mol}$ de fótons. $\mathrm{m}^{-2} \cdot \mathrm{s}^{-1} \mathrm{e} 600 \mu \mathrm{mol}$ de fótons. $\mathrm{m}^{-2} \cdot \mathrm{s}^{-1}$.

Figura 10: Atividade antioxidante de amostras de Gracilariopsis tenuifrons submetidas a uma semana a $60 \mu \mathrm{mol}$ de fótons. $\mathrm{m}^{-2} \cdot \mathrm{s}^{-1} \mathrm{e} 600 \mu \mathrm{mol}$ de fótons. $\mathrm{m}^{-2} \cdot \mathrm{s}^{-1}$.

Figura 11: Porcentagens de inibição do DPPH e de proteção do sistema $\beta$ caroteno/ácido linoleico de diferentes concentrações de padrões e de amostras de Gracilariopsis tenuifrons submetidas a uma semana a $60 \mu \mathrm{mol}$ de fótons. $\mathrm{m}^{-2} \cdot \mathrm{s}^{-1}$ e $600 \mu \mathrm{mol}$ de fótons. $\mathrm{m}^{-2} \cdot \mathrm{s}^{-1}$.

Figura 12: Fluorescência relativa de espécies reativas de oxigênio (ROS) de amostras de Gracilariopsis tenuifrons após uma semana sob $60 \mu \mathrm{mol}$ de fótons. $\mathrm{m}^{-2} . \mathrm{s}^{-1}$ e $600 \mu \mathrm{mol}$ de fótons. $\mathrm{m}^{-2} \cdot \mathrm{s}^{-1}$.

Figura 13: Fluorescência relativa de oxido nítrico (NO) de amostras de Gracilariopsis tenuifrons após uma semana sob $60 \mu \mathrm{mol}$ de fótons. $\mathrm{m}^{-2} \cdot \mathrm{s}^{-1}$ e $600 \mu \mathrm{mol}$ de fótons. $\mathrm{m}^{-2} \cdot \mathrm{s}^{-1}$.

Figura 14: Representação esquemática de modelo proposto para ilustrar o efeito da alta luminosade no metabolismo de Gracilariopsis tenuifrons e sua relação com o aumento de NO. 


\section{Lista de Abreviaturas:}

APX: $\quad$ ascorbato peroxidase

BHA: $\quad$ hidroxianisol butilado, do inglês, butylated hydroxyanisole

CHN: $\quad$ carbono, hidrogênio e nitrogênio tissulares

$\mathrm{CO}_{2}$ : $\quad$ gás carbônico

DAF-FM-DA: 4-amino-5-metilamino-2',7'-difluorofluoresceina diacetato

DNA: ácido desoxirribonucléico, do inglês, deoxyribonucleic acid

DPPH: 2,2-difenil-1-picril-hidrasil

GR: $\quad$ glutationa redutase

H2DCF-DA: $\quad$ 2',7'- diclorodihidrofluoresceína diacetato

MAAs: $\quad$ aminoácidos tipo micosporina, do inglês, micosporin like amino acids

MF: (bio)massa fresca

MS: $\quad$ (bio)massa seca

$\mathrm{N}_{2} \mathrm{O}$ : $\quad$ óxido nitroso

NH $_{3}$ : amônia

NO: $\quad$ óxido nítrico, do inglês, nitric oxide

$\mathrm{NO}_{2}^{-}: \quad$ nitrito

$\mathrm{NO}_{3}^{-}: \quad$ nitrato

NOS: $\quad$ óxido nítrico sintase, do inglês, nitric oxide synthase

NR:

PAR:

PSI:

PSII:

RNS:

ROS:

nitrato redutase, do inglês, nitrate reductase

radiação fotossinteticamente ativa, do inglês, Photosynthetically Active Radiation

SNP:

fotossistema I, do inglês, Photosystem I

fotossistema II, do inglês, Photosystem II

espécies reativas de nitrogênio, do inglês, Reactive nitrogen species

espécies reativas de oxigênio, do inglês, Reactive oxygen species

SOD: sódio nitroprussido, do inglês, sodium nitroprusside

ufr: superóxido dismutase

UV/UVR:

XOR: unidade de fluorescência relativa radiação ultra violeta xantina óxido redutase, do inglês, xanthine oxidoreductase 


\section{Resumo}

Algas são seres adaptados às constantes e bruscas mudanças abióticas característica do ambiente marinho, causadoras de estresse e responsáveis por alterações fisiológicas capazes de danificar funções biológicas básicas. O excesso de PAR pode causar estresse oxidativo em algas marinhas resultando na oxidação de pigmentos e proteínas, comprometendo o crescimento e conduzindo a alterações que podem levar à morte. Esse estresse oxidativo conduz ao acúmulo de ROS e NO que de forma direta ou indireta prejudicam o andamento metabólico do organismo. Para mitigar e controlar os efeitos danosos desses radicais, o organismo conta com diversas defesas antioxidativas, como aumento de compostos fenólicos, degradação de pigmentos fotossintetizantes, disponibilização de polissacarídeos e espessamento da parede e ativação de sistemas enzimáticos e não enzimáticos antioxidativos. Deste modo, com o objetivo de entender o funcionamento da fisiologia de Gracilariopsis tenuifrons em resposta a intensa irradiância foram avaliados teor de pigmentos fotossintetizantes, proteínas solúveis totais, carbono, hidrogênio e nitrogênio tissulares, taxa de crescimento, quantidade de substâncias fenólicas totais, atividade antioxidante total e peroxidação lipídica e produção de ROS e NO. Assim sendo, ápices de $3 \mathrm{~cm}$ da macroalga vermelha $G p$. tenuifrons foram expostos a dois regimes de irradiância $\left(60 \mu \mathrm{mol}\right.$ fótons. $\mathrm{m}^{-2} . \mathrm{s}^{-1}$ e 600 $\mu \mathrm{mol}$ fótons. $\left.\mathrm{m}^{-2} . \mathrm{s}^{-1}\right)$ durante uma semana e coletadas durante o dia e a noite. $\mathrm{O}$ excesso de irradiância provocou respostas de estresse oxidativo, que resultaram em significativa redução de pigmentos fotossintetizantes, proteínas solúveis e nitrogênio tissular, elevação do carbono e hidrogênio tissulares, das substâncias fenólicas, da atividade antioxidante total e da quantidade de NO. Gracilariopsis tenuifrons demonsmostrou efetiva ativação de diversos sistemas antioxidativos ao estímulo de elevada irradiância. Esta indução de atividade antioxidante pode ser melhor explorada em aplicações para a indústria alimentícia, medica, farmacêutica e cosmética. Também foram relacionados protocolos metodológicos e resultados inovadores em relação à formação de NO em condições de estresse, que poderão auxiliar abordagens fisiológicas no Laboratório de Algas Marinhas "Édison José de Paula" e outros grupos de pesquisa nacionais e internacionais. 


\begin{abstract}
Algae are organisms adapted to constant and abrupt abiotic changes characteristic of marine environment, that cause stress and are responsible for physiological alterations able to damage basic biological functions. The intense PAR can produces oxidative stress on seaweed, resulting in oxidation of pigments and proteins, affecting the growth and driven to alterations that can conduce to cell death. This oxidative stress leads ROS and NO accumulation that directly or indirectly prejudice the metabolic fitness of the organism. To mitigate and control the deleterious effect of these radicals, the organism has diverse antioxidative defenses, as to increase phenolic compounds, degradation of photosynthetic pigments, providing polysaccharides and wall thickness and activation of enzymatic and non-enzymatic antioxidative systems. Thus, aiming to understand the physiological responses of Gracilariopsis tenuifrons to intense irradiance were evaluated levels of photosynthetic pigments, proteins, tissular carbon, hydrogen and nitrogen, growth rate, amount of total phenolic compounds, total antioxidant activity and lipid peroxidation, and ROS and NO production. Therefore, apices of $3 \mathrm{~cm}$ from the red seaweed Gp. tenuifrons were exposed to $60 \mu \mathrm{mol}$ photons. $\mathrm{m}^{-2} \cdot \mathrm{s}^{-1}$ and $600 \mu \mathrm{mol}$ photons. $\mathrm{m}^{-2} \cdot \mathrm{s}^{-1}$ for one week and sampling during the day and night. The excess of irradiance promoted oxidative stress responses, observing significant reduction of pigments, soluble proteins and tissular nitrogen, and elevation of tissular carbon and hydrogen, phenolic compounds, total antioxidant activity and quantity of NO. Gracilariopsis tenuifrons showed effective activation of diverse antioxidant systems stimulated by high light. This antioxidant induction should be better explored in applications for food, medical, pharmaceutical and cosmetic industries. Moreover this study shows innovative results related to NO production under stress condition and methodological protocols will be of great help for physiological approaches in the Laboratory of Marine Algae "Édison José de Paula" and for other national and international research groups.
\end{abstract}




\section{Introdução geral}

\subsection{Luz}

A luz visível corresponde a uma pequena porção da radiação eletromagnética, compreendida aproximadamente entre 400 e 700 nm (Falkowski \& Raven, 1997; Dawes et al., 1999; Falkowski \& Raven, 2007; Heldt et al, 2011). Essa faixa de comprimentos de onda é a região espectral captada pelos pigmentos fotossintetizantes e efetivamente utilizada na fotossíntese, por isso, denominada radiação fotossinteticamente ativa, PAR (do inglês Photosynthetically Active Radiation; Figura 1) (Plastino \& Mansilla, 2004; Falkowski \& Raven, 2007).

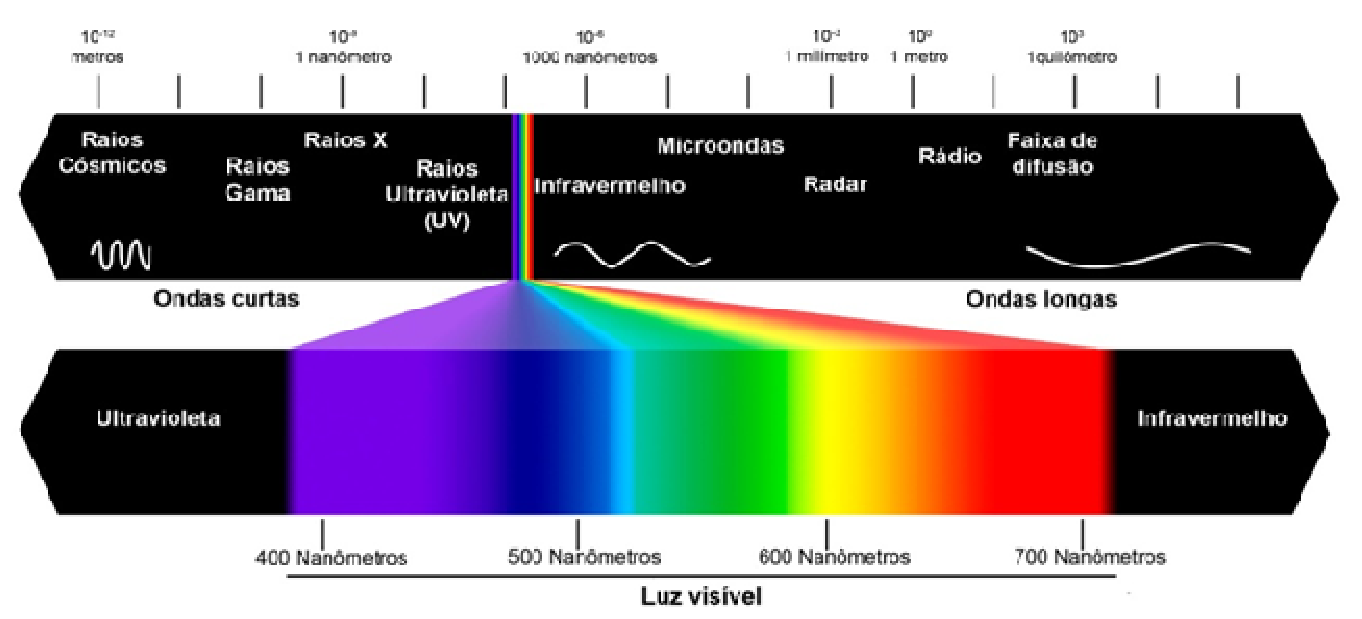

Figura 1: Esquema das radiações eletromagnéticas de frequências curtas (raios cósmicos, gama, X e ultravioleta; abaixo de $370 \mathrm{~nm}$ ) e longas (infravermelho, microondas, radar e rádio; acima de $740 \mathrm{~nm}$ ). Em destaque, no esquema inferior, a faixa de 370 a $740 \mathrm{~nm}$ que corresponde à luz visível e também à radiação fotossinteticamente ativa (PAR).

\subsection{Irradiância}

A irradiância é definida como fluxo de energia radiante incidente sobre uma superfície (área) em tempo determinado (Kirk, 1986; Lattore, 1998; Lobban \& Harrison, 2000; Plastino \& Mansilla, 2004). É um dos principais fatores abióticos que influencia direta ou indiretamente crescimento, desenvolvimento, reprodução (Henly \& Ramus, 1989; Lobban \& Harisson, 2000), distribuição e sazonalidade (Rossel et al., 2002; Necchi Jr., 2005; Bautista \& Necchi Jr., 2007) de macroalgas, incluindo alterações na eficiência fotossintetizante, adaptação e performance de aclimatação (Demming et al, 1988; Aguilera et al., 1999 a e b; Carnicas et al., 1999; Dawes et al. 1999; Spath-Wiley et al., 2008). 
Em ambientes naturais, organismos fotossintetizantes estão sujeitos a alterações na irradiância e qualidade da PAR e tais mudanças podem ocorrer numa sobretaxa temporal e espacial (Murchie \& Horton, 1997). As flutuações na luz ocorrem em escala de segundos e controlam o nível de energia para a membrana fotossintetizante e atividades enzimáticas de assimilação (Murchie \& Horton, 1997). Adicionalmente, a composição do aparato fotossintetizante é altamente sensível a longas mudanças em irradiância e qualidade espectral da luz. Sombreamento natural para folhas reduz a relação rendimento/rendimento fotossintetizante devido à deficiência de PAR pela filtragem dos pigmentos fotossintetizantes, além disso, as plantas podem enfrentar dificuldades não só por mudanças na irradiância, mas também com a variação dos tipos de espectros de sombra (Smith, 1982).

\subsection{Atividade fotossintetizante}

A atividade fotossintetizante, assim como os processos metabólicos dela dependentes, muda em função da disponibilidade qualitativa e quantitativa da luz, sendo a taxa fotossintetizante dependente da disponibilidade de irradiância (Dawes et al., 1999; Plastino \& Mansilla, 2004; Heldt et al., 2011). Deste modo, a energia necessária para excitar um pigmento fotossintetizante depende da estrutura do próprio pigmento. Assim, um pigmento atingido por um fóton vai absorver comprimentos de onda específicos. A energia absorvida estimula elétrons do pigmento, que ao estarem carregados de energia passam para camadas elétricas de maior energia, transferindo energia para a molécula de pigmento mais próxima e emitindo fluorescência e calor. Após a redução da energia, os elétrons retornam ao estado inicial e voltam às camadas eletrônicas de origem (Buchannan et al., 2000; Heldt et al., 2011).

A fotossíntese eficiente só é possível quando a energia de fótons de vários comprimentos de onda é capturada a partir do complexo antena, que são proteínas ligadas a moléculas de clorofila-a. Este complexo antena absorve os fótons e transfere a energia para o centro de reação fotossintetizante (fotossistemas I (PSI) e II (PSII)).

O complexo antena encontra-se na membrana dos tilacoides, apresentando organização transmembrana, com uma face interna e outra externa. A face externa compreende os complexos de coleta de luz (formados por polipeptídeos atrelados às clorofilas -a e -b, xantofilas e carotenoides) e a antena interna é composta por complexos nucleares (proteínas de ligação, que transferem a energia da antena externa 
para o centro de reação) e o centro de reação. Desta forma, a antena externa coleta luz enquanto a interna conduz a energia até os centros de reação do PSI e PSII (Figura 2A) (Heldt et al., 2011). Nesse processo de transporte de elétrons através do complexo antena da fotossíntese são formados ATP e NADPH, que serão usados para a assimilação de $\mathrm{CO}_{2}$ e de nitrato nas vias de síntese de carboidratos e aminoácidos, respectivamente (Eberhard et al., 2008).

Nos fotossistemas ocorre uma série de reações químicas, mediadas por metais, não metais, enzimas, proteínas e água. Embora o PSII, composto por quatro complexos coletores, seja maior do que o PSI, ambos são similares. Os PSI e PSII têm absorção máxima sob excitação de 700 e 680 nm, respectivamente (Figura 2B). Normalmente, para liberar uma molécula de $\mathrm{O}_{2}$ da água, o PSII deve obter quatro elétrons, portanto, ser estimulado por quatro fótons. O tempo entre a captura de um único fóton no fotossistema depende da intensidade da irradiância. As duas subunidades de clorofilaproteínas atreladas a 15 moléculas de clorofila, que formam o núcleo da antena do citocromo b559, encontram-se arranjadas no interior e fora dos complexos coletores de luz e não parecem estar envolvidas no transporte de elétrons no PSII. Sua função, provavelmente, é proteger o PSII de fotodanos. A proteína D1 do PSII é constantemente ressintetizada, pois aparentemente sofre desgaste durante a fotossíntese por danos causados pelo estresse oxidativo. Estima-se que a D1 seja substituída a cada 106/107 ciclos catalíticos do PSII (Apel \& Hirt, 2004; Heldt et al., 2011). 


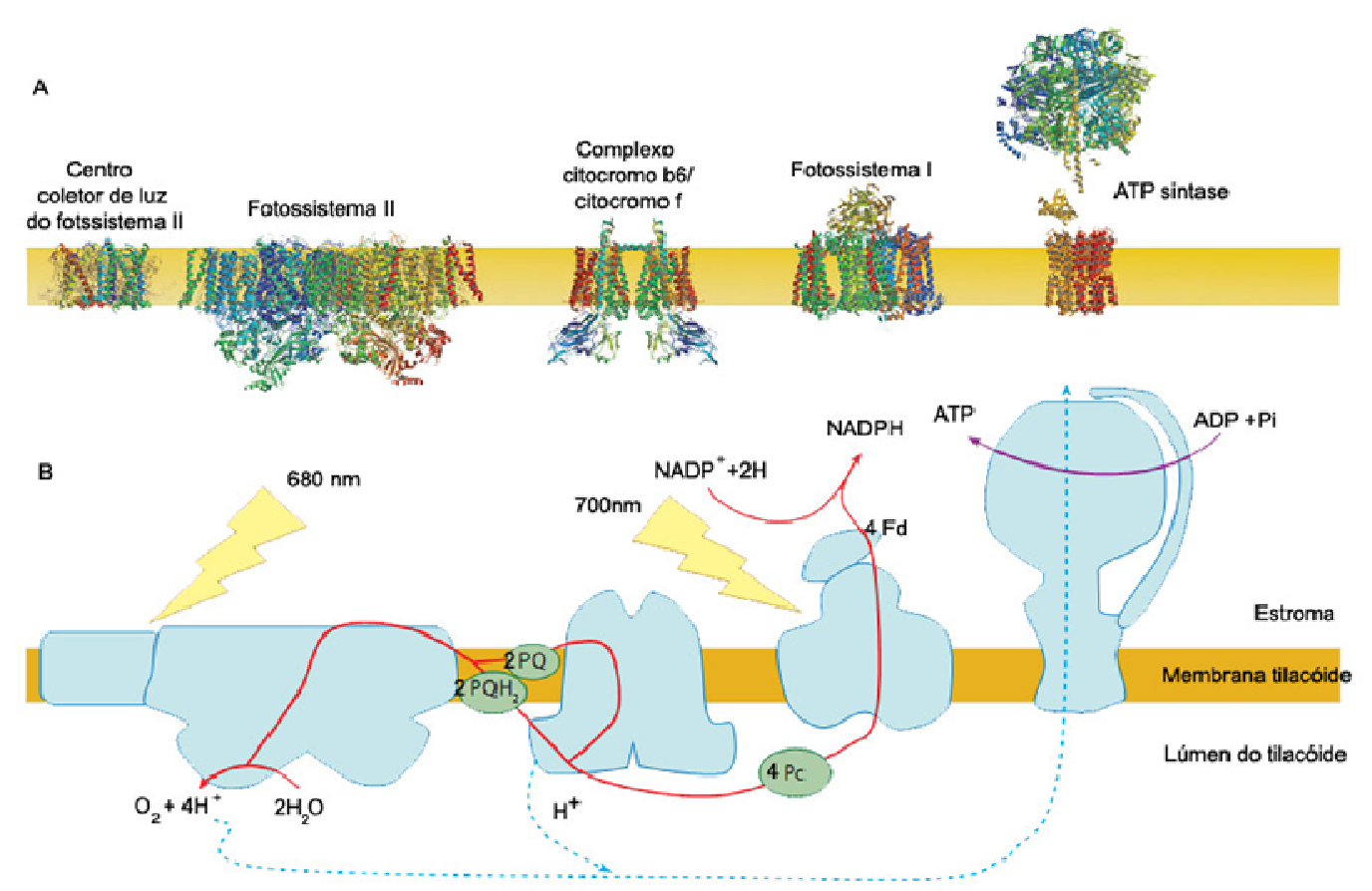

Figura 2: Representação simplificada do aparato fotossintetizante e fluxo de elétrons no processo de fotossíntese, enfatizando a captação de luz e transporte de energia. A: organização transmembrana das maiores proteínas fotossintetizantes (centro coletor de luz do PSII, PSI, complexo citocromos e ATP sintase). B: representação esquemática do fluxo eletrônico através das proteínas representadas em A. Os elétrons são liberados pela fotólise da água no interior do tilacoide no cloroplasto e utilizados na formação de NADPH. Para isso, a transferência de elétrons é direcionada para os fotossistemas II e I (PSII e PSI) que são estimulados por 680 e $700 \mathrm{~nm}$, respectivamente, transferindo as cargas para a clorofila-a e os receptores de moléculas fotossensíveis. O transporte de elétrons entre o PSII e o complexo citocromo b6/f (Cit b6/f; formado pelos citocromo b6 e f) é mediado pela plastohidroquinona $\left(\mathrm{PQH}_{2}\right)$ e pela plastoquinona (PQ). Os elétrons são transferidos do complexo $\mathrm{Cit}$ b6/f e conduzidos para o PSI pela plastocianina (Pc). No PSI, o subproduto da Pc sofre redução pela ferrodoxina (Fd), resultando, no estroma, em NADPH. Os elétrons transferidos do $\mathrm{NADP}^{+}$e prótons são transportados através da membrana para gerar energia e promover a síntese de ATP (modificado de Eberhard et al., 2008).

\subsection{Pigmentos de Rhodophyta}

As algas vermelhas apresentam três grandes grupos de pigmentos coletores de luz: clorofilas, ficobiliproteínas e carotenoides (Plastino \& Mansilla, 2004). A clorofila (clorofila-a) e as ficobiliproteínas (principalmente ficoeritrinas, ficocianinas e aloficocianinas) cumprem papel principal de máxima absorção de luz para a fotossíntese, enquanto os carotenoides (por exemplo, $\beta$-caroteno, zeaxantina, anteraxantina e luteína) atuam como coletores de energia, transferindo elétrons provenientes da fonte luminosa para a clorofila-a, e como protetores (atuam junto à 
clorofila - superexcitada pelo excesso de energia - e os radicais livres capturando elétrons de ambos e liberando-os em forma de calor) (Rmiki et al.,1996).

Essas algas apresentam ainda estruturas que ampliam a captação de luz. Essas estruturas, os ficobilissomos, absorvem a energia de comprimentos de onda de baixíssima intensidade, principalmente luz verde e azul, que são os comprimentos de onda que atingem maior profundidade na coluna d'água. Assim, muitas algas vermelhas são capazes de sobreviver em locais profundos de águas transparentes e de aproveitar esta energia pouco utilizada pela maioria dos organismos fotossintetizantes. Os ficobilissomos se encontram organizados em cima da membrana dos tilacoides, próximos ao PSII. Ligam-se aos tilacoides através de proteínas e são constituídos de ficobilinas, predominantemente ficoeritrina, ficocianina e aloficocianina, ligadas covalentemente entre si (Heldt et al., 2011). Na maioria das vezes, esse complexo proteína-ficobilina está fortemente associado, por isso, a denominação de ficobiliproteína.

Os ficobilissomos são um sistema de transferência de energia altamente eficiente. Um único ficobilissomo pode transferir energia para quatro ou mais PSII. A energia é transferida via ficoeritrina-ficocianina-aloficocianina para o PSII através de cromóforos posicionados diferentemente ao longo do canal de transferência. As ficobiliproteínas reunidas nos ficobilissomos, captam a luz de forma mais eficaz sob baixa irradiância, aumentando a atividade do PSII e otimizando a eficiência fotossintetizante (Heldt et al., 2011). Embora sejam muito eficientes, os ficobilissomos não transferem $100 \%$ da energia absorvida para a clorofila-a, pois seus pigmentos apresentam autofluorescência.

\subsection{Fotoinibição}

A composição pigmentar em Rhodophyta é severamente afetada pelo nível de irradiância. Então, sob alta irradiância a autofluorescência das ficobiliproteínas tende a aumentar. Desta forma, sob prolongada exposição ao excesso de irradiância há dissipação de energia, em forma de fluorescência durante a transferência para os fotossistemas. Nessas condições, as ficobiliproteínas são os primeiros pigmentos fotossintetizantes a sofrerem fotodano, sendo eles muito mais sensíveis do que os outros pigmentos. Depois das ficobiliproteínas, os pigmentos a sofrer degradação mais 
facilmente são os carotenoides, enquanto a clorofila é o pigmento mais resistente à fotodestruição (Donkor \& Häder, 1996).

Deste modo, o excesso de estímulo luminoso pode causar redução de componentes de transporte de elétrons no aparato fotossintetizante. Embora a aclimatação às mudanças de irradiância em organismos fotossintetizantes possa ocorrer em escala de minutos a horas, a mudança mais dramática durante a exposição desses organismos ao excesso de irradiância é a fotoinibição. A fotoinibição ocorre quando a taxa de conversão de energia luminosa é menor do que a taxa de absorção de energia luminosa (Raven, 2011).

\subsection{Espécies reativas de oxigênio (ROS) e espécies reativas de nitrogênio (RNS - NO)}

Durante a exposição ao excesso de irradiância, o primeiro componente do aparato fotossintetizante a ser afetado é o PSII, pois neste centro de reação se acumulam moléculas de clorofila em estado triplete e singlete, que contém muita energia agregada à molécula. Em estado singlete, a clorofila se torna altamente eletrofílica e é capaz de oxidar muitas outras moléculas (Barros et al., 2005; Eberhard et al., 2008; KriegerLiszkay et al., 2008; Vass \& Cser, 2009; Vass, 2011), reagindo com $\mathrm{O}_{2}$ e promovendo a formação de espécies reativas de oxigênio, ROS do inglês Reactive Oxygen Species, e espécies reativas de nitrogênio, RNS do inglês Reactive Nitrogen Species (Yan et al., 1998; Pietta, 2000; Jiménez-Escrig et al., 2001; Lim et al., 2002; Neill et al., 2002; Rossel et al., 2002; Collén et al., 2003; Apel \& Hirt, 2004; Bhandari \& Sharma, 2006; Nishiyama et al., 2011).

A produção desenfreada e o acúmulo dessas espécies oxidantes nas células ocorrem sob diversas condições de estresse, como luz excessiva ou radiação UV, dessecação, deficiência de nutrientes, exposição a metais pesados, temperaturas altas e baixas, mudanças abruptas de temperatura, hipoxia ou anoxia e, ainda, como produto de atividades antrópicas: despejo de esgotos ou substâncias tóxicas, entre outros (Neill, et al., 2002; Blokhina et al., 2003; Dummermuth et al., 2003; Scandalios, 2005; Couée et al., 2006; Krieger-Liszkay et al., 2008; Vass \& Cser, 2009; Foyer \& Shigeoka, 2011; Vass, 2011).

Embora o excesso das ROS ocorra principalmente sob condições estressantes, todas as células que respiram e fotossintetizam produzem ROS naturalmente em baixas 
concentrações. A formação constitutiva e homeostática de ROS está diretamente relacionada com funções metabólicas fundamentais em diferentes compartimentos celulares, principalmente peroxissomos, glioxissomos, mitocôndrias e cloroplastos (Apel \& Hirt, 2004; Barros et al, 2005; Lesser, 2006). A sinalização mediada pelas ROS se integra com o entrecruzamento de outros sinalizadores, podendo seu acúmulo ser ativado ou inibido ou, ainda, acumular ou inibir outros sinalizadores em resposta ao estímulo destas redes. Uma das propriedades das ROS como sinalizadores é que a célula é capaz de produzir e consumir simultaneamente diferentes tipos de ROS de forma rápida, promovendo o equilíbrio das ROS de maneira cada vez mais dinâmica. Deste modo, as células apresentam habilidade significante para desintoxicar, consumir ou tamponar as ROS produzidas localmente e em quantidade reduzida (por exemplo: partes de uma membrana ou organela), controlando ROS altamente específicas (Mittler et al., 2011).

Além disso, para serem geradas, as ROS exigem grande concentração de $\mathrm{O}_{2}$. A redução contínua do $\mathrm{O}_{2}$ promove a produção fotoquímica do $\mathrm{O}_{2}{ }^{-}$(radical superóxido) e $\mathrm{H}_{2} \mathrm{O}_{2}$ (peróxido de hidrogênio), que reduzido produz $\mathrm{HO}^{\bullet}$ (radical hidroxila) e água. Em estresse oxidativo, a produção e o acúmulo de ROS ocorrem além da capacidade do organismo combater e neutralizar as ROS, desencadeando danos em lipídios, proteínas e DNA, agindo inclusive no sinal de transdução de importantes metabolismos celulares (Apel \& Hirt, 2004; Barros et al, 2005; Lesser, 2006).

O termo ROS é usado para radicais livres e oxidantes não radicais. Radicais livres são átomos ou compostos que contém um ou mais elétrons não pareados em seus orbitais externos. Entre os mais potentes e importantes encontram-se os radicais superóxido $\left(\mathrm{O}_{2^{-}}\right)$e hidroxila $\left(\mathrm{HO}^{\bullet}\right)$. Esses radicais são altamente reativos e instáveis. Existem por apenas micro ou nanosegundos antes de dispararem reações em cadeia e ser transformados em compostos ainda mais reativos. Os principais oxidantes não radicais são o $\mathrm{H}_{2} \mathrm{O}_{2}$ e o oxigênio singlete $\left({ }^{1} \mathrm{O}_{2}\right)$. Estes compostos podem durar minutos, principalmente o $\mathrm{H}_{2} \mathrm{O}_{2}$, e causam danos oxidativos em biomoléculas (Monaghan et al., 2009).

Assim como as ROS, a produção excessiva e o acúmulo de RNS nas células ocorrem sob condição de estresse. O radical livre óxido nítrico (NO), molécula bioativa e gás hidro e lipo solúvel com alta reatividade bioquímica (Tun et al., 2001; Wendehenne et al., 2001; Belligni \& Lamatina, 2002; Neill et al., 2003; Lamotte et al., 
2004; Delledone et al., 2005; Abat et al., 2008; Benson-Bard et al., 2008a) possui capacidade de se difundir rapidamente através das células e habilidade mediadora de várias reações fisiológicas agindo como regulador, citotóxico ou ainda como citoprotetor (Boveris et al., 2000; Chow, 2002; Crawford, 2006; Estevez \& Puntarulo, 2005; Benson-Bard et al., 2008a, 2008b; Chow et al., 2013). O NO pode ser formado enzimaticamente e não enzimaticamente. As enzimas responsáveis pela sua formação são a óxido nítrico sintase (NOS), a nitrato redutase (NR) e a xantina oxidorredutase (XOR). Não enzimaticamente pode ser produzido a partir de reações de nitrificação ou desnitrificação pela redução do $\mathrm{NO}_{2}$ - mediada por carotenoides e luz (Rockel et al., 2002; Benson-Bard et al., 2008 a e b; Hong et al., 2008; Neil et al., 2008; Rümer et al., 2009; Hayat et al, 2010; Misra et al., 2011). Sob estresse, o NO pode ser sintetizado de ambos os modos (Hao \& Zhang, 2010).

Uma vez produzido, o NO difunde-se dentro da célula ou de uma célula para outra, ou seja, limita-se à célula em que é gerado ou à célula vizinha. Entretanto, é responsável por ativar respostas globais em todo o organismo (ex. alterações no desenvolvimento morfo-anatômico, reprodução e crescimento), promovendo a atuação de mensageiros secundários ou radicais como ânion superóxido $\left(\mathrm{O}_{2}^{-}\right)$e $\mathrm{H}_{2} \mathrm{O}_{2}$ e sugeridos como moléculas sinalizadoras em plantas, que desencadeiam respostas de estresse oxidativo (Squadrito \& Pryor, 1998; Neill et al., 2002, Neill et al., 2003). Tais respostas têm sido registradas particularmente durante interações patogênicas nas plantas (Delledonne et al., 2001; 2005). Além disso, experimentos em plantas vasculares demonstraram que o NO confere proteção às células contra injúrias oxidativas e atua como consumidor das ROS (Wendehenne et al., 2001; Beligni \& Lamattina, 2002; Neill et al., 2002; Guo et al., 2003; Neill, et al., 2003; Silveira et al., 2006; Santa-Catarina et al., 2007; Benson-Bard et al., 2008a; Hao \& Zhang, 2010; Hsu \& Lee, 2012).

\subsection{Sistemas antioxidantes}

Ativados em situação de estresse em que são produzidas grandes quantidades de ROS e RNS, os sistemas de defesa antioxidantes são reconhecidamente essenciais para a desintoxicação e neutralização destes radicais, processo fundamental para a sobrevivência dos organismos. Em macroalgas, esses mecanismos são semelhantes aos das embriófitas e uma maneira de ativarem-se é em resposta à alta irradiância (Young \& 
Britton, 1993; Andersson et al., 2006; Bhandari \& Sharma, 2006; Lesser, 2006). Apresentam-se como parte de dois grandes grupos: os enzimáticos e os não enzimáticos. Os enzimáticos incluem reações mediadas por enzimas protetoras como superóxido dismutase (SOD), ascorbato peroxidase (APX), glutationa redutase (GR) e catalase (CAT); os não enzimáticos abrangem moléculas antioxidantes como os florotaninos, ácido ascórbico, tocoferois, carotenoides, fosfolipídios, compostos relacionados à clorofila como bromofenois, catequinas, aminoácidos tipo micosporinas (MAAs), polissacarídeos, etc. (Le Tutour et al., 1998; Yuan et al., 2005). Substâncias antioxidantes, mesmo em baixas concentrações, conseguem atrasar ou prevenir a oxidação de extratos facilmente oxidáveis (Athukorala et al., 2003; Sreenivasan et al., 2007; Szabo et al., 2007).

A ausência de danos oxidativos evidentes em componentes estruturais das macroalgas (ex. ácidos lipídicos poliinsaturados) e sua estabilidade metabólica durante a oxidação sob forte radiação UV sugerem que suas células possuem sistemas de defesa antioxidativos ativos e eficientes (Matsukawa et al., 1997; Zubia et al., 2007). Apesar de muitos autores terem ressaltado a atividade antioxidante de muitas macroalgas (Anggadiredja et al., 1997; Matsukawa et al., 1997; Yan et al., 1998; Jiménez-Escrig et al., 2001; Matanjun et al., 2008), ainda são poucos os estudos dessa natureza com macroalgas tropicais (Anggadiredja et al., 1997; Lim et al., 2002; Fallarero et al., 2003; Zubia et al., 2007).

\subsection{Substâncias fenólicas}

As substâncias fenólicas são formadas a partir do metabolismo secundário de vegetais e seu acúmulo pode ser disparado sob diferentes condições de estresse: defesa contra patógenos (Soares et al., 2008), herbivoria, agentes alelopáticos, transdução de sinal (Rozema et al., 2002), fatores climáticos e poluentes (Swain, 1977). Em adição, atuam como sistema antioxidativo protegendo contra irradiância em demasia e ação de raios UV, absorvendo-os e evitando a produção de ROS (Paul \& Hay, 1986; Hay \& Fenical, 1988; Yan et al., 1998; Pietta, 2000; Yuan \& Walsh, 2006; Devi, et al., 2008).

A capacidade das substâncias fenólicas de neutralização do processo oxidativo se deve à sua estrutura química, formada por pelo menos um anel aromático com grupamentos hidroxilas. Além da sua atividade antioxidante direta, pesquisas recentes têm destacado múltiplas funções e mecanismos importantes relacionados à habilidade 
de se ligarem a receptores celulares e transportadores de membranas, influenciando a expressão gênica, sinalização e adesão celular (Soares et al., 2008).

A estabilidade das macroalgas durante oxidação sugere que fenois de algas marinhas (ex. florotaninos e floroglucinol) são provavelmente bons antioxidantes (Yan et al., 1996; Jimenez-Escrig et al., 2001; Athukorala et al., 2006; Zubia, et al., 2007; Matanjun et al., 2008). Sendo assim, as substâncias fenólicas de algas além de atuar em respostas fisiológicas vegetais, vêm despertando interesse, pois como antioxidantes têm sido testados na indústria alimentícia (como conservantes naturais) e na área médica, nesta com abrangência maior, sendo avaliados efeitos de prevenção de problemas e a capacidade de debelá-los (Aherne \& Obrien, 2002; Jayaraj et al., 2008; Audibert et al., 2010; Pise et al,. 2010; Wijesekara et al., 2011).

\subsection{Gracilariopsis tenuifrons}

De acordo com Wynne (2011), a classificação da macroalga vermelha Gracilariopsis tenuifrons (Bird et Oliveira) Fredericq et Hommersand, apresenta-se da seguinte forma:

Super grupo: Archaeplastida

Filo: Rhodophyta

Classe: Florideophyceae

Subclasse: Rhodymenikophycidae

Ordem: Gracilariales

Família: Gracilariaceae

Gênero: Gracilariopsis

Espécie: Gracilariopsis tenuifrons

Gracilariopsis tenuifrons foi elegida como objeto de estudo deste trabalho por se tratar de uma espécie com bom crescimento, fácil cultivo em laboratório (Plastino, 1991) e produtora de ágar de qualidade (Brito, 2000; Brito \& Silva, 2005). Por isso, no Brasil, é considerada espécie potencial para ser produzida em larga escala (Oliveira, 1998). Na costa brasileira pode ser encontrada desde o estado de Alagoas até São Paulo (Bird \& Oliveira, 1986; Plastino, 1991). Segundo Oliveira \& Miranda (1998) e Plastino \& Oliveira (2002) esta espécie vem sendo explorada como agarófita no nordeste há várias décadas. 


\section{Justificativa}

Esta proposta constitui vertente da linha de pesquisa da Dra. Fungyi Chow e é parte do projeto maior "Fisiologia integrativa de macroalgas: estudo exploratório da biodiversidade química" (FAPESP, Processo $N^{\circ}$ 10/02948-3). As informações procedentes desta proposta permeiam diversas áreas do conhecimento relacionadas às algas marinhas, portanto, poderão auxiliar com respostas e/ou levantar questões para novas pesquisas. Assim sendo, as análises da atividade antioxidante poderão contribuir com o melhoramento e/ou expansão da utilização de produtos provenientes de algas na indústria alimentícia, médica, farmacêutica e cosmética. Já os aspectos fisiológicos poderão influir para o aperfeiçoamento da produção de algas, além de fornecer esclarecimentos sobre o comportamento do óxido nítrico nas macroalgas. Aspectos fisiológicos e bioquímicos relacionados às condições de estresse em macroalgas marinhas são pouco abordados no Brasil. Sendo assim, para o país este é um trabalho pioneiro no que se refere à aferição de NO em algas marinhas.

\section{Objetivo geral}

O objetivo geral do trabalho foi caracterizar o padrão fisiológico de Gp. tenuifrons referente a atividade oxidante e antioxidante em resposta a diferentes tratamentos de intensidade luminosa, e adequar protocolos metodológicos à realidade da pesquisa.

\section{Objetivos específicos}

1) Estabelecer os protocolos de análise de atividade antioxidante total.

2) Estabelecer o protocolo de análise de compostos fenólicos totais.

3) Estabelecer o protocolo para a quantificação da produção de óxido nítrico.

4) Verificar em laboratório a taxa de crescimento, o teor de pigmentos fotossintetizantes, a quantidade de proteínas solúveis totais, a atividade antioxidante total, a quantidade de compostos fenólicos totais e a produção de óxido nítrico de Gp. tenuifrons submetida a diferentes regimes de irradiância.

\section{Material e métodos geral}

\subsection{Material biológico}

O cultivo unialgáceo de Gp. tenuifrons foi estabelecido a partir da cepa 39 do Banco de Germoplasma do Laboratório de Algas Marinhas "Édison José de Paula" 
(LAM) do Instituto de Biociências da USP. Os exemplares correspondem à fase gametofítica feminina (haploide, n) e foram obtidos a partir da germinação de tetrásporos, oriundos de tetrasporófitos (diploide, 2n) coletados pela Profa. Dra. Estela M. Plastino em 6 de julho de 1987 na lagoa de Araruama, Cabo Frio, RJ.

\subsection{Cultivo do material estoque de Gracilariopsis tenuifrons}

As condições do cultivo do material estoque e do material em experimento foram as mesmas descritas a seguir, salvo quando especificada mudança de algum parâmetro. Para o cultivo foi usada água do mar esterilizada com 32 ups, enriquecida com solução de von Stosch (VS; Edwards, 1970) diluída a 50\%. A proporção biomassa/meio de cultura do material estoque foi de $3 \mathrm{~g}$ de massa fresca (MF) por $1 \mathrm{~L}$ de meio de cultivo, temperatura de $25 \pm 1^{\circ} \mathrm{C}, 14 \mathrm{~h}$ de fotoperíodo $(65 \pm 5 \mu$ mol de fótons. $\mathrm{m}^{-2} \cdot \mathrm{s}^{-1}$ ) e $10 \mathrm{~h}$ de escuro e aeração a cada $30 \mathrm{~min}$.

A limpeza dos talos e a troca do meio de cultura foram realizadas semanalmente. A água do mar utilizada foi coletada no litoral norte do estado de São Paulo, município de São Sebastião. Sua esterilização foi feita por meio de dupla filtragem, filtro CUNO de porosidade 5 e $1 \mu \mathrm{m}$ e aquecimento em banho-maria a $\pm 98^{\circ} \mathrm{C}$ durante 60 minutos contabilizados a partir do momento da fervura (Oliveira et al., 1995). A irradiância foi fornecida por lâmpadas fluorescentes (Philips, modelo luz do dia, 5200K/40 W), periodicamente mensurada com auxílio de medidor de quanta LI-COR modelo LI-250 (EUA) e sensor esférico LI-COR modelo LI-193SB (EUA). A aeração foi fornecida por compressor radial IBRAM CR03, isento de óleo.

\subsection{Delineamento experimental}

Ápices de $3 \mathrm{~cm}$ de comprimento, procedentes do material estoque, foram mantidos durante uma semana sob duas condições de irradiância: (a) $60 \pm 5 \mu$ mol de fótons. $\mathrm{m}^{-2} \cdot \mathrm{s}^{-1}$ (controle) e (b) $600 \pm 10 \mu \mathrm{mol}$ de fótons. $\mathrm{m}^{-2} \cdot \mathrm{s}^{-1}$ (tratamento). A proporção experimental biomassa/volume de meio de cultura foi de $1 \mathrm{~g}$ MF por $1 \mathrm{~L}$ de meio de cultivo. As demais condições experimentais foram as mesmas que as descritas para o cultivo do material estoque.

Ao fim do período experimental, os ápices foram pesados para cálculo da taxa de crescimento. Em seguida, os ápices foram cortados para padronizar o tamanho de $3 \mathrm{~cm}$ inicial e novamente incubados sob suas respectivas condições experimentais supridas 
com solução de enriquecimento de VS $50 \%$ por mais 24 h para padronização do estado metabólico, a fim de reduzir respostas por limitação de nutrientes que possam interferir na interpretação dos dados (Chow, 2005). No dia seguinte, amostras de Gp. tenuifrons foram coletadas em dois momentos do dia: (a) durante o fotoperíodo, entre 4-6 h após o início deste (tratamento DIA) e (b) durante a noite, entre 2-3 h após o início do período escuro (tratamento NOITE) (Figura 3). Estas amostras foram pesadas de acordo com a massa de material necessária para cada protocolo, congeladas em nitrogênio liquido e armazenadas em ultrafreezer $\left(-80^{\circ} \mathrm{C}\right)$ para posteriores análises de teor de pigmentos fotossintetizantes, proteínas solúveis totais, carbono, hidrogênio e nitrogênio teciduais $(\mathrm{CHN})$, atividade antioxidante total e quantidade de compostos fenólicos totais.

As quantificação das espécies reativas de oxigênio (ROS) e do óxido nítrico (NO) foram realizadas in vivo. Por isso as coletas foram efetuadas apenas em um período (DIA). Além disso, dos ápices de $3 \mathrm{~cm}$ submetidos ao período experimental foram utilizados apenas $0,5 \mathrm{~cm}$ destes mesmos ápices, seccionados, durante a manutenção nutricional do cultivo $24 \mathrm{~h}$ antes dos testes.

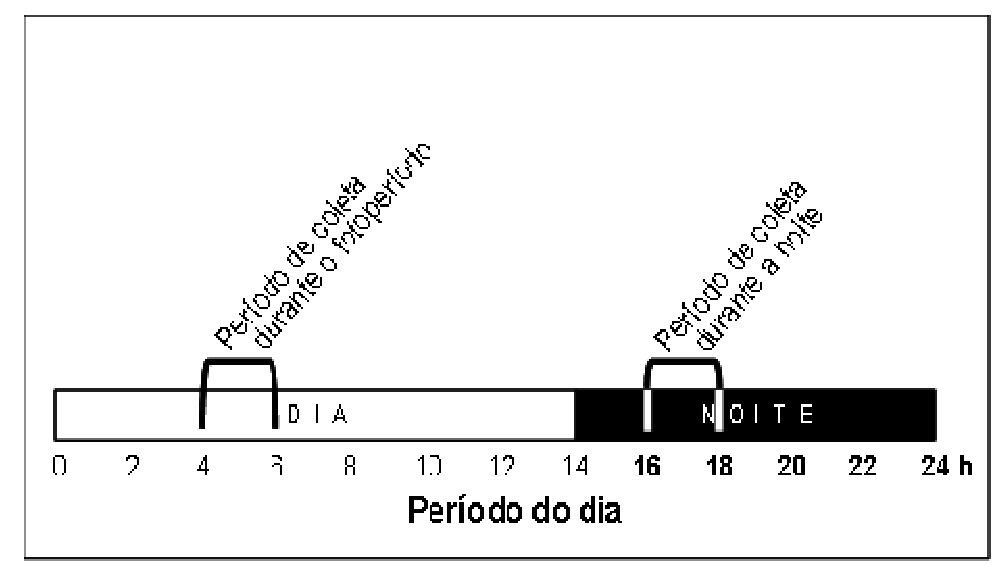

Figura 3: Esquema representativo dos períodos de coleta durante o fotoperíodo (tratamento DIA, controle) e durante a noite (tratamento NOITE).

Foram elaborados códigos para alusão aos tratamentos. Assim, os códigos 60D ou 60 DIA referem-se a tratamentos que ficaram sob a irradiância de $60 \mu$ mol de fótons. $\mathrm{m}^{-2} \cdot \mathrm{s}^{-1}$ e foram coletadas durante o dia. Da mesma forma, os códigos $60 \mathrm{~N}$ ou 60 NOITE dizem respeito a algas que estiveram sob a mesma irradiância, mas foram coletadas durante a noite. O mesmo se aplica para os códigos 600D ou 600 DIA e 600N ou 600 NOITE, que serão atribuídos a amostras obtidas a partir de talos que estiveram 
sob irradiância de $600 \mu \mathrm{mol}$ de fótons. $\mathrm{m}^{-2} \cdot \mathrm{s}^{-1}$ e foram coletados de dia ou à noite respectivamente.

\subsection{Análise estatística}

Todos os experimentos foram realizados com pelo menos três réplicas e quando possível o número de amostras foi aumentado segundo as especificações descritas em cada capítulo. Os resultados da taxa de crescimento, biomassa seca e úmida, teor tissular de carbono, hidrogênio e nitrogênio ( $\mathrm{CHN})$, ROS e NO foram analisados com teste $\mathrm{t}$ de Student. Os dados de pigmentos, proteínas solúveis totais, substâncias fenólicas e atividade antioxidante foram avaliados a partir de análise de variância ANOVA unifatorial. Testes a posteriori de Tukey foram aplicados de acordo com a significância das análises. Antes da execução de cada análise foi avaliada distribuição normal (teste de Kolmogorov-Smirnov). Todas as análises foram realizadas dentro de um intervalo de confiança de $95 \%$ ( $\mathrm{p}<0,05)$. As análises estatísticas foram avaliadas com o programa STATISTICA v. 6.0, segundo descrições de Zar (1999).

\section{Referências Bibliográficas (parte I)}

Abat, J. K.; Matoo, A. K.; Deswal, R. 2008. S-nitrosylated proteins of a medicinal CAM plant Kalanchoe pinnata- ribulose-1,5-bisphosphate carboxylase/oxygenase activity targeted for inhibition. FEBS Journal. 275: 2862-2872.

Aherne, S. A. \& O’Brien, N. M. 2002. Dietary Flavonols: Chemistry, Food Content, and Metabolism. Nutrition 18:75-81.

Aguilera, J.; Dummermuth A.; Karsten, U.; Schriek, R.; Wiencke1, C. 1999a. Enzymatic defences against photooxidative stress induced by ultraviolet radiation in Arctic marine macroalgae. Polar Biol. 25: 432-441.

Aguilera, J.; Karsten, U.; Lippert, H.; Vogele, B.; Philipp, E.; Hanelt, D.; Wiencke, C. 1999b. Effects of solar radiation on growth, photosynthesis and respiration of marine macroalgae from the Arctic. Mar Ecol Prog Ser Vol. 191: 109-119.

Andersson, M.; Schubert, H.; Pedersén, M.; Snoeijs, P. 2006. Different patterns of carotenoid composition and photosynthesis acclimation in two tropical red algae. Marine Biology 149:653-665.

Anggadiredja, J.; Andyani, R.; Hayati, M. 1997. Antioxidant activity of Sargassum polycystum (Phaeophyta) and Laurencia obtuse (Rhodophyta) from Seribu Islands. Journal of Applied Phycology 9: 477-479. 
Apel, K. \& Hirt, H. 2004. Reactive oxygen species: metabolism, oxidative stress, and signal transduction. Annual Review of Plant Biology 55: 373-399.

Athukorala, Y.; Lee, K-W; Song, C.; Ahn, C-B; Shin, T-S; Cha, Y-J; Shahid, F.; Jeon, Y-J. 2003. Potential, antioxidant activity of marine red alga Grateloupia filicina extracts. Journal of Food Lipids 10: 251-265.

Athukorala, Y.; Kim, K-N; Jeon, Y-J. 2006. Antiproliferative and antioxidant properties of an enzymatic hydrolysate from brown alga, Ecklonia cava. Food and Chemical Toxicology 44: 1065-1074.

Audibert, L.; Fauchon, M.; Blanc, N.; Hauchard, D.; Gall, E. A. 2010. Phenolic compounds in the brown seaweed Ascophyllum nodosum: distribution and radicalscavenging activities. Phytochem. Anal. 21: 399-405..

Barros, M.P.; Pinto, E.; Sigaud-Kutner, T.C.S.; Cardozo, K.H.M.; Colepicolo, P. 2005. Rhythmicity and oxidative/nitrosative stress in algae. Biological Rhythm Research 36: 67-82.

Bautista, A.I.N. \& Necchi Jr., O. 2007. Photoacclimation in three species of freshwater red algae. Brazilian Journal of Plant Physiology 19: 23-34.

Beligni, M.V. \& Lamattina, L. 2002. Nitric oxide interferes with plant photo-oxidative stress by detoxifying reactive oxygen species. Plant, Cell and Environment 25: 737-748.

Benson-Bard, A.; Plugin, A.; Wendehenne, D. 2008a. New insights into nitric oxide signaling in plants. Annual Review of Plant Biology 59: 21-39.

Besson-Bard, A.; Griveau, S.; Bedioui, F.; Wendehenne, D. 2008b. Real-time electrochemical detection of extracellular nitric oxide in tobacco cells exposed to cryptogein, an elicitor of defense responses. Journal of Experimental Botany. 1-8.

Bhandari, R. \& Sharma, P.K. 2006. High-light-induced changes on photosynthesis, pigments, sugars, lipids and antioxidant enzymes in freshwater (Nostoc spongiaeforme) and marine (Phormidium corium) cyanobacteria. Photochemistry and Photobiology. 82: $702-710$

Bird, C.J. \& Oliveira, E.C. 1986. Gracilaria tenuifrons sp. nov. (Gigartinales, Rhodophyta), a species from the tropical western Atlantic with superficial spermatangia. Phycologia 25: 313-320.

Blokhina, O; Virolainen, E.; Fargestedt, K.V. 2003. Antioxidants, oxidative damage and oxygen deprivation stress: a review. Annals of Botany 91: 179-194.

Boveris, A. D.; Galatro, A.; Puntarulo, S. 2000. Effect of nitric oxide and plants antioxidants on microsomal content lipids radicals. Biol. Res. 33(2): 5p. doi: 104067/S0716-97602000000200016.

Brito, L.L. 1999. Influencia del tratamiento alcalino sobre el agar de Gracilariopsis tenuifrons (Gracilariales: Rhodophyta). Instituto Oceanográfico de Venezuela, Universidad de Oriente, Cumaná, Venezuela. perbrica@telcel.net.ve. 67-70. 
Brito, L. L. \& Silva, S. 2005. Fenología y ciclo de vida del alga Gracilariopsis tenuifrons (Gracilariaceae) en Sucre, Venezuela. Rev. Biol. Trop. (Int. J. Trop. Biol. ISSN-0034-7744). (www.tropiweb.com). 53: 67-73.

Buchanan, B.; Gruissem, W. \&; Jones, R. L. 2000. Biochemistry and molecular biology of plants. American Society of Plant Physiologists. 1367p.

Carnicas, E.; Jimenez, C.; Niell, F.X. 1999. Effects of changes of irradiance on the pigment composition of Gracilaria tenuistipitata var. liui Zhang et Xia. Journal Photochemistry and Photobiology B: Biol. 50: 149-158.

Chow, F. 2002. Atividade in vitro e regulação da enzima nitrato redutase na alga vermelha Gracilaria chilensis (Gracilariales, Rhodophyta). Universidade de São Paulo. Tese de doutorado. 136p.

Chow, F.; Pedersén, M.; Oliveira, M.C. 2013. Modulation of nitrate reductase activity by photosynthetic eléctron transport chain and nitric oxide balance on the red macroalga Gracilaria chilensis (Gracilariales, Rhodophyta). Journal of Applied Phycology DOI 10.1007/s10811-013-0005-8.

Collén, J.; Pinto, E.; Pedersén, M.; Colepicolo, P. 2003. Induction of oxidative stress in the red macroalga Gracilaria tenuistipitata by pollutant metals. Archives of Environmental Contamination and Toxicology 45: 337-342.

Couée, I.; Sulmon, C.; Gouesbet, G.; El Amrani, A. 2006. Involvement of soluble sugars in reactive oxygen species balance and responses to oxidative stress in plants. Journal of Experimental Botany 57: 449-459.

Crowford, N. M. 2006. Mechanisms for nitric oxide synthesis in plants. Journal of Experimental Botany. 57: 471-478.

Dawes, C.J.; Orduña-Rojas, J.; Robledo, D. 1999. Response of the tropical red seaweed Gracilaria cornea to temperature salinity and irradiance. Journal of Applied Phycology 10: 419-425.

Delledonne, M.; Zeier, J.; Marocco, A.; Lamb, C. 2001. Signal interactions between nitric oxide and reactive oxygen intermediates in the plant hypersensitive disease resistance response. Proceedings of the National Academy of Sciences, USA 98: $13454-13459$.

Delledonne, M. 2005. NO news is good news for plants. Current Opinion in Plant Biology. 8: 390-396.

Demmig, B.; Winter, K.; Kruger, A.; Czygan, F.-C. 1988. Zeaxanthin and the heat dissipation of excess light energy in Nerium oleander exposed to a combination of high light and water stress. Plant Physiol. 87: 17-24.

Devi, K.P.; Suganthy, N.; Kesika, P.; Pandian, S.K. 2008. Bioprotective properties of seaweeds: In vitro evaluation of antioxidant activity and antimicrobial activity against food borne bacteria in relation to polyphenolic content. Complementary and Alternative Medicine (http://www.biomedcentral.com/1472-6882/8/38) 1-11p. 
Donkor, V. A. A., Hader, D.-P. 1996. Effects of ultraviolet irradiation on photosynthetic pigments in some filamentous cyanobacteria. Aquat Microb Ecol Vol. 11: $143-149$.

Dummermuth, A.L.; Karsten, U.; Fisch, K.M.; König, G.M.; Wiencke, C. 2003. Responses of marine macroalgae to hydrogen-peroxide stress. Journal of Experimental Marine Biology and Ecology 289: 103-121.

Eberhard, S.; Finazzi, G.; Wollman, F.-A. 2008. The Dynamics of Photosynthesis. Annu. Rev. Genet. 42:463-515.

Edwards, P. 1970. Illustrated guide to the seaweeds and seagrasses in the vicinity of Porto Aransas, Texas. Contributions to Marine Science, University of Texas at Austin 15: $1-228$.

Estevez, M. S. \& Puntarulo, S. 2005. Nitric oxide generation upon growth of Antarctic Chlorella sp. Cells. Physiologia Plantarum 125: 192-201.

Falkowski, P.G. \& Raven, J.A. 1997. Aquatic photosyntesis. Blackwell Science. 375p.

Falkowski, P.G. \& Raven, J.A. 2007. Aquatic Photosynthesis: Second Edition. Princeton University Press. 484p.

Fallarero, A.; Loikkanen, J.J.; Mansito, P.T.; Castañeda, O.; Vidal, A. 2003. Effects of aqueous extracts of Halimeda incrassata (Ellis) Lamouroux and Bryothamnion triquetrum (S.G. Gmelin) Howe on hydrogen peroxide and methyl mercury-induced oxidative stress in GT1-7 mouse hypothalamic immortalized cells. Phyto-medicine 10: $39-47$.

Foyer, C. H. \& Shigeoka, S. 2011. Understanding oxidative stress and antioxidant functions to enhance photosynthesis. Plant Physiology 155: 93-100.

Guo, F.Q.; Okamoto, M.; Crawford, N. M. 2003. Identification of a plant nitric oxide synthase gene involved in hormonal signaling. Science 302: 100-103.

Hao, G-P \& Zang, J-H. 2010. The role of NO as a bioactive signaling molecule in plants under abiotic stress. Chapter 9. pp. 115-137. In: NO on plant Physiology. Edited by Hayat, S. Mori, M.; Pitchel, J.; Ahmad, A. Wiley-VCH Verlag GmbH \& Co. KGaA, Weinheim.

Hay, M. E. \& Fenical, W. 1988. Marine plant-herbivore interaction: the ecology of chemical defense. Ann. Rev. Ecol. Sist. 19: 111-145.

Hayat, S.; Hasan, S.A.; Mori, M.; Fariduddin, Q.; Ahmad, A. 2010. Nitric Oxide: Chemistry, Biosynthesis and Physiological role. Chapter 1. pp. 115-137. In: NO on plant Physiology. Edited by Hayat, S. Mori, M.; Pitchel, J.; Ahmad, A. Wiley-VCH Verlag GmbH \& Co. KGaA, Weinheim.

Heldt, H-W. 2011. Plant Biochemistry. Fourth edition. Elsevier. 618 p. 
Henley, H. J. \& Ramus, J. 1989. Time course of physiological response of Ulva rotundata to growth irradiance transitions Mar. Ecol. Prog. Ser. 54: 171-177.

Hong, J. K.; Yun, B.W.; Kang, J.-G.; Raja, M. U.; Kwon, E.; Sorhagen, K.; Chu, C.; Wang, Y.; Loake, G.J. 2008. Nitric oxide function and signalling in plant disease resistance Journal of Experimental Botany, Vol. 59, No. 2, pp. 147-154.

Hsu Y-T \& Lee, T-M. 2012. Nitric Oxide up-regulates the expression of methionine sulfoxide reductase genes in the intertidal macroalga Ulva fasciata for high light acclimation. Plant Cell Physiol. 53(2): 445-456.

Jiménez-Escrig, A.; Jiménez-Jiménez, I.; Pulido, R.; Saura-Calixto, F. 2001. Antioxidant activity of fresh and processed edible seaweeds. Journal of the Science of Food and Agriculture 1: 530-534.

Jayaraj, J.; Wan, A.; Rahman, M.; Punja, Z.K. 2008. Seaweed extract reduces foliar fungal diseases on carrot. Crop Protection 27:1360-1366.

Kirk, J.T.O. 1986. Light and photosintesis in aquatic ecosystems. Cambridge University Press. 401p.

Krieger-Liszkay, A.; Fufezan, C.; Trebst, A. 2008. Singlet oxygen production in photosystem II and related protection mechanism Photosynth Res 98:551-564.

Krieger-Liszkay, A; B. Kós, P. B. and Hideg, E. 2011. Superoxide anion radicals generated by methylviologen in photosystem I damage photosystem II. Physiologia Plantarum 142: 17-25.

Lachnit, T.; Blümel, M.; Imhoff, J. F.; Wahl, M. 2009. Specific epibacterial communities on macroalgae: phylogeny matters more than habitat. Aquatic Biology 5: 181-186.

Lamotte, O.; Gould, K.; Lecourieux, D.; Sequeira-Legrand, A.; Lebrun-Garcia, A.; Durner, J.; Pugin, A.; Wendehenne, D. 2004. Analysis of nitric oxide signaling functions in Tobacco cells challenged by the elicitor cryptogein. Plant Physiology 135: $516-529$.

Lattore, M. L. 1998. Utilização de um método de correção atmosférica para o processamento de dados hiperespectrais do sensor AVIRIS em regiões tropicais. Instituto Nacional de esquisas Espaciais. Dissertação de mestrado. 192p.

Le Tutour, B.; Benslimane, F.; Gouleau, M.P.; Gouygou, J.P.; Saadan, B.; Quemeneur, F. 1998. Antioxidant and pro-oxidant activities of the brown algae, Laminaria digitata, Himanthalia elongata, Fucus vesiculosus, Fucus serratus and Ascophyllum nodosum. Journal of Applied Phycology 10: 121-129.

Lesser, M.P. 2006. Oxidative stress in marine environments: Biochemistry and Physiological Ecology. Annual Review of Physiology 68: 253-78. 
Lim, S.N.; Cheung, P.C.K.; Ooi, V.E.C.; Ang, P.O. 2002. Evaluation of antioxidative activity of extracts from a brown seaweed, Sargassum siliquastrum. Journal of Agricultural and Food Chemistry 50: 3862-3866

Lobban C.S. \& Harrison P.J. 2000. Seaweed ecology and physiology, Cambridge Univ. Press, Cambridge, 366 p.

Matanjun, P.; Mohamed, S.; Mustapha, N.M.; Muhammad, K.; Ming, C.H. 2008. Antioxidant activities and phenolics content of eight species of seaweeds from north Borneo. Journal of Applied Phycology 20: 367-373.

Matsukawa, R.; Dubinsky, Z.; Kishimoto, E.; Masaki, K.; Masuda, Y.; Takeuchi, T.; Chihara, M.; Yamamoto, Y.; Niki, E.; Karube, I. 1997. A comparison of screening methods for antioxidant activity in seaweeds. Journal of Applied Phycology 9: 29-35.

Misra, A. N.;Misra, M.; Singh, R. 2011. Nitric oxide: A ubiquitous signaling molecule with diverse role in plants. African Journal of Plant Science Vol. 5(2), pp. 57-74.

Mittler, R.; Vanderauwera, S.; Suzuki, N.; Miller, G.; Tognetti, V.B.; Vandepoele, K.; Gollery, M.; Shulaev, V.; Breusegem, F.V. 2011. ROS signaling: the new wave? Trends in Plant Science.16(6): 300-309.

Monaghan, P.; Metcalfe, N. B.; Torres, R. 2009. Oxidative stress as a mediator of life history trade-offs: mechanisms, measurements and interpretation. Ecology Letters, 12: 75-92.

Murchie, E. H. \& Horton, P. 1997. Acclimation o f photosynthesis to irradiance and spectral quality in British plant species: chlorophyll content, photosynthetic capacity and habitat preference. Plant Cell and Environment. 20:438-448.

Necchi Jr., O. 2005. Light-related photosynthetic characteristics of freshwater rhodophytes. Aquatic Botany 82: 193-209.

Neill, S.J.; Desikan, R.; Clark, A.; Hurst, R.D.; Hancock, J.T. 2002. Hydrogen peroxide and oxide nitric as signalling molecules in plants. Journal of Experimental Botany. 53: 1237-1247.

Neill, S.J.; Desikan, R.; Hancock, J.T. 2003. Nitric oxide signaling in plants. New Phytologyst 159: 11-35.

Neill, S.; Barros, R.; Bright, J.; Desikan, R.; Hancock, J.; Harrison, J.; Morris, P.; Ribeiro, D.; Wilson, I. 2008. Nitric oxide, stomatal closure, and abiotic stress. Journal of Experimental Botany, Vol. 59, No. 2, pp. 165-176.

Neill, S.; Bright, J.; Desikan, R.; Hancock, J.; Harrison, J.; Wilson, I. 2008. Nitric oxide evolution and perception. Journal of Experimental Botany, Vol. 59, No. 1, pp. 25-35.

Nishiyama, Y.; Allakhverdiev, S. I.; Murata, N. 2011. Protein synthesis is the primary target of reactive oxygen species in the photoinhibition of photosystem II. Physiologia Plantarum 142: 35-46. 
Oliveira Filho, E.C.; Paula, E.J.; Plastino, E.M.; Petti, R. 1995. Metodologías para el cultivo no axénico de macroalgas marinas in vitro. In Manual de métodos ficológicos (K. Alveal, M.E. Ferrario, E.C. Oliveira \& E. Sar, eds.). Universidad de Concepción, Concepción, Chile, p.429-447.

Oliveira Filho, E. C. \& Miranda, G.E.C. 1998. Aspectos sociais e econômicos da explotação de algas marinhas no Brasil.. In: Congresso Brasileiro, Latinoamericano e Ibérico de Ficologia, Caxambu. Anais do IV Congresso Latino-Americano, II Reunião Ibero-Americana e VII Reunião Brasileira de Ficologia. S. Paulo: Exata Editoração, 1996. v. 2. p. 149-156.

Oliveira Filho, E. C. 1998. Seaweeds resources of Brazil. In: Critchelly A.T. Ohno M. (eds), seaweeds resources of the world. Japan international Cooperation Agency. 366371.

Paul, V.J. \& Hay, M.E. 1986. Seaweed susceptibility to herbivory: chemical and morphological correlates. Mar. Ecol. Prog. Ser. 33: 255-264.

Pérez-Rodriguez, E.; Aguilera, J.; Goméz, I.; Figueroa, F. L. 2001. Excretion of coumarins by the mediterranean green alga Dasycladus vermicularis in responses to environment stress. Marine Biology. 139: 633-639.

Pietta, P.G. 2000. Flavonoids as antioxidants. Journal of Natural Products 63: 10351042.

Pise, N.; Jena, K.; Maharana, D.; Gaikwad, D.; Jagtap, T. 2010. Free radical scavenging potential, reducing power, phenolic and biochemical constituents of Porphyra species from India J. Algal Biomass Utln. 1(3): 29-42.

Plastino, E.M. 1991. Cultivo in vitro, estudos reprodutivos e biossistemática de algas gracilarióides (Rhodophyta, Gracilariales) de talo cilíndrico. Universidade de São Paulo. Tese de doutorado.

Plastino, E.M. \& Mansilla, A. 2004. Luz y fotosíntesis. In: Werlinger, C. Biología Marina y Oceanografía: conceptos y procesos. Consejo Nacional del Libro y Lectura Universidad de Concepción. Trama Impressos S.A. Chile. 229-252p.

Plastino, E.M. \& Oliveira Filho, E. C. 2002. Gracilaria birdiae (Gracilariales, Rhodophyta), a new species from the tropical south Atlantic, with a terete frond and deep spermatangial onceptacles. Phycologia 41: 389-396.

Raven, J. A. 2011. The cost of photoinhibition. Physiologia Plantarum 142: 87-104.

Rmiki, N-E.; Brunet, C.; Cabioch, J.; Lemoine, Y. 1996. Xanthophyll-cycle and photosynthetic adaptation to environment in macro-and microalgae. Hydrobiologia 326/327: 407-413.

Rockel, P.; Strube, F.; Rockel, A.; Wildt, J.; Kaiser, W. M. 2002. Regulation of nitric oxide (NO) production by plant nitrate reductase in vivo and in vitro. Journal of Experimental Botany, Vol. 53, No 366, pp. 103-110. 
Rossel, J.B.; Wilson, I.W.; Pogson, B.J. 2002. Global changes in gene expression in response to high light in Arabidopsis. Plant Physiology 130: 1109-1120.

Rozema, J.; Bjorn, L.O.; Bornman ,J.F.; Gaberscik, A.; Hader, D.-P.; Trost, T.; Germ, M.; Klisch, M.; Groniger, A.; Sinha, R.P.; Lebert, M.; He, Y.-Y.; Buffoni-Hall, R.; de Bakker, N.V.J.; van de Staaij, J.; Meijkamp, B.B. 2002. The role of UV-B radiation in aquatic and terrestrial ecosystems - an experimental and functional analysis of the evolution of UV-absorbing compounds. Journal of Photochemistry and Photobiology B: Biology 66: 2-12.

Rümer, S.; Gupta, K. J.; Kaiser, W. M. 2009. Plant cells oxidize hydroxylamines to NO. Journal of Experimental Botany, Vol. 60, No. 7, pp. 2065-2072.

Santa-Catarina, C.; Silveira, V.; Scherer, G.F.E.; Floh, EI.S. 2007. Polyamine and nitric oxide levels relate with morphogenetic evolution in somatic embryogenesis of Ocotea catharinensis. Plant Cell Tissue and Organ Culture 90: 93-101.

Scandalios, J.G. 2005. Oxidative stress: molecular perception and transduction of signals triggering antioxidant gene defenses. Braz. J. Med. Biol. Res. 38: 995-1014.

Silveira, V.; Santa-Catarina, C.; Tun, N.N.; Scherer, G.F. E.; Handro, W.; Floh, E. I. S. 2006. Polyamine effects on the endogenous polyamine contents, nitric oxide release, growth and differentiation of embryogenic suspension cultures of Araucaria angustifolia (Bert.) O. Ktze. Plant Sci 171:91-98.

Skriptsova, A.V.; Yakovleva, I.M. 2002. The influence of variations in irradiance upon morphology in an unattached form of Gracilaria gracilis (Stackhouse) Steentoft during field cultivation, South Primorye, Russia. Aquatic Ecology 36: 511-518.

Smith, H. 1982. Light quality, photoreception and plant strategy. Ann. Rev. Plant. Physiol. 33:481-518.

Soares, M.; Welter, L.; Gonzaga, L.; Lima, A.; Mancini-Filho, J.; Fett, R. 2008. Avaliação da atividade antioxidante e identifcação dos ácidos fenólicos presentes no bagaço de maçã cv. Gala. Ciênc. Tecnol. Aliment., Campinas, 28(3): 727-732.

Sonoike, K. 2011. Photoinhibition of photosystem I. Physiologia Plantarum 142: 56-64.

Spath-Wiley, P.; Neefus, C.D.; Jahnke, L.S. 2008. Seasonal effects of sun exposure and emersion on intertidal seaweed physiology: fluctuations in antioxidant contents, photosynthetic pigments and photosynthetic efficiency in the red alga Porphyra umbilicalis Kützing (Rhodophyta, Bangiales). Journal of Experimental Marine Biology and Ecology 361: 83-91

Squadrito, G. L. \& Pryor, W. A. 1998. Oxidative chemistry of nitric oxide: the roles of Superoxide, Peroxynitrite, and Carbon Dioxide. Free Radical Biology \& Medicine, Vol. 25, Nos. 4/5, pp. 392- 403.

Sreenivasan, S.; Ibraim, D.; Kassim, J.K.M. 2007. Free radical scavenging activity and total phenolic compounds of Gracilaria changii. International Journal of Natural and Engineering Sciences 1: 115-117. 
Swain, T. 1977. Secondary compounds as protective agents. Ann. Rev. Plant Physiol. 28:479-501.

Szabo, M. R.; Iditoiu, C.; Chambre, D.; Lupea, A. X. 2007. Improved DPPH determination for antioxidant activity spectrophotometric assay. Chem. Pap. 61 (3) $214-216$.

Tun, N.N.; Holk, A.; Scherer, G.F.E. 2001. Rapid increase of NO release in plant cell cultures induced by cytokinin. FEBS Lett. 509: 174-176.

Vass, I. 2011. Role of charge recombination processes in photodamage and photoprotection of the photosystem II complex. Physiologia Plantarum 142: 6-16.

Vass, I.; Cser, K. 2009. Janus-faced charge recombinations in photosystem II photoinhibition. Trends in Plant Science, Vol.14, No.4, 200-205p.

Wendehenne, D.; Pugin, A.; Klessig, D.F. Durner, J. 2001. Nitric oxide: comparative synthesis and signaling in animal and plant cells. Trends in Plant Science 6: 177-183.

Wijesekara, I.; Senevirathne, M.; Li, Y-X; Kim, S-K. 2012. Functional ingredients from marine algae as potential antioxidants in the food industry. Handbook of Marine Macroalgae: Biotechnology and Applied Phycology. pp. 398-402.

Wynne, M. J. 2011. A checklist of benthic marine algae of the tropical and subtropical Western Atlantic: third revision. J. Cramer. Stuttgart. 166p.

Yan, X.; Nagata, T.; Fan, X. 1998. Antioxidant activities in some common seaweeds. Plant Foods or Human Nutrition 52: 253-262.

Young, A. \& Britton, G. 1993. Carotenoids in photosynthesis. Chapman \& Hall. 498p.

Yuan, Y. V. \& Walsh, N. A. 2006. Antioxidant and antiproliferative activities of extracts from a variety of edible seaweeds. Food and Chemical Toxicology 44:11441150.

Yuan, Y.V.; Bone, D.E.; Carrington, M.F. 2005. Antioxidant activity of dulse (Palmaria palmata) extract evaluated in vitro. Food Chemistry 91: 485-494.

Zar, J.H. 1999. Biostatistical analysis. Prentice Hall, Englewood Cliffs, New Jersey. 471p.

Zubia, M.; Robledo, D.; Freile-Pelegrin, Y. 2007. Antioxidant activities in tropical marine macroalgae from the Yucatan Peninsula, México. Journal of Applied Phycology 19: 449-458. 


\title{
CAPÍTULO I
}

Efeito da alta irradiância em Gracilariopsis tenuifrons (Gracilariales-Rhodophyta) sobre a taxa de crescimento, carbono, hidrogênio e nitrogênio tissulares, pigmentos e proteínas solúveis totais em laboratório

\begin{abstract}
Resumo
O excesso de PAR pode causar estresse luminoso em algas marinhas alterando pigmentos fotossintetizantes e proteínas, afetando também o desempenho da fotossíntese e interferindo em processos metabólicos básicos que refletem no crescimento do organismo e na produtividade primária. Com o objetivo de contribuir com o entendimento dos efeitos provocados pela irradiância em algas vermelhas, ápices de $3 \mathrm{~cm}$ de Gracilariopsis tenuifrons foram sujeitados a $60 \mu \mathrm{mol}$ de fótons. $\mathrm{m}^{-2} \cdot \mathrm{s}^{-1}$ e 600 $\mu$ mol de fótons. $\mathrm{m}^{-2} \cdot \mathrm{s}^{-1}$ durante uma semana, sendo as amostras coletadas durante o DIA e a NOITE. Sob alta PAR houve redução dos níveis de pigmentos fotossintetizantes, proteínas solúveis totais e conteúdo tissular de nitrogênio, enquanto o crescimento foi similar em ambos os tratamentos e o conteúdo tissular de carbono e hidrogênio reduzido.
\end{abstract}

\begin{abstract}
The excessive PAR can promote light stress in marine macroalgae, modifying the contents of photosynthetic pigments and proteins, affecting basic metabolic processes related to growth rate and primary productivity. The aim of this work was to understanding the effect of high irradiance on red macroalgae. Then, apical sections of 3 $\mathrm{cm}$ of Gracilariopsis tenuifrons were exposed to $60 \mu \mathrm{mol}$ of fótons. $\mathrm{m}^{-2} \cdot \mathrm{s}^{-1}$ and 600 $\mu$ mol of fótons. $\mathrm{m}^{-2} \cdot \mathrm{s}^{-1}$ for one week, and samples were collected during DAY and NIGHT periods. Under high light it was observed a decrease in photosynthetic pigments, total soluble proteins and tissular nitrogen contents, while growth rate was similar for both treatments and the contents of tissular carbon and hydrogen were diminished.
\end{abstract}




\section{Introdução}

A radiação fotossinteticamente ativa (PAR) é a faixa de luz visível, compreendida entre 400 e $700 \mathrm{~nm}$, usada pelos organismos para a execução da fotossíntese. A luz age influenciando direta e indiretamente aspectos fisiológicos de macroalgas como crescimento, desenvolvimento, reprodução (Henly \& Ramus, 1989; Lobban \& Harisson, 2000), desempenho fotossintetizante e de aclimatação (Demming et al., 1988; Aguilera et al., 1999; Carnicas et al., 1999; Dawes et al., 1999; Spath-Wiley et al., 2008). Também interfere em aspectos ecológicos como distribuição e sazonalidade (Rossel et al., 2002; Necchi Jr., 2005; Bautista \& Necchi Jr., 2007).

Deste modo, a intensidade da PAR age diretamente na fotossíntese e sua flutuação modifica a dinâmica fotossintetizante e pigmentar das algas marinhas. Quando intensificada, a PAR promove o aumento no transporte de energia através da cadeia transportadora de elétrons, havendo a elevação da produção de espécies reativas de oxigênio (ROS), que são moléculas altamente reativas, responsáveis, em parte, pelo estresse oxidativo, causando a oxidação de biomoléculas como proteínas, lipídeos e DNA.

O estresse luminoso pode ocasionar, em organismos fotossintetizantes, alterações anatômicas, fisiológicas, bioquímicas e moleculares. Sob excesso de luz, as macroalgas entram em processo de aclimatação, então são disparadas respostas em cadeia. Por isso, nos primeiros momentos de estresse, tendem a apresentar aumento na taxa de crescimento para evitar o acúmulo das ROS (Viñegla \& Figueroa, 2009; Torres, 2012). Entretanto, a continuação do estresse promove seu declínio (Mallick et al., 2002; Estevez \& Puntarullo, 2005), devido ao acúmulo de energia causado pelo excesso de irradiância disponível. Os pigmentos fotossintetizantes também sofrem os efeitos do estresse causado pelo excesso de irradiância. Em geral, sofrem degradação devido ao dano fotoxidativo (Foyer \& Shigeoka, 2011), disponibilizando assim componentes orgânicos (fontes de carbono) e inorgânicos (fontes nitrogenadas) que podem ser translocados para a formação de outros compostos para manutenção e defesa das células.

Em macroalgas, as ROS têm sido relacionadas à redução na quantidade de pigmentos fotossintetizantes, alterações do PSII (Häder et al., 2007) e diminuição e/ou modificação na composição de proteínas (Karsten \& Wiencke, 1999). Ademais, as ROS agem afetando a fluidez e permeabilidade de membranas (Karsten et al., 1998; Sinha et al., 2001; Korbee et al., 2006), a morfologia (Karsten \& Wiencke, 1999; Navarro et al., 
2010; Schmidt et al., 2010) e causando interferências de processos fisiológicos (por exemplo, fotossíntese - Häder et al. (2011); assimilação de nutrientes - Xu \& Gao (2010); crescimento - Aguilera et al. (1999); Altamirano et. al. (2000)), alterações genéticas e morte (Bischof et al, 2006). Esses efeitos conduzem à redução de produtividade e, consequentemente, afetam a estrutura e dinâmica ecológica da população e da comunidade associada (Karsten \& Wiencke, 1999; Bischof et al., 2006; Korbee et al., 2006).

Portanto, com o objetivo de contribuir para o entendimento do efeito da alta PAR, em condições de laboratório, sobre a fisiologia de macroalgas foi selecionada a agarófita nativa Gracilariopsis tenuifrons, mensurando-se o crescimento, a composição tecidual de carbono, hidrogênio e nitrogênio $(\mathrm{CHN})$, a composição pigmentar e as proteínas solúveis totais dos talos submetidos a dois regimes de irradiância de $60 \mu$ mol de fótons. $\mathrm{m}^{-2} \cdot \mathrm{s}^{-1}$ e $600 \mu \mathrm{mol}$ de fótons. $\mathrm{m}^{-2} \cdot \mathrm{s}^{-1}$. Além disso, foi estudada a possível variação decorrente do dia e da noite durante o período diário.

\section{Material e métodos}

\subsection{Delineamento experimental}

Talos de $3 \mathrm{~cm}$ de Gracilariopsis tenuifrons, em proporção de cultivo de $1 \mathrm{~g} \mathrm{MF}$ por $1 \mathrm{~L}$ de meio de cultivo VS $50 \%$, foram submetidos durante uma semana a dois regimes de irradiância: $60 \pm 5 \mu \mathrm{mol}$ de fótons. $\mathrm{m}^{-2} \cdot \mathrm{s}^{-1}$ (controle) e $600 \pm 10 \mu \mathrm{mol}$ de fótons. $\mathrm{m}^{-2} \cdot \mathrm{s}^{-1}$. As condições de cultivo em laboratório e demais especificações experimentais seguiram os procedimentos descritos em Material e métodos geral. Para não haver estresse nutricional, foi feita adição de VS 50\% $24 \mathrm{~h}$ antes das coletas de amostras para as análises químicas. Além disso, para minimizar variações no teor químico dos ápices submetidos às duas irradiâncias devido a diferenças no comprimento dos ápices, todos eles foram cortados para $3 \mathrm{~cm}$ antes de serem congelados para posteriores análises.

A coleta das amostras para as análises químicas foi realizada em dois momentos durante o período diário: durante o DIA, em que a alga foi coletada entre 4-6 h após o início do fotoperíodo, e a NOITE, quando a coleta ocorreu entre 2-3 h depois do início do período escuro. 
2.2. Taxa de crescimento e quantificação tecidual de carbono, hidrogênio e nitrogênio (CHN)

A taxa de crescimento (TC) foi mensurada com base na variação da massa fresca antes e depois do período experimental de 7 dias.

A porcentagem da taxa de crescimento foi calculada segundo a fórmula descrita por Lignell \& Pedersén (1989):

$$
\mathrm{TC}\left(\% . \mathrm{dia}^{-1}\right)=\left[\left(\mathrm{MF}_{\mathrm{f}} / \mathrm{MF}_{\mathrm{i}}\right)^{1 / \mathrm{t}}-1\right] \times 100
$$

onde, $\mathrm{MF}_{\mathrm{f}}=$ massa fresca final $\mathrm{MF}_{\mathrm{i}}=$ massa fresca inicial e $\mathrm{t}=$ tempo em dias.

As análises de biomassa seca e úmida foram feitas a partir do resíduo da padronização das amostras realizada $24 \mathrm{~h}$ antes da coleta. Essas análises foram feitas com base no registro da biomassa úmida do resíduo da padronização das amostras de Gp. tenuifrons em ambas as irradiâncias, que consecutivamente foram colocadas em estufa durante $48 \mathrm{~h}$ sob temperatura de $60^{\circ} \mathrm{C}$ e realizado o registro da biomassa seca. Os resultados de biomassa seca e úmida foram expressos em miligramas.

Ápices provenientes de ambos os tratamentos foram observados em microscópio óptico (MO) (Leica modelo DM4000B Alemanha) e em estereomicroscópio (Leica modelo Wild M3C, Alemanha). A análise anatômica foi realizada a partir de cortes transversais a mão livre, realizados com lâmina descartável. A coloração dos cortes foi feita com anilina $(0,1 \%)$ acidificada. Os cortes foram avaliados com e sem corante.

A quantificação tecidual de CHN foi realizada pela Central Analítica do Instituto de Química da USP utilizando o analisador de elementos CHN Perkin Elmer (EUA) modelo 2400. Amostras de Gp. tenuifrons secas em estufa até massa constante e trituradas (1 mg) foram carbonizadas a $926^{\circ} \mathrm{C}$ em presença de oxigênio puro, promovendo a completa oxidação da matéria. Todo o carbono das amostras foi convertido em gás carbônico $\left(\mathrm{CO}_{2}\right)$, o hidrogênio em água $\left(\mathrm{H}_{2} \mathrm{O}\right)$ e o nitrogênio formou vários óxidos $\left(\mathrm{N}_{\mathrm{x}} \mathrm{O}_{\mathrm{x}}\right)$, que em seguida foram reduzidos para gás nitrogênio $\left(\mathrm{N}_{2}\right)$. Esses elementos resultantes da combustão foram arrastados por gás hélio até uma coluna cromatográfica de redução $\left(\right.$ a $640^{\circ} \mathrm{C}$ ), que separa os produtos e os detecta por condutividade térmica. Os resultados dessas análises foram calculados de acordo com o porcentual dos elementos obtidos na análise $\mathrm{CHN}$ e expressos em miligramas por grama de massa seca (mg.g $\left.\mathrm{MS}^{-1}\right)$.

As análises de taxa de crescimento, biomassa seca e úmida e conteúdo tecidual de $\mathrm{CHN}$ foram realizadas apenas comparando $60 \mu \mathrm{mol}$ de fótons. $\mathrm{m}^{-2} . \mathrm{s}^{-1}$. e $600 \mu \mathrm{mol}$ de fótons. $\mathrm{m}^{-2} \cdot \mathrm{s}^{-1}$. 


\subsection{Pigmentos fotossintetizantes e proteínas solúveis totais (PST)}

Análises dos teores de ficobiliproteínas, proteínas solúveis totais (PST), clorofila-a (Chl-a) e carotenoides totais foram realizadas a partir de amostras de $70 \mathrm{mg}$ $\mathrm{MF}$, congeladas em nitrogênio líquido e armazenas em ultrafreezer $\left(-80^{\circ} \mathrm{C}\right)$ até sua análise.

As análises foram feitas de acordo com o descrito por Wanderley (2009) com leves modificações. Cada amostra foi triturada com mixer (Omnit-TIP, EUA) em microtubo e nitrogênio líquido até obter-se pó fino. $\mathrm{O}$ material foi suspenso em $1 \mathrm{~mL}$ de tampão fosfato de sódio $(50 \mathrm{mM})$, gelado $\left(4^{\circ} \mathrm{C}\right) \operatorname{com} \mathrm{pH}$ 5,5. Após suspensão, o homogeneizado foi preservado da fotodegradação e acondicionado em gelo para reduzir a deterioração dos pigmentos. $\mathrm{O}$ homogeneizado foi centrifugado a $14000 \mathrm{rpm}, 4^{\circ} \mathrm{C}$ por 20 min. O sobrenadante foi recolhido e mantido no escuro a $4^{\circ} \mathrm{C}$ até leitura da absorbância das ficobiliproteínas e PST e o pellet foi preservado sob temperatura de $4^{\circ} \mathrm{C}$ para extração da Chl-a e carotenoides totais.

As ficobiliproteínas foram analisadas em espectrofotômetro UV-visível Hewlett Packard, modelo 8452A (EUA), com varredura entre 400-700 nm e usando cubeta de quartzo de $1 \mathrm{~cm}$ de percurso ótico. A calibragem e zeragem do equipamento foram feitas com o mesmo tampão fosfato de extração. Os dados de ficobiliproteínas foram padronizados pela massa fresca (MF) e a concentração determinada de acordo com as fórmulas de Beer \& Eshel (1985):

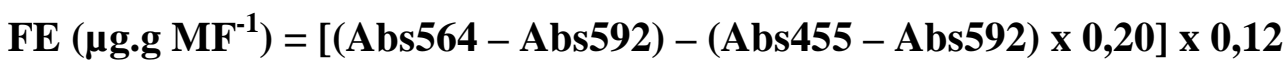

$$
\begin{aligned}
& \text { FC }\left(\mu \mathrm{gg.g} \mathrm{MF}^{-1}\right)=[(\text { Abs618 }- \text { Abs645 })-(\text { Abs592 - Abs645 }) \text { x 0,51] x 0,15 }
\end{aligned}
$$

onde, $\mathrm{FE}$ corresponde ao pigmento ficoeritrina, $\mathrm{FC}$ a ficocianina e Abs à absorbância no comprimento de onda especificado para cada absorbância.

O teor de PST foi mensurado a partir de uma alíquota de $40 \mu \mathrm{L}$ do extrato das ficobiliproteínas baseando-se no método de Bradford (1976). Para isso foi utilizado o reagente para ensaio protéico da Bio-Rad (Bio-Rad, EUA) em concentração de 25\%, diluído em água Milli-Q. A curva de calibração padrão foi construída com albumina de soro de bovino (BSA). As PST foram analisadas em espectrofotômetro UV-visível Hewlett Packard, modelo 8452A (EUA) sob comprimento de onda de $595 \mathrm{~nm}$ e usando cubetas de quartzo com $1 \mathrm{~cm}$ de percurso ótico. A calibragem e zeragem do equipamento foram feitas com reagente Bio-Rad diluído em 25\% com água Milli-Q. 
O material sedimentado (pellet) e reservado após a centrifugação do extrato para a quantificação de ficobiliproteínas foi ressuspendido em 1,5 mL de dimetilformamida (DMF), homogeneizado e extraído por mais de $3 \mathrm{~h}$ no escuro e $4^{\circ} \mathrm{C}$ para estimar o teor de Chl-a e carotenoides totais. O extrato foi centrifugado a $14000 \mathrm{rpm}$ e $4^{\circ} \mathrm{C}$ pelo período de 15 min. A absorbância do sobrenadante foi lida em espectrofotômetro UVvisível Hewlett Packard, modelo 8452A (EUA), com varredura entre 400-700 nm e usando cubeta de quartzo de $1 \mathrm{~cm}$ de percurso ótico. A calibragem e zeragem do equipamento foram realizadas com DMF. Os resultados de Chl-a e carotenoides totais foram padronizados pela massa fresca (MF) e as concentrações destes pigmentos determinadas de acordo com as fórmulas modificadas segundo Chow \& Wanderley (com. pess.):

\section{Chl-a $\left(\mu \mathrm{g} . \mathrm{g} \mathrm{MF}^{-1}\right)=11,0607 \times$ Abs664 \\ Carotenoides $\left(\mu \mathrm{g} . \mathrm{g} \mathrm{MF} \mathrm{MF}^{-1}\right)=(1000 \times \mathrm{Abs480}$ - 0,89 $\times$ Chl-a $) / 245$}

onde, Chl-a corresponde à clorofila-a e Abs664 e Abs480 às absorbâncias registradas em $664 \mathrm{~nm}$ e $480 \mathrm{~nm}$, respectivamente.

\subsection{Análise estatística}

A taxa de crescimento, biomassa seca e úmida e o conteúdo tecidual de $\mathrm{CHN}$ foram analisados aplicando o teste t de Student. O teor de ficobiliproteínas, proteínas solúveis totais, clorofila e carotenoides foram avaliados a partir de análise de variância (ANOVA) uni-fatorial, prévio testes de normalidade de Kolgomorov-Smirnof e homocedasticidade de Bartlett, e testes a posteriori de Tukey foram aplicados de acordo com a significância das análises. As análises foram realizadas dentro de um intervalo de confiança de $95 \%$ ( $\mathrm{p}<0,05)$, utilizando o programa STATISTICA v. 6.0 e seguindo especificações de Zar (1999).

\section{Resultados}

\subsection{Taxa de crescimento e composição tecidual (CHN)}

Ápices de $3 \mathrm{~cm}$ de comprimento de Gracilariopsis tenuifrons submetidos às condições de $60 \pm 5 \mu \mathrm{mol}$ de fótons. $\mathrm{m}^{-2} \cdot \mathrm{s}^{-1}$ (controle) e $600 \pm 10 \mu \mathrm{mol}$ de fótons. $\mathrm{m}^{-2} . \mathrm{s}^{-1}$ (tratamento) mostraram coloração diferente após uma semana de experimento. Sob 600 $\mu$ mol de fótons. $\mathrm{m}^{-2} \cdot \mathrm{s}^{-1}$, os ápices apresentaram coloração esverdeada a amarelada (Figura 4A), enquanto os submetidos a $60 \mu \mathrm{mol}$ de fótons. $\mathrm{m}^{-2} \cdot \mathrm{s}^{-1}$ apresentaram coloração avermelhada normal (Figura 4B). 


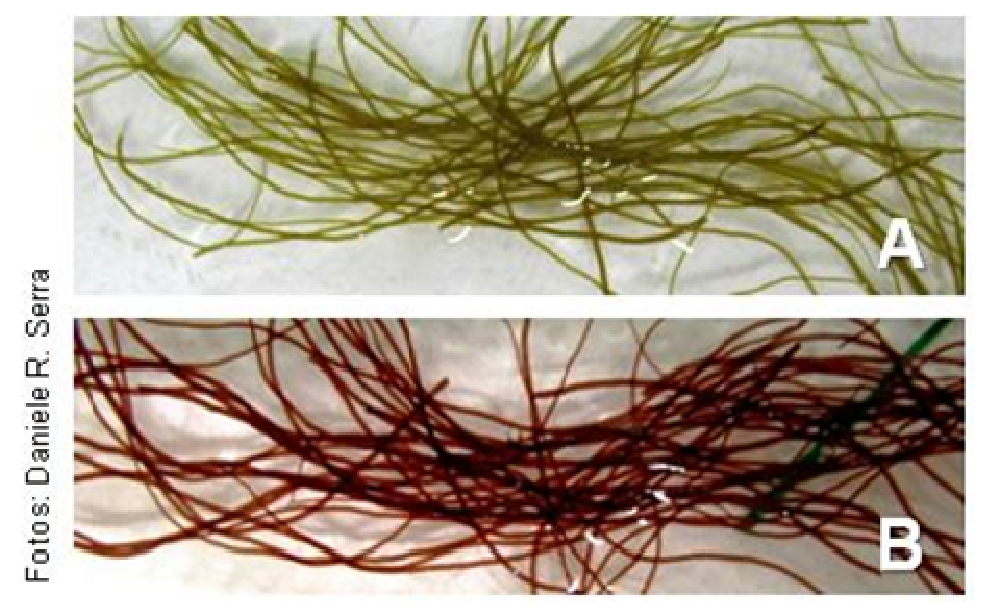

Figura 4: Aspecto geral dos ápices de Gracilariopsis tenuifrons após uma semana em condições experimentais. A: algas submetidas a $600 \mu \mathrm{mol}$ de fótons. $\mathrm{m}^{-2} . \mathrm{s}^{-1}$ e $\mathbf{B}$ : algas submetidas a $60 \mu \mathrm{mol}$ de fótons. $\mathrm{m}^{-2} \cdot \mathrm{s}^{-1}$.

Também foi possível perceber variações no comprimento dos ápices sob 600 $\mu \mathrm{mol}$ de fótons. $\mathrm{m}^{-2} \cdot \mathrm{s}^{-1}$, que embora tenham apresentado maior comprimento (Figura $5 \mathrm{~A}$ e B), a taxa de crescimento não mostrou diferenças significativas a do grupo controle. Além disso, ápices submetidos a $600 \mu \mathrm{mol}$ de fótons. $\mathrm{m}^{-2} . \mathrm{s}^{-1}$ apresentaram-se enrolados ou com as extremidades enroladas (Figura 5C). Os talos submetidos a alta PAR exibiram ainda regiões descoradas e até necrosadas (Figura 5C). Ápices submetidos a $600 \mu \mathrm{mol}$ de fótons. $\mathrm{m}^{-2} \cdot \mathrm{s}^{-1}$ apresentaram maior resistência e elasticidade do que os submetidos a $60 \mu \mathrm{mol}$ de fótons. $\mathrm{m}^{-2} \cdot \mathrm{s}^{-1}$.
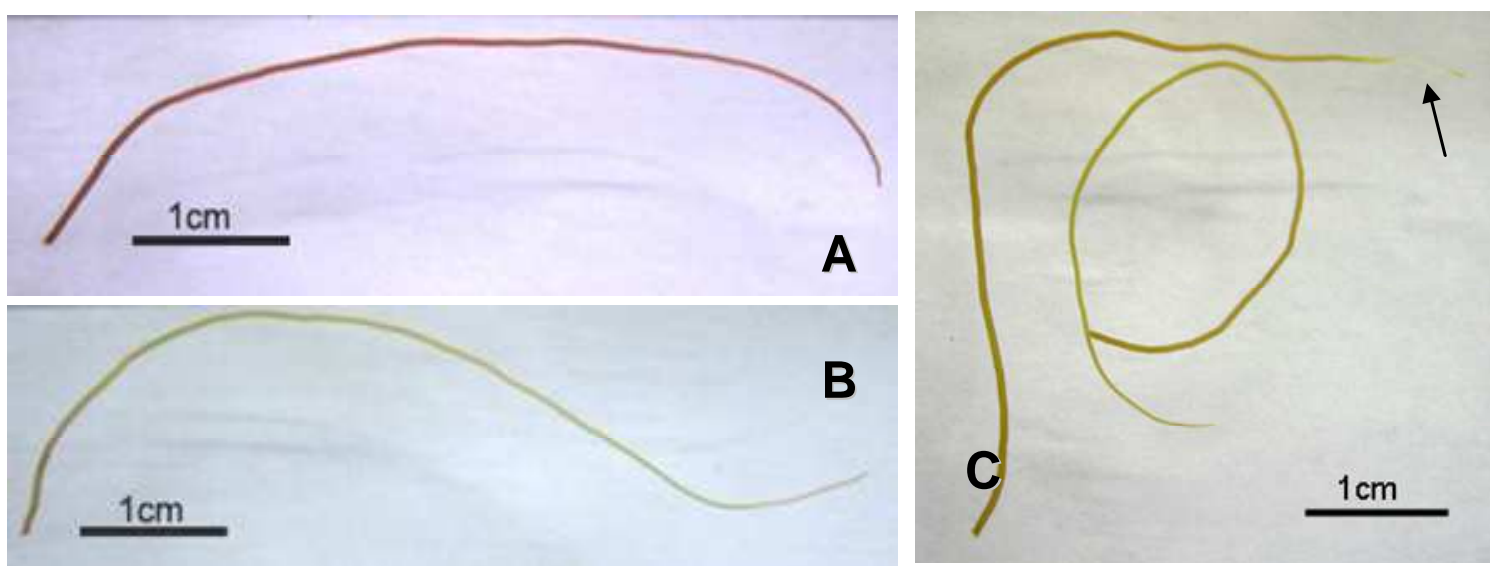

Figura 5: Imagens de Gracilariopsis tenuifrons após período experimental. A: ápice avermelhado exposto a $60 \mu \mathrm{mol}$ de fótons. $\mathrm{m}^{-2} \cdot \mathrm{s}^{-1}$. B: ápice curvado e esverdeado submetido a $600 \mu \mathrm{mol}$ de fótons. $\mathrm{m}^{-2} . \mathrm{s}^{-1}$. C: Talos expostos a $600 \mu \mathrm{mol}$ de fótons. $\mathrm{m}^{-2} . \mathrm{s}^{-1}$ enrolados. Flecha negra aponta região esbranquiçada do ápice. 
Amostras do controle e do tratamento foram observadas em microscópio óptico (Figura 6). E ao examinar o aspecto geral dos ápices, percebeu-se que os talos submetidos a $60 \mu \mathrm{mol}$ de fótons. $\mathrm{m}^{-2} \cdot \mathrm{s}^{-1}$ exibiram superfície lisa (Figura 6A), enquanto nos ápices do tratamento pôde-se notar a presença de numerosos "pêlos" hialinos (Figura 6B).

Cortes anatômicos permitiram a comparação da organização celular dos talos sob os diferentes tratamentos. Algas submetidas ao tratamento de $60 \mu \mathrm{mol}$ de fótons.m ${ }^{-}$ ${ }^{2} . \mathrm{s}^{-1}$ apresentaram células corticais menores, de formato oblongo e espaçadas entre elas (Figura 6C). Entretanto, ao observar e comparar a anatomia dos talos submetidos a 600 $\mu$ mol de fótons. $\mathrm{m}^{-2} \cdot \mathrm{s}^{-1}$ com os do controle foi possível notar que as células corticais exibiram maior tamanho, parede celular espessada, formato globoso e densa disposição (Figura 6D).

Os resultados de taxa de crescimento não mostraram diferença significativa entre os tratamentos (teste $\mathrm{t}: \mathrm{p}=0,518$ ). A taxa de crescimento das algas submetidas a 60 $\mu$ mol de fótons. $\mathrm{m}^{-2} . \mathrm{s}^{-1}$ foi de $12,54 \pm 2,11 \% \cdot \mathrm{dia}^{-1}$, enquanto os talos do tratamento apresentaram taxa de crescimento de $12,86 \pm 2,54 \% \cdot \operatorname{dia}^{-1}$ (Figura 7A). 


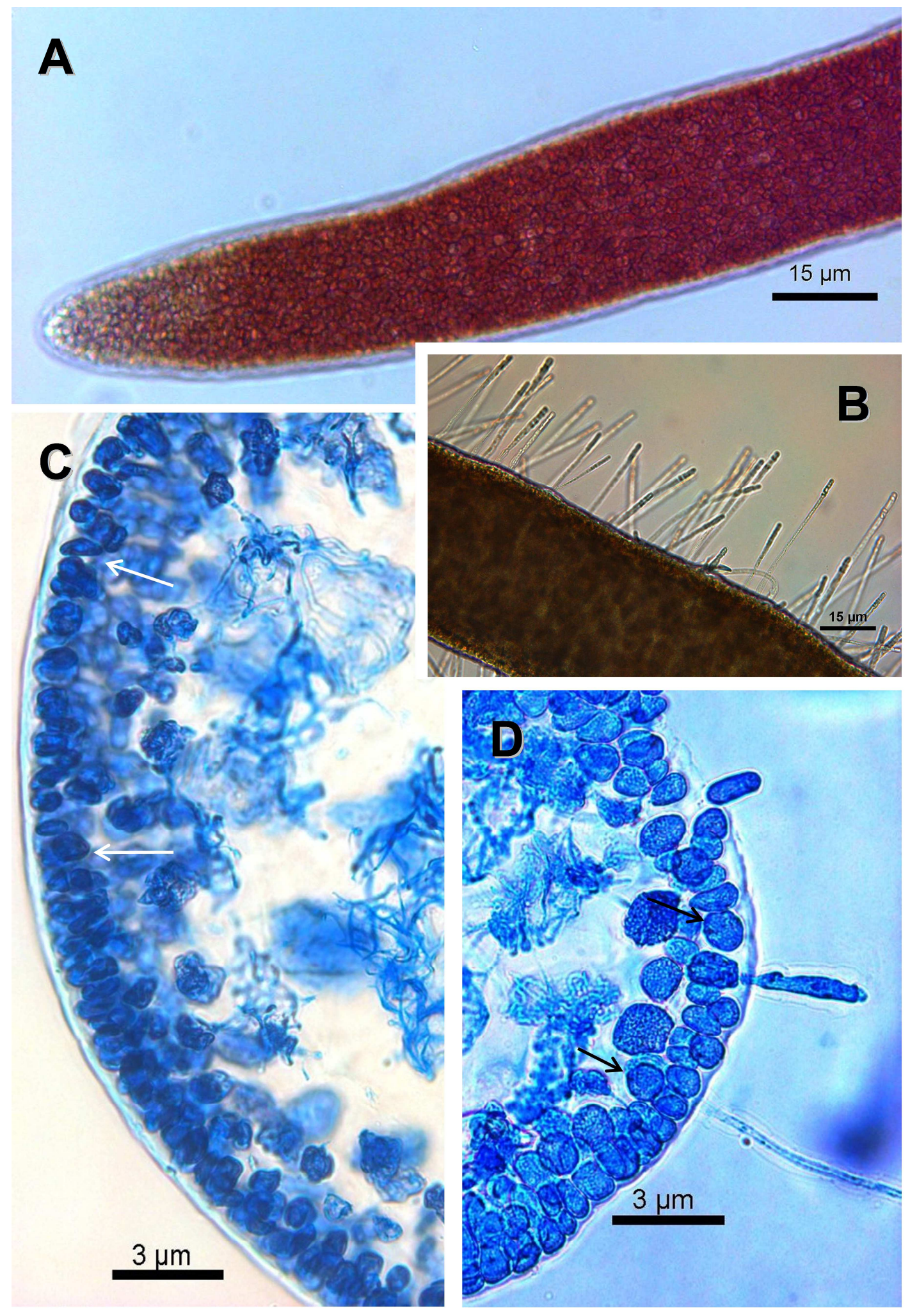

Figura 6: Imagens de Gracilariopsis tenuifrons após período experimental. A: aspecto geral de ápice do grupo controle livre dos "pêlos". B: aspecto geral de ápice do grupo tratamento evidenciando "pêlos". C: seção transversal da região subapical de talo submetido a $60 \mu \mathrm{mol}$ de fótons. $\mathrm{m}^{-2} \cdot \mathrm{s}^{-1}$ (controle) corado com azul de anilina acidificada $(0,1 \%)$. Flechas brancas apontam células corticais. D: seção transversal da região subapical do talo submetido a $600 \mu \mathrm{mol}$ de fótons. $\mathrm{m}^{-2} \cdot \mathrm{s}^{-1}$ (tratamento) corado com azul de anilina acidificada $(0,1 \%)$. Flechas negras apontam células do córtex. 
Como a taxa de crescimento, os resultados de biomassa úmida após o período experimental não apresentaram diferença significativa entre os tratamentos (teste $t: p=$ 0,663), sendo 288, $2 \pm 170,8 \mathrm{mg}$ para os talos sob $60 \mu \mathrm{mol}$ de fótons. $\mathrm{m}^{-2} \cdot \mathrm{s}^{-1}$ e de $303 \pm$ $144,9 \mathrm{mg}$ para os talos expostos a $600 \mu \mathrm{mol} \mathrm{de}$ fótons. $\mathrm{m}^{-2} \cdot \mathrm{s}^{-1}$ (Figura 7B). Por outro lado, houve diferença significativa (teste t: $\mathrm{p}=0,003$ ) para a biomassa seca, sendo de $39,4 \pm 21,6 \mathrm{mg}$ para os talos sob $60 \mu \mathrm{mol}$ de fótons. $\mathrm{m}^{-2} \cdot \mathrm{s}^{-1}$ e de 44,8 $\pm 18,3 \mathrm{mg}$ para os ápices sujeitados a $600 \mu \mathrm{mol}$ de fótons. $\mathrm{m}^{-2} \cdot \mathrm{s}^{-1}$ (Figura 7B).

A

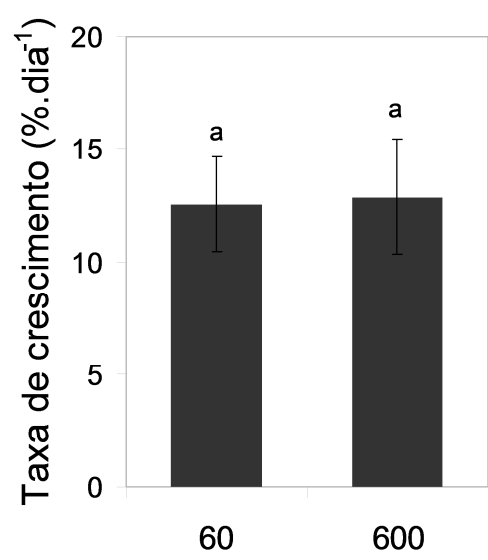

D

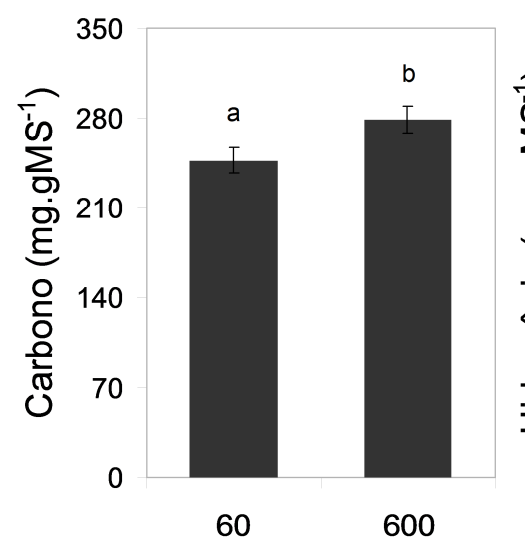

B

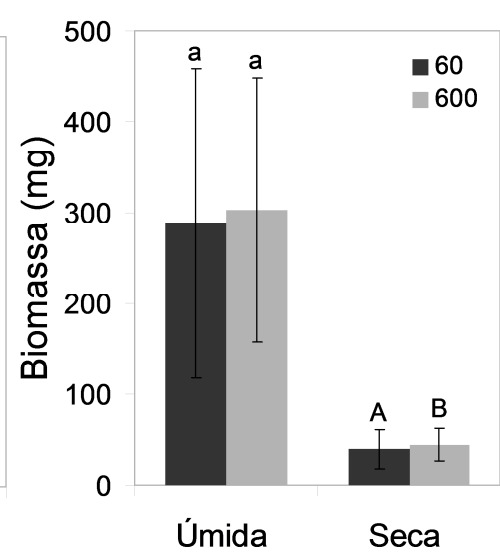

$\mathbf{E}$

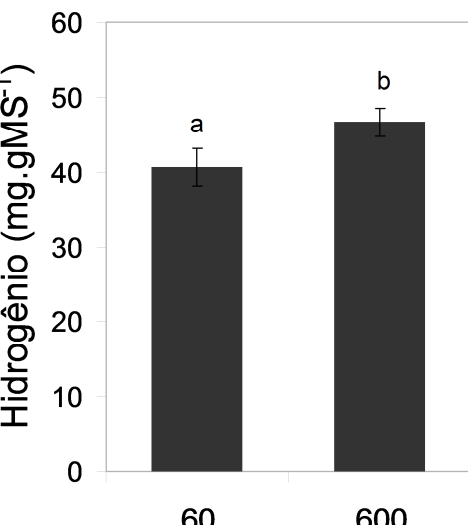

C

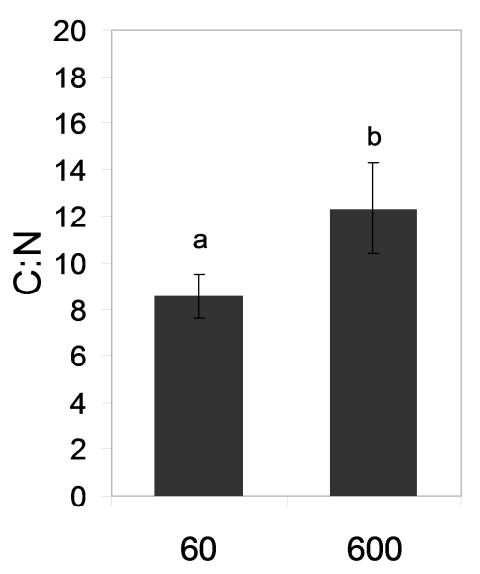

$\mathbf{F}$

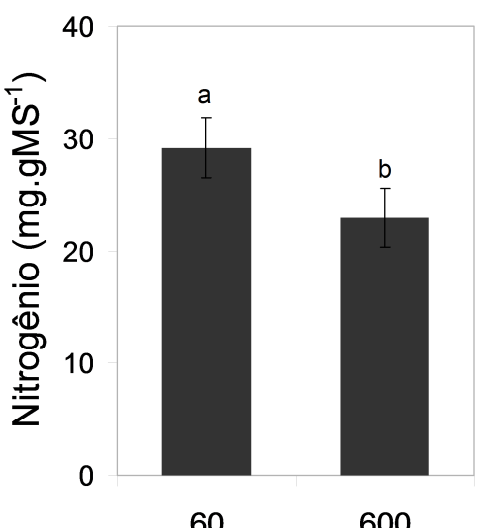

Figura 7: A: taxa de crescimento $(n=46), \mathbf{B}$ : porcentagem de biomassa seca $(n=42)$ e úmida $(\mathrm{n}=42)$, C: proporção carbono e nitrogênio $(\mathrm{C}: \mathrm{N}), \mathbf{D}$ : teor tissular de carbono $(\mathrm{n}$ $=20)$, E: teor tissular de hidrogênio $(n=20)$ e $\mathbf{F}$ : teor tissular de nitrogênio $(n=20)$ de Gracilariopsis tenuifrons após uma semana sob 60 e $600 \mu \mathrm{mol}$ de fótons. $\mathrm{m}^{-2} . \mathrm{s}^{-1}$. Letras diferentes representam diferenças significativas $(\mathrm{p}<0,05)$.

A razão carbono/nitrogênio $(\mathrm{C}: \mathrm{N})$ exibiu diferença significativa (teste $\mathrm{t}: \mathrm{p}=$ $0,000)$ entre os tratamentos. Os talos submetidos a $60 \mu \mathrm{mol}$ de fótons. $\mathrm{m}^{-2} \cdot \mathrm{s}^{-1}$ exibiram $8,5 \pm 0,9$, sendo então uma proporção de $247 \mathrm{C}: 29 \mathrm{~N}$ e os talos sob $600 \mu$ mol de fótons. $\mathrm{m}^{-2} \cdot \mathrm{s}^{-1}$ apresentaram 12,3 $\pm 1,9$ com proporção de 278C:23N (Figura 7C). 
Os dados individuais da análise tecidual de $G p$. tenuifrons mostram diferenças significativas para os três elementos analisados (teste t: $\mathrm{p}=0,000$ para todas as análises). Os valores de carbono registrados para o grupo controle foram de 247,025 \pm 9,54 mg.gMS ${ }^{-1}, 11 \%$ menores do que os talos do tratamento, que apresentaram 278,465 $\pm 10,45$ mg.gMS ${ }^{-1}$ de carbono (Figura 7D). O valor de hidrogênio foi $12 \%$ maior para o grupo tratamento $\left(46,67 \pm 2,55 \mathrm{mg} \cdot \mathrm{gMS}^{-1}\right)$ do que para o grupo controle $(40,63 \pm 1,87$ mg.gMS ${ }^{-1}$ ) (Figura 7E). Diferente do padrão de $\mathrm{C}$ e $\mathrm{H}$, os dados de nitrogênio foram $21 \%$ maiores para o grupo controle $\left(29,14 \pm 2,68 \mathrm{mg} \cdot \mathrm{gMS}^{-1}\right)$ em relação ao grupo tratamento $\left(22,915 \pm 2,59 \mathrm{mg} \cdot \mathrm{gMS}^{-1}\right)$ (Figura $\left.7 \mathrm{~F}\right)$.

\subsection{Composição pigmentar e teor de proteínas solúveis totais}

Os resultados da quantificação de ficoeritrina (FE) e ficocianina (FC) exibiram diferenças significativas entre as irradiâncias $60 \mu \mathrm{mol}$ de fótons. $\mathrm{m}^{-2} . \mathrm{s}^{-1}$ e $600 \mu \mathrm{mol} \mathrm{de}$ fótons. $\mathrm{m}^{-2} \cdot \mathrm{s}^{-1}$ (ANOVA: $\mathrm{p}=0,000$ para FE e $\mathrm{p}=0,000$ para FC). Entretanto, não houve diferenças significativas entre DIA e NOITE. O teor de ficobiliproteínas foi maior em algas submetidas à irradiância de $60 \mu \mathrm{mol}$ de fótons. $\mathrm{m}^{-2} \cdot \mathrm{s}^{-1}$ do que $600 \mu \mathrm{mol}$ de fótons. $\mathrm{m}^{-2} \cdot \mathrm{s}^{-1}$ (Figura $8 \mathrm{~A}$ para FE e Figura B para FC).

Os ápices expostos a $60 \mu \mathrm{mol}$ de fótons. $\mathrm{m}^{-2} \cdot \mathrm{s}^{-1}$ exibiram valores de $\mathrm{FE}$ de $1386,318 \pm 285,16 \mu \mathrm{g} \cdot \mathrm{gMF}^{-1}$ para o DIA e $1361,699 \pm 154,682 \mu \mathrm{g} \cdot \mathrm{gMF}^{-1}$ para a NOITE, enquanto os talos expostos a $600 \mu \mathrm{mol}$ de fótons. $\mathrm{m}^{-2} \cdot \mathrm{s}^{-1}$ apresentaram concentração de FE de 358,317 $\pm 113,357 \mu \mathrm{g} \cdot \mathrm{gMF}^{-1}$ para o DIA e 422,38 \pm 85,605 $\mu \mathrm{g} \cdot \mathrm{gMF}^{-1}$ para a NOITE (Figura $8 \mathrm{~A}$ ). Os resultados de FE foram cerca de $74 \%$ e $69 \%$ menores nos talos expostos a $600 \mu \mathrm{mol}$ de fótons. $\mathrm{m}^{-2} \cdot \mathrm{s}^{-1}$ para DIA e NOITE respectivamente. 
A

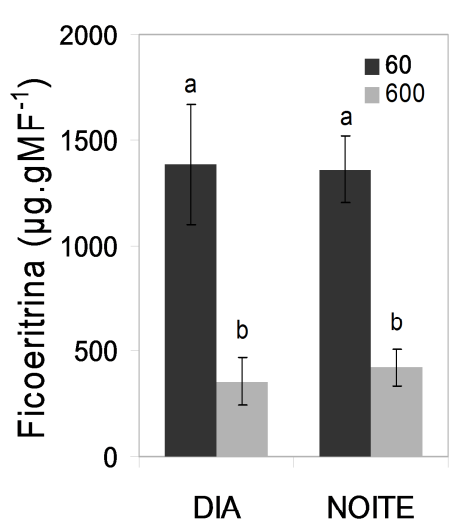

D
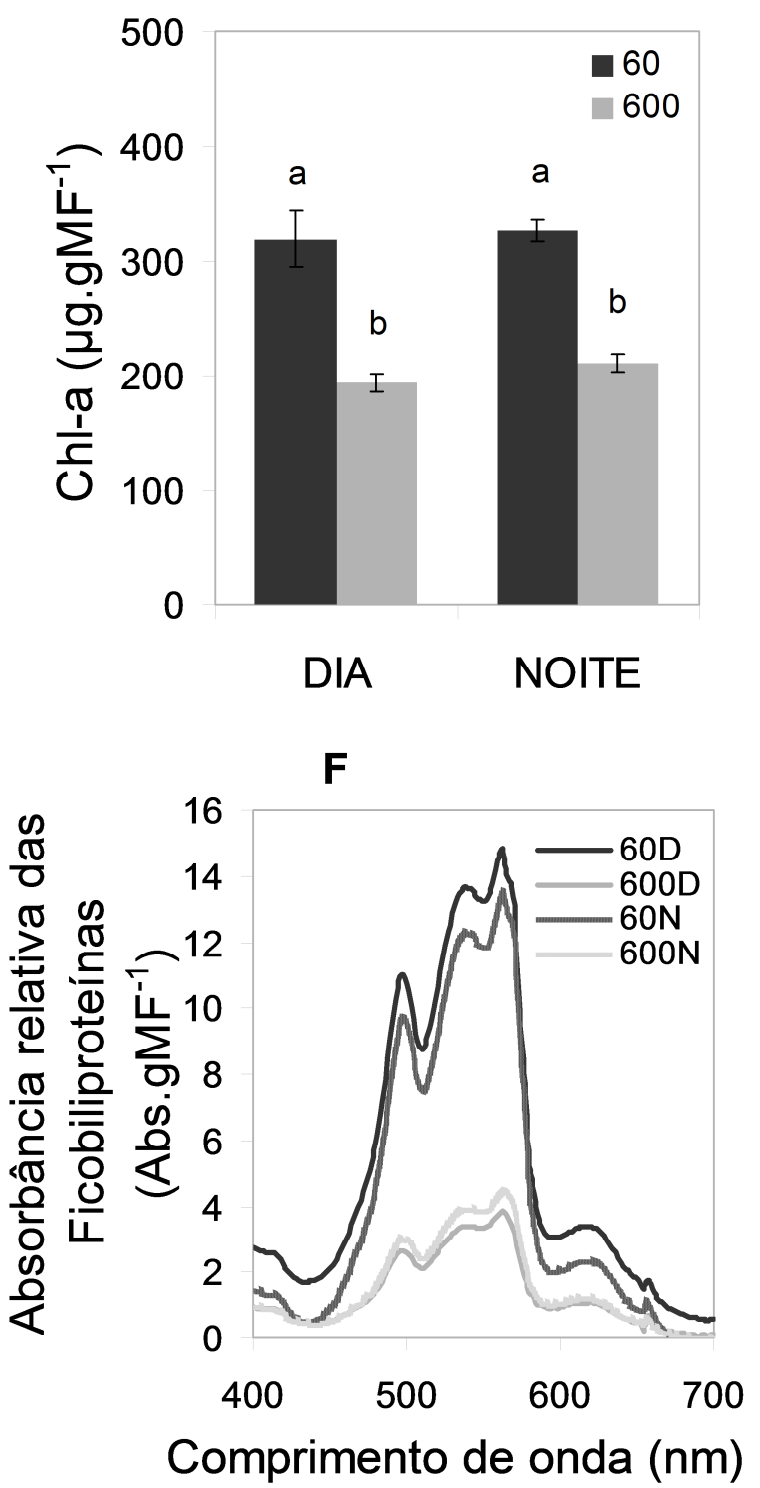

B

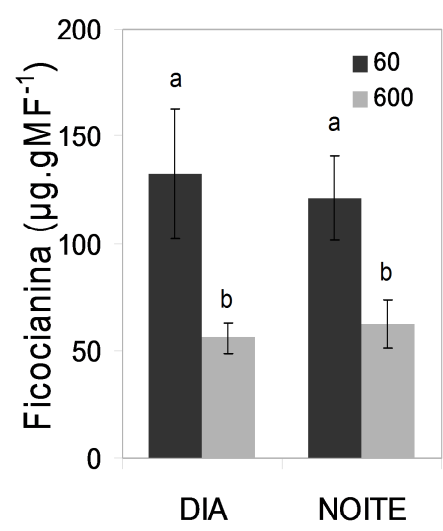

C

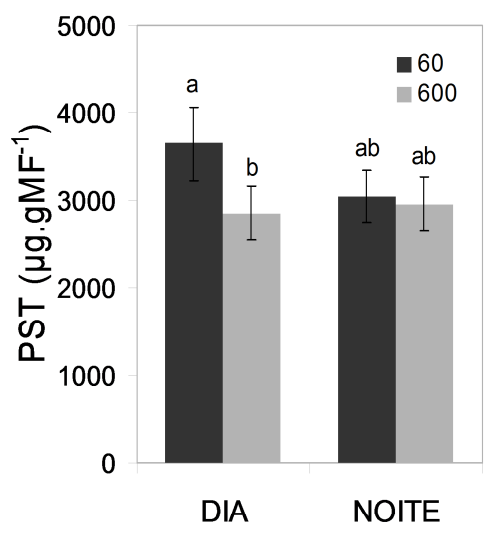

E

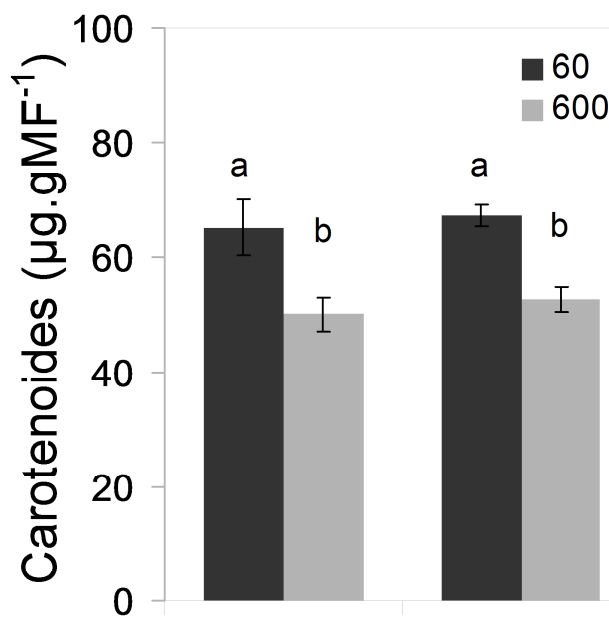

DIA

NOITE

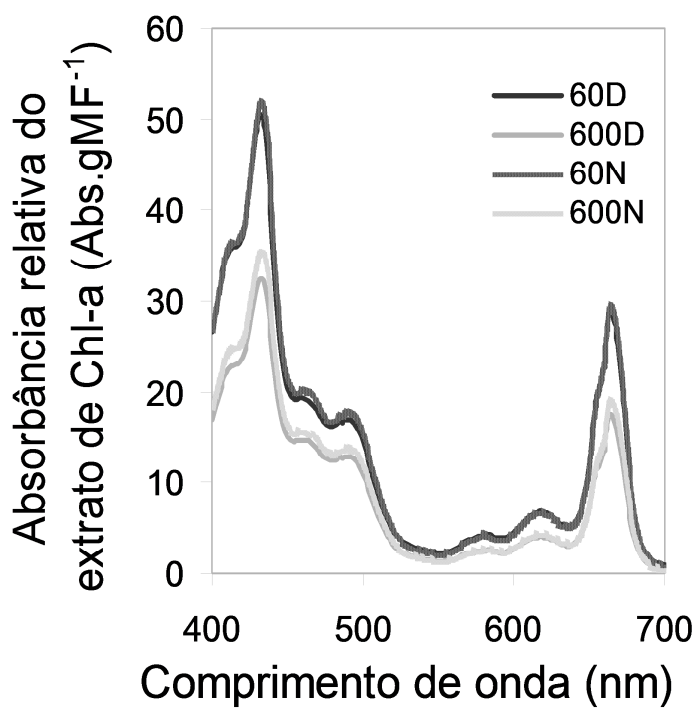

Figura 8: Teor de pigmentos fotossintetizantes e proteínas solúveis totais de amostras de Gracilariopsis tenuifrons submetidas às irradiâncias de $60 \mu \mathrm{mol}$ de fótons. $\mathrm{m}^{-2} \cdot \mathrm{s}^{-1} \mathrm{e}$ $600 \mu \mathrm{mol}$ de fótons. $\mathrm{m}^{-2} . \mathrm{s}^{-1}$ por uma semana. Amostras coletadas em dois momentos: DIA e NOITE. A: ficoeritrina, B: ficocianina, C: proteínas solúveis totais (PST), D: 
clorofila-a (Chl-a) e E: carotenoides totais. Letras diferentes representam diferenças significativas $(\mathrm{p}<0,05)$. F e G: espectros de varredura $(400-700 \mathrm{~nm})$ da absorbância relativa padronizada pela biomassa fresca $(\mathrm{MF})\left(\mathrm{Abs}_{\mathrm{gMF}} \mathrm{gM}^{-1}\right)(\mathrm{n}=5)$ de $\mathbf{F}$ : extratos de ficobiliproteínas e G: extratos de clorofila-a e carotenoides.

$\mathrm{Na}$ análise das FC observou-se maiores quantidades para o $60 \mu \mathrm{mol}$ de fótons.m ${ }^{-}$ ${ }^{2} . \mathrm{s}^{-1}$ do que $600 \mu \mathrm{mol}$ de fótons.m ${ }^{-2} \cdot \mathrm{s}^{-1}$, sendo $132,257 \pm 30,355 \mu \mathrm{g} \cdot \mathrm{gMF}^{-1}$ e $121,216 \pm$ $19,58 \mu \mathrm{g} \cdot \mathrm{gMF}^{-1}$ para DIA e NOITE, respectivamente, para o grupo controle (Figura 8B). Os teores de FC foram de $57 \%$ e $48 \%$ a mais para o controle do que para as algas em intensidade de $600 \mu \mathrm{mol}$ de fótons. $\mathrm{m}^{-2} . \mathrm{s}^{-1}$, que exibiram 55,985 \pm 7,38 $\mu \mathrm{g} \cdot \mathrm{gMF}^{-1}$ DIA e $62 \pm 11,35 \mu \mathrm{g} \cdot \mathrm{gMF}^{-1}$ NOITE (Figura 8B).

A quantidade de proteínas solúveis totais (PST) apresentou diferenças significativas entre os tratamentos (ANOVA: $p=0,037$ ). Os valores de PST em 60 $\mu$ mol de fótons. $\mathrm{m}^{-2} . \mathrm{s}^{-1}$ foram de $3641,15 \pm 420,5 \mu \mathrm{g} \cdot \mathrm{gMF}^{-1}$ para $60 \mathrm{D}$ e $2853,58 \pm$ 310,01 $\mu \mathrm{g} \cdot \mathrm{gMF}^{-1}$ para 600D (Figura 8C), sendo estatisticamente diferentes. Não houve diferença significativa entre os tratamentos para a NOITE, 3044,66 $\pm 292,09 \mu \mathrm{g} . \mathrm{gMF}^{-1}$ para $60 \mathrm{~N} \mathrm{e} 2953,58 \pm 312,64 \mu \mathrm{g} \cdot \mathrm{gMF}^{-1}$ para $600 \mathrm{~N}$ (Figura $8 \mathrm{C}$ ).

Os resultados da quantificação da clorofila-a e carotenoides apresentaram diferenças significativas entre as irradiâncias de $60 \mu \mathrm{mol}$ de fótons. $\mathrm{m}^{-2} \cdot \mathrm{s}^{-1}$ e $600 \mu \mathrm{mol}$ de fótons. $\mathrm{m}^{-2} \cdot \mathrm{s}^{-1}$, independente do período de coleta (ANOVA: $\mathrm{p}=0,00001$ para clorofila e $\mathrm{p}=0,00019$ para os carotenoides). Não detectou-se diferença significativa entre DIA e NOITE. A quantidade de clorofila-a e carotenoides foi maior em algas submetidas à irradiância de $60 \mu \mathrm{mol}$ de fótons. $\mathrm{m}^{-2} \cdot \mathrm{s}^{-1}$ do que as que ficaram sob 600 $\mu$ mol de fótons. $\mathrm{m}^{-2} \cdot \mathrm{s}^{-1}$ pelo período de uma semana (Figura 8D e E, respectivamente).

O teor de clorofila dos talos submetidos a $60 \mu \mathrm{mol}$ de fótons. $\mathrm{m}^{-2} \cdot \mathrm{s}^{-1}$ para os ápices coletados durante o DIA e a NOITE, foi de aproximadamente 39\% e 35\% maior em relação aos ápices do tratamento. Algas submetidas à irradiância de $60 \mu$ mol de fótons. $\mathrm{m}^{-2} \cdot \mathrm{s}^{-1}$ apresentaram valores de clorofila-a de 319,41 $\pm 24,21 \mu \mathrm{g} \cdot \mathrm{gMF}^{-1}$ durante o DIA e 326,08 \pm 9,32 $\mu \mathrm{g} \cdot \mathrm{gMF}^{-1}$ a NOITE, enquanto os talos sob $600 \mu \mathrm{mol}$ de fótons.m ${ }^{-}$ ${ }^{2} \cdot \mathrm{s}^{-1}$, exibiram quantidades de $193,5 \pm 7,58 \mu \mathrm{g} \cdot \mathrm{gMF}^{-1}$ para o DIA e $210,7 \pm 7,91$ $\mu \mathrm{g} \cdot \mathrm{gMF}^{-1}$ para a NOITE (Figura $8 \mathrm{D}$ ).

Para os carotenoides, os talos sob $60 \mu \mathrm{mol}$ de fótons. $\mathrm{m}^{-2} \cdot \mathrm{s}^{-1}$ exibiram quantidade $23 \%$ (DIA) e $21 \%$ (NOITE) maior em relação aos ápices do tratamento. Foram obtidas quantidades de $65,24 \pm 4,83 \mu \mathrm{g} \cdot \mathrm{gMF}^{-1}$ para $60 \mathrm{D}$ e $67,39 \pm 1,91 \mu \mathrm{g} \cdot \mathrm{gMF}^{-1}$ para $60 \mathrm{~N}$ e 
para $600 \mu \mathrm{mol}$ de fótons. $\mathrm{m}^{-2} . \mathrm{s}^{-1}$ foram registrados valores de 50,01 $\pm 2,85 \mu \mathrm{g} . \mathrm{gMF}^{-1}$ para $600 \mathrm{D}$ e $52,71 \pm 2,19 \mu \mathrm{g} \cdot \mathrm{gMF}^{-1}$ para $600 \mathrm{~N}$ (Figura $8 \mathrm{E}$ ).

Finalmente, as figuras $8 \mathrm{~F}$ e $8 \mathrm{G}$ mostram a varredura dos espectros dos extratos de ficobiliproteínas e clorofila-a e carotenoides dos talos de Gp. tenuifrons submetidos a $60 \mu \mathrm{mol}$ de fótons. $\mathrm{m}^{-2} . \mathrm{s}^{-1}$ e $600 \mu \mathrm{mol}$ de fótons. $\mathrm{m}^{-2} . \mathrm{s}^{-1}$. Nestas figuras pôde-se constatar que os maiores espectros correspondem a $60 \mu \mathrm{mol}$ de fótons. $\mathrm{m}^{-2} \cdot \mathrm{s}^{-1}$, com diminuição para $600 \mu \mathrm{mol}$ de fótons. $\mathrm{m}^{-2} \cdot \mathrm{s}^{-1}$.

\section{Discussão}

\subsection{Taxa de crescimento e composição tecidual}

A exposição a PAR elevada é capaz de promover fotoinibição (Hanelt et al., 1997; Holzinger et al., 2011), provocando efeitos similares e comparáveis ao da radiação UV para todos os tipos de organismos aquáticos fotossintetizantes (Osakabe \& Osakabe, 2001; Hanelt \& Roleda, 2009; Raven, 2011).

De acordo com Altamirano et al. (2000) o crescimento é um bom indicador dos efeitos causados por condições de estresse. Deste modo, em condições normais de crescimento, a energia captada pelos pigmentos fotossintetizantes (clorofilas, ficobiliproteínas e carotenoides) é utilizada eficientemente pela fotossíntese. Em contrapartida, a inibição da fotossíntese ou cadeia de transporte de elétrons sob luz excessiva pode elevar o processo de fotossíntese e a formação de ROS, causando dano na proteína D1. Esse desequilíbrio pode causar mudanças que conduzirão a alterações em proteínas, lipídeos e DNA e, consequentemente, redução da taxa de crescimento (He \& Häder, 2002; Schmidt et al., 2010).

Sob esta óptica, o resultado de taxa de crescimento para Gp. tenuifrons sob as condições experimentais foi diferente do esperado, pois supunha-se que as algas sob irradiância de $600 \mu \mathrm{mol}$ de fótons. $\mathrm{m}^{-2} . \mathrm{s}^{-1}$ cresceriam menos, porque esta condição extrapola em 10 vezes o controle $\left(60 \mu \mathrm{mol}\right.$ de fótons. $\left.\mathrm{m}^{-2} \cdot \mathrm{s}^{-1}\right)$. No entanto, os talos sob elevada PAR apresentaram taxa de crescimento igual ao do grupo controle. Mesmo não havendo redução na taxa de crescimento, na condição de $600 \mu \mathrm{mol}$ de fótons. $\mathrm{m}^{-2} . \mathrm{s}^{-1}$, supõe-se que prolongando o tempo de exposição da alga a essa irradiância, haveria déficit na taxa de crescimento no tratamento. É possível que sob a alta irradiância, pelo período de uma semana, Gp. tenuifrons ainda estivesse sob a dinâmica de aclimatação a ponto de não comprometer seu crescimento. 
Adicionalmente, Gp. tenuifrons submetida a $600 \mu \mathrm{mol}$ de fótons. $\mathrm{m}^{-2} . \mathrm{s}^{-1}$ exibiu ápices com extremidades enroladas, descoradas e necrosadas. Esta resposta é semelhante à observada por Schmidt et al. (2010) que estudaram o efeito da radiação UVB em Gracilaria domingensis. Os autores relataram que uma maneira de proteção das regiões apicais à radiação UVB é tornarem-se enroladas ou apresentar diversas ramificações, sendo este comportamento resultado de mudanças no metabolismo e danos no DNA pela formação de dímeros de pirimidinas. Skriptsova \& Yakovleva (2002) e Navarro et al. (2010) obtiveram resultados similares estudando Gracilaria gracilis e Iridaea cordata sob condições de PAR $\left(740-800 \mu \mathrm{mol}\right.$ de fótons. $\left.\mathrm{m}^{-2} . \mathrm{s}^{-1}\right)$ e de PAR (55 $\mu$ mol de fótons. $\left.\mathrm{m}^{-2} . \mathrm{s}^{-1}\right)+\mathrm{UVA}+\mathrm{UVB}$, respectivamente.

Os ápices submetidos a $600 \mu \mathrm{mol}$ de fótons. $\mathrm{m}^{-2} \cdot \mathrm{s}^{-1}$ também apresentaram maior resistência, elasticidade e "pêlos" dispostos em toda sua extensão. Estes "pêlos" podem ser colônias de epibiontes que toleram altas irradiâncias e que colonizam a superfície do talo, devido a condições desfavoráveis para a macroalga (Lachnit et al., 2009).

Além da presença de "pêlos" em Gp. tenuifrons sob $600 \mu \mathrm{mol}$ de fótons. $\mathrm{m}^{-2} \cdot \mathrm{s}^{-1}$, células corticais apresentaram-se maiores e globosas. Skriptsova \& Yakovleva (2002) observaram que sob altas irradiâncias, G. gracilis sofreu espessamento na parede celular das células corticais. Schmidt et al. (2010, 2012) estudando G. domingensis e Gelidiela floridanum e Navarro et al. (2010) estudando I. cordata observaram respostas anatômicas semelhantes nas células corticais. Pesquisadores que investigaram os efeitos de patógenos em algas (Weinberger, 2007) também observaram células com parede mais espessada. Esse espessamento na parede das células corticais pode atuar na atenuação física da irradiância em excesso em algas vermelhas, pois há aumento na reflexão de ondas curtas (Raven, 2011). De forma similar, Rowell (2005) afirma que em vegetais vasculares submetidos a condições de estresse há um aumento na quantidade de hemicelulose da parede celular, enquanto Coueé et al. (2006) propõem que a fotossíntese estimula o acúmulo de açúcares e que os mecanismos de defesa antioxidante sinalizados por açúcares estão relacionados a flutuações de intensidade de luz.

Desta forma, o espessamento na parede de células corticais dos talos de $G p$. tenuifrons expostos a $600 \mu \mathrm{mol}$ de fótons. $\mathrm{m}^{-2} . \mathrm{s}^{-1}$ pode ser atribuído provavelmente à produção de polissacarídeos que fazem parte da composição da parede. Essa produção e acúmulo de polissacarídeos de parede pode ser atribuída às maiores quantidades de carbono e hidrogênio mensuradas nos talos de Gp. tenuifrons expostos ao tratamento de 
$600 \mu \mathrm{mol}$ de fótons. $\mathrm{m}^{-2} \cdot \mathrm{s}^{-1}$. A elevação dos níveis de açúcares foi observada em diversas situações de estresse, com finalidade de estocagem de energia (Pacoda et al., 2004), atuação como antioxidante (Coueé et al., 2006; Foyer \& Noctor, 2009; Blokina \& Fagerstedt, 2010; Wijesekara et al., 2011), atuação como barreira física espessando a parede celular e atenuando o excesso de luz (An et al., 2005; Navarro, 2011), e/ou mitigando a exposição a patógenos (Weinberger, 2007) ou favorecimento da produção das ROS (Coueé et al., 2006; Foyer \& Noctor, 2009; Blokina \& Fagerstedt, 2010).

Molecularmente, a produção e acúmulo de açúcares em células sob excesso de estímulo luminoso é disparada pela presença das ROS e pode ser orquestrada pelo óxido nítrico (NO; Hua et al., 2003; Pacoda et al., 2004; An et al., 2005), pois em algas o NO além de regular o crescimento, tem sua produção estimulada pelas ROS em resposta ao estresse (Capítulo III; Mallick et al., 2002; Cohen \& Yamasaki, 2003; Estevez \& Puntarulo, 2005; Bouchard et al., 2008; Qian et al., 2009; Hsu \& Lee, 2012)

Ademais, a variação da proporção C:N são respostas a estocagem de carbono e nitrogênio, indicando uma possível limitação do nitrogênio que seria direcionado para o crescimento. Deste modo, talos sob baixos regimes de nutrientes apresentam valores de proporção C:N maiores (Atkinson \& Smith, 1983; Wanderley, 2009). Comparando os resultados do presente trabalho com o de Wanderley (2009) que também estudou as respostas de $G p$. tenuifrons sob diferentes disponibilidades de nitrato $\left(\mathrm{NO}_{3}{ }^{-}\right)$sob irradiância de $65 \pm 5 \mu \mathrm{mol}$ de fótons. $\mathrm{m}^{-2} \cdot \mathrm{s}^{-1}$, a autora observou que talos em meio com menor disponibilidade de nitrato apresentaram maior quantidade de carbono e hidrogênio tecidual. Neste contexto, é possível afirmar que os talos de Gp. tenuifrons submetidos a alta PAR apresentaram limitação de nitrogênio em relação aos talos sob menor irradiância, evidenciada pela maior quantidade de carbono e hidrogênio teciduais, menor teor de nitrogênio tecidual e redução do conteúdo pigmentar. O menor teor de nitrogênio tecidual nesse tratamento possivelmente foi devido a elevação da demanda de nitrogênio para manutenção do metabolismo primário e produção de substâncias para a mitigação dos efeitos nocivos da luz em Gp. tenuifrons, como aminoácidos tipo micosporinas (MAAs).

Sob a mesma perspectiva, Lobban \& Harrison (2000) mencionaram que a luz afeta a captação de nutrientes indiretamente através da fotossíntese que: (1) fornece energia (ATP) para o transporte ativo, (2) produz esqueletos de carbono que são necessários para a incorporação do nitrogênio em macromoléculas orgânicas e (3) aumenta a taxa de crescimento, desencadeando maior necessidade de nutrientes. 


\subsection{Composição pigmentar e teor de proteínas solúveis totais}

Segundo Jordan (2002), os pigmentos fotossintetizantes são a primeira linha de defesa contra o estresse luminoso em organismos que fazem fotossíntese. Gracilariopsis tenuifrons, sob intensa irradiância, exibiu descoloração dos talos, também observada por Torres (2012). Houve também diminuição na quantidade de ficobiliproteínas quando comparado com a condição de $60 \mu \mathrm{mol}$ de fótons. $\mathrm{m}^{-2} \cdot \mathrm{s}^{-1}$. Resultados semelhantes foram descritos por Skriptsova \& Yakovleva (2002) para G. gracilis e Schmidt et al. (2010, 2012) para G. domingensis e G. floridanum.

Supõe-se que os ficobilissomos, estruturas formadas pelas ficobiliproteínas, e suas subunidades têm propriedades fotocrômicas e estão envolvidos em processos de dissipação de energia para prevenir um possível fotodano no PSII sob luminosidade excessiva (Talarico \& Maranzana, 2000). Ademais, ficobiliproteínas apresentam dinâmica de síntese e degradação em reação à qualidade de luz. Essa característica permite que esses pigmentos sejam fonte orgânica e imediata de nitrogênio (Barufi et al., 2012).

A diminuição das proteínas solúveis totais (PST) de Gp tenuifrons durante o DIA nos talos sob elevada PAR provavelmente foi causada pela degradação de proteínas em consequência da irradiância excessiva. De acordo com Hsu \& Lee (2012), as proteínas também são conhecidas por estarem associadas com a resposta das plantas vasculares a condições de estresse, sendo constantemente sintetizadas, acumuladas e consumidas, pois para lidar com condições estressantes as plantas adotam mecanismos de reparo de proteínas oxidadas, estabilização, remoção de proteínas danificadas e sintetização e ressintetização de proteínas (Roleda et al., 2009; Harnedy \& Fitzgerald, 2011; Hsu \& Lee, 2012). Além disso, em macroalgas, a elevação de carboidratos pode ser um sinal associado à variação nos níveis de proteínas, pois estudos indicam que quando a síntese de carboidrato é maior a síntese de proteínas é menor e vice-versa (Harnedy \& Fitzgerald, 2011).

Entretanto, à NOITE não houve diferença significativa entre os talos submetidos a 60 e $600 \mu \mathrm{mol}$ de fótons. $\mathrm{m}^{-2} \cdot \mathrm{s}^{-1}$. Tal resultado indica que embora a alta irradiância promova consumo das PST durante o DIA, à NOITE, efetivamente isso não aconteceu, provavelmente devido à constante reparação dessas proteínas em $G p$ tenuifrons. Pesquisas com Scenedesmus quadricauda sob radiação UVA e UVB apontaram elevação na quantidade de aminoácidos livres, registrados como fator essencial para o aumento da biossíntese de proteínas (Kovacik et al., 2010) 
Sob alta irradiância, $600 \mu \mathrm{mol}$ de fótons. $\mathrm{m}^{-2} \cdot \mathrm{s}^{-1}$, a quantidade de clorofila-a e carotenoides em $G p$. tenuifrons sofreram diminuição, assim como as ficobiliproteínas. Essa redução no teor de pigmentos fotossintetizantes em $G p$. tenuifrons, coincidem com o descrito por Bischof et al. (2000), Yakovleva \& Tilyanov (2001), Eswaran (2002) e Skriptsova \& Yakovleva (2002).

De acordo com Yakovleva \& Tilyanov (2001), a exposição prolongada a elevadas irradiâncias, promove não só o declínio significante na eficiência fotossintetizante, mas a perda substancial dos pigmentos. Essas alterações variam de acordo com a exposição à PAR e à UVR, podendo causar gradativamente danos mais sérios ao aparato fotossintetizante. O excesso de luz interfere na fotossíntese, desequilibrando taxas de reações fotoquímicas e consumo de ATP e NADPH pela fixação de gás carbônico, sendo o complexo protéico do PSII mais susceptível aos danos. Essa sensibilidade se deve a proteína D1, que sob condição de estresse luminoso, apresenta degradação (Zeeshan \& Prasad, 2009; Sonoike, 2010; Krieger-Liszkay et al., 2011).

Por outro lado, o PSII exibe recuperação mais rápida do que o PSI, devido à constante ressintetização da proteína D1. A fotoinibição do PSI causa sua degradação, que pode ocorrer junto com o rompimento da ligação da clorofila. Este evento é considerado uma medida de emergência e não de dano, pois a presença dos pigmentos, complexos protéicos absorvedores de luz, quando fotoinibidos perdem a capacidade de transferir elétrons. A perda da capacidade de transferência de elétrons é resultado de um dano secundário e, por isso, esses pigmentos estão sujeitos a rápida degradação a fim de evitar o agravamento dos efeitos danosos, causados, provavelmente, pelo acúmulo de moléculas oxidantes como ROS e espécies reativas de nitrogênio (RNS). Deste modo, há um "branqueamento" (desgaste) da clorofila e/ou degradação de proteínas dos centros de reação dos fotossistemas PSI e PSII. Essa degradação dos pigmentos ocasiona redução da absorção de fótons $(700$ nm) (Sonoike, 2010; Keren \& KriegerLiszkay, 2011).

Por outro lado, a redução do conteúdo de clorofila ocasionado pelo $\mathrm{NO}$ em sementes de feijão sujeitadas à forte radiação UVB causou atenuação do efeito da radiação e mitigação do dano oxidativo na membrana do tilacoide (Shi et al., 2005) Enquanto Keren \& Krieger-Liszkay (2011) e Krieger-Liszkay et al. (2011) sugerem que o principal agente de degradação parcial ou completa da clorofila, bem como da proteína D1, é o radical oxigênio singlete $\left({ }^{1} \mathrm{O}_{2}\right)$. 
O teor de carotenoides de Gp. tenuifrons exibiu diminuição sob alta PAR. No entanto, sua redução foi menor do que a ocorrida nos outros pigmentos mensurados. Possivelmente a resistência desses pigmentos ocorreu devido ao seu caráter antioxidante, pois devem sofrer constante desgaste e reparação. Por isso, mesmo os carotenoides tendo sofrido redução, pode-se afirmar que estes pigmentos atuaram como fortes fotoprotetores e inibidores das ROS em Gp tenuifrons.

Torres (2012), também estudando Gp. tenuifrons sob elevada irradiância, observou redução de carotenoides e clorofila. Dentre os carotenoides identificados pela autora estão $\beta$-caroteno e zeaxantina, sendo a zeaxantina predominante nos ápices de Gp. tenuifrons sob alta PAR. Schubert \& Mendoza-García (2008) afirmam que zeaxantina é um dos carotenoides chave envolvidos na fotoproteção em resposta ao estresse luminoso. Eles declaram ainda que espécies que possuem altos teores de zeaxantina têm maior tolerância a alta irradiância, pois respondem cerca de 20 a 30 vezes mais rápido em relação a espécies que apresentam outros carotenoides. Carotenoides apresentam papel regulatório da atividade de fotossíntese sob estresse luminoso, dissipando excesso de energia através de fluorescência; e sua livre localização na membrana lipídica dos cloroplastos pode facilitar seu desempenho na extinção das ROS (Schubert \& Mendoza-García, 2008).

Finalmente, avaliando os resultados obtidos para Gp. tenuifrons sob elevada PAR e comparando-os com as respostas do controle, pode-se inferir que a condição de $600 \mu \mathrm{mol}$ de fótons. $\mathrm{m}^{-2} . \mathrm{s}^{-1}$ é estressante para Gp. tenuifrons pois, embora a taxa de crescimento não tenha sido afetada, o fotoestresse foi verificado a partir: (1) da elevação dos níveis de carbono e hidrogênio e espessamento da parede celular, indicando um possível aumento no teor de carboidratos, resposta que a literatura relaciona com mecanismos de defesa químico e físico frente a estresse luminoso; (2) da diminuição do nitrogênio tecidual, indicando limitação de nitrogênio para o metabolismo geral; (3) da redução das proteínas e pigmentos fotossintetizantes, como resultado de fotoproteção e fotodano do aparato fotossintetizante. Além disso, à NOITE não houve diferença significativa entre os ápices submetidos a $60 \mu \mathrm{mol}$ de fótons. $\mathrm{m}^{-2} \cdot \mathrm{s}^{-1}$ e $600 \mu \mathrm{mol}$ de fótons. $\mathrm{m}^{-2} \cdot \mathrm{s}^{-1}$. Tal resultado aponta que embora a alta irradiância promova consumo dos pigmentos e proteínas solúveis durante o DIA, à NOITE, efetivamente isso não ocorre, demonstrando que em Gp. tenuifrons o propósito para mitigar os efeitos nocivos da luz ocorrem independente do período do ciclo diário. 


\section{Referências Bibliográficas}

Aguilera, J.; Karsten, U.; Lippert, H.; Vogele, B.; Philipp, E.; Hanelt, D.; Wiencke, C. 1999b. Effects of solar radiation on growth, photosynthesis and respiration of marine macroalgae from the Arctic. Marine Ecology Progress Series 191: 109-119.

Altamirano, M.; Flores-Moya, A.; Conde, F.; Figueroa, F.L. 2000. Growth seasonality, photosynthetic pigments, and carbon and nitrogen content in relation to environmente factors: a field study of Ulva olivascens (Ulvales, Chlorophyta). Phycologia 39: 50-58.

Altamirano, M.; Flores-Moya, A.; Figueroa, F.L. 2000. Long-Term Effects of Natural Sunlight under Various Ultraviolet Radiation Conditions on Growth and Photosynthesis of Intertidal Ulva rigida (Chlorophyceae) CultivatedIn Situ Botanica Marina Vol. 43: 119-126.

An, L.; Liu, Y.; Zhang, M.; Chen,T.; Wang, X. 2005. Effects of NO on growth of maize seedling leaves in the presenceor absence of UVB. Journal of plant physiology. 162: 317-326.

Atkinson, M. J. \& Smith, S. V. 1983. C:N:P Ratios of Benthic Marine Plants. Limnology and Oceanography 28 (3): 568-574.

Barufi, J. B.; Mata, M. T.; Oliveira, M. C.; Figueroa, F. L. 2012. Nitrate reduces the negative effect of UV radiation on photosynthesis and pigmentation in Gracilaria tenuistipitata (Rhodophyta): the photoprotection role of mycosporine-like amino acids. Phycologia 51: 636-648.

Bautista, A.I.N. \& Necchi Jr., O. 2007. Photoacclimation in three species of freshwater red algae. Brazilian Journal of Plant Physiology 19: 23-34.

Beer, S. \& Eshel, A. 1985. Determining phycoeritrin and phycocyanin concentration in aqueous crude extracts of red algae. Australian Journal of Marine and Freshwater Research 36: 785-792.

Bischof, K.; Gómez, I.; Molis, M.; Hanelt, D.; Karsten, U.; Lüder, U.; Roleda, M. Y.; Zacher, K.; Wiencke, C. 2006. Ultraviolet radiation shapes seaweed communities. Rev Environ Sci Biotechnol 5:141-166.

Bischof, K.; Hanelt, D.; Wiencke, C. 2000. Effects of ultraviolet radiation photosynthesis and related enzymes reaction of marine macroalgae. Planta 211: 555562.

Blokhina, O. \& Fagerstedt, K. V. 2010. Reactive oxygen species and nitric oxide in plant mitochondria: origin and redundant regulatory systems. Physiologia Plantarum 138: $447-462$.

Bouchard, J. N. \& Yamasaki, H. 2008. Heat Stress Stimulates Nitric Oxide Production in Symbiodinium microadriaticum: A Possible Linkage between Nitric Oxide and the Coral Bleaching. Phenomenon Plant Cell Physiol. 49(4): 641-652. 
Bradford, M. 1976. A rapid sensitive method for the qualification of microgram quantities of protein utilizing the principle of protein-dye binding. Analytical Biochemistry 72: 248-254.

Carnicas, E.; Jimenez, C.; Niell, F.X. 1999. Effects of changes of irradiance on the pigment composition of Gracilaria tenuistipitata var. liui Zhang et Xia. Journal Photochemistry and Photobiology B: Biology 50: 149-158.

Cohen, M. F. \& Yamasaki, H. 2003. Involvement of nitric oxide synthase in sucroseenhanced hydrogen peroxide tolerance of Rhodococcus sp. strain APG1, a plantcolonizing bacterium. Nitric Oxide 9: 1-9.

Couée, I.; Sulmon, C.; Gouesbet, G.; El Amrani, A. 2006. Involvement of soluble sugars in reactive oxygen species balance and responses to oxidative stress in plants. Journal of Experimental Botany 57: 449-459.

Dawes, C.J.; Orduña-Rojas, J.; Robledo, D. 1999. Response of the tropical red seaweed Gracilaria cornea to temperature salinity and irradiance. Journal of Applied Phycology 10: 419-425.

Demmig, B.; Winter, K.; Kruger, A.; Czygan, F.-C. 1988. Zeaxanthin and the heat dissipation of excess light energy in Nerium oleander exposed to a combination of high light and water stress. Plant Physiol. 87: 17-24.

Estevez, M. S.; Puntarulo, S. 2005. Nitric oxide generation upon growth of Antarctic Chlorella sp. cells. Physiologia Plantarum 125: 192-201.

Eswaran, K.; Mairh, O. P.; Subba Rao, P.V. 2002. Inhibition of pigments and phycocolloid in marine red alga Gracilaria edulis by ultraviolet-B radiation. Biologia Plantarum 45: 157-159.

Foyer, C. H. \& Noctor, G. 2009. Redox Regulation in Photosynthetic Organisms: Signaling, Acclimation, and Practical Implications. Antioxidants \& Redox Signaling 11 (4): 862-905.

Foyer, C.H. \& Shigeoka, S. 2011. Understanding oxidative stress and antioxidant functions to enhance photosynthesis. Plant Physiology 155: 93-100.

Häder, D.-P.; Kumar, H. D.; Smith, R. C.; Worrest, R. C. 2007. Effects of solar UV radiation on aquatic ecosystems and interactions with climate change Photochem. Photobiol. Sci. 6: 267-285.

Häder, D.P.; Helbling, E. W.; Williamson, C. E.; Worrest, R. C. 2011. Effects of UV radiation on aquatic ecosystems and interactions with climate change. Photochem. Photobiol. Sci.10: 242-260.

Hanelt, D. \& Roleda, M. Y. 2009. UVB Radiation may ameliorate photoinhibition in specific shallow-water tropical. Aquat. Bot. (2009), doi:10.1016/j.aquabot.2008.12.005.

Hanelt, D.; Wiencke, C.; Nultsch, W. 1997. Influence of UV radiation on the photosynthesis of Arctic macroalgae in the field. Journal of Photochemistry and Photobiology 38: 40-47. 
Harnedy, P. A. \& Fitzgerald, R. J. 2011. Bioactive Proteins, Peptides, and Amino Acids From Macroalgae. J. Phycol. 47: 218-232.

He, Y. Y.; Häder, D. P. 2002. Reactive oxygen species and UV-B: e $\square$ ect on cyanobacteria Photochem. Photobiol. Sci. 1, 729-736.

Henley, H.J. \& Ramus, J. 1989. Time course of physiological response of Ulva rotundata to growth irradiance transitions. Marine Ecology Progress Series 54: 171177.

Holzinger, A.; Piazza, L. Di; Lütz, C.; Roleda, M. Y. 2011. Sporogenic and vegetative tissues of Saccharina latissima (Laminariales, Phaeophyceae) exhibit distinctive sensitivity to experimentally enhanced ultraviolet radiation: photosynthetically active radiation ratio. Phycological Research 59: 221-235.

Hsu, Y.; Lee, T. 2012. Nitric Oxide Up-Regulates the Expression of Methionine Sulfoxide Reductase Genes in the Intertidal Macroalga Ulva fasciata for High Light Acclimation. Plant Cell Physiol. 53(2): 445-456.

Hua, Z.; Wen-Biao, S. Lang-Lai, X. 2003. Effects of Nitric Oxide on the Germination of Wheat Seeds and It's Reactive Oxygen Species Metabolisms Under Osmotic Stress. Acta Botanica Sinica 45 (8): 901-905.

Jordan, B. R. 2002. Molecular response of plant cellsto UV-B stress. Funct. Plant Biol., 29: 909-916.

Karsten, U.; Sawall, T.; Hanelt, D.; Bischof, K.; Figueroa, F. L.; Flores-Moyac, A.; Wiencke, C. 1998. An inventory of UV-absorbing mycosporine-like amino acids in macroalgae from polar to warm-temperate regions. Botanica Marina 41: 443-453.

Karsten, U. \& Wiencke, C. 1999. Factors Controlling the Formation of UV-absorbing Mycosporine-like Amino Acids in the Marine Red Alga Palmaria palmata from Spitsbergen (Norway). J. Plant Physiol. 155: 407-415.

Keren, N.; Krieger-Liszkay, A. 2011. Photoinhibition: molecular mechanisms and physiological significance Physiologia Plantarum 142: 1-5.

Korbee, N.; Figueroa, F. L.; Aguilera, J. 2006. Acumulación de aminoácidos tipo micosporina (MAAs): biosíntesis, fotocontrol y funciones ecofisiológicas. Revista Chilena de Historia Natural 79: 119-132.

Kovácik, J.; Klejdus, B.; Backor, M. 2010. Physiological Responses of Scenedesmus quadricauda (Chlorophyceae) to UV-A and UV-C Light. Photochemistry and Photobiology. 86: 612-616.

Krieger-Liszkay, A; B. Kós, P. B. and Hideg, E. 2011. Superoxide anion radicals generated by methylviologen in photosystem I damage photosystem II. Physiologia Plantarum 142: 17-25.

Lachnit, T.; Blümel, M.; Imhoff, J. F.; Wahl, M. 2009. Specific epibacterial communities on macroalgae: phylogeny matters more than habitat. Aquatic Biology 5: 181-186. 
Lignell, A. \& Pedersén, M. 1989. Effects of $\mathrm{Ph}$ and inorganic carbon concentration on growth of Gracilaria secundata. Br. Phycol. J. 24: 83-89.

Lobban C.S. \& Harrison P.J. 2000. Seaweed Ecology and Physiology. Cambridge University Press. 366 p.

Mallick, N.; Mohn, F. H.; Soeder, C. J.; Grobbelaar, J. U. 2002. Ameliorative role of nitric oxide on $\mathrm{H} 2 \mathrm{O} 2$ toxicity to a chlorophycean alga Scenedesmus obliquus. J. Gen. Appl. Microbiol., 48: 1-7.

Navarro, N. P.; Mansilla, A.; Plastino, E. M. 2010. UVB radiation induces changes in the ultra-structure of Iridaea cordata. Micron 41:899-903.

Navarro, N. P.; Palacios, M.; Mansilla, A.; Jofre, J. 2010. Morphological and growth alterations on early development stages of Iridaea cordata (Rhodophyta) under different intensities of UVB radiation. Revista de Biología Marina y Oceanografía Vol. 45, $\mathrm{N}^{\circ} 2: 255-265$.

Necchi Jr., O. 2005. Light-related photosynthetic characteristics of freshwater rhodophytes. Aquatic Botany 82: 193-209.

Osakabe, K. \& Osakabe, Y. 2001. Plant Light Stress. In : eLS. Jhon Wiley \& Sons. 15.

Pacoda, D.; Montefusco, A.; Piro, G.; Dalessandro, G. 2004. Reactive oxygen species and nitric oxide affect cell wall metabolism in tobacco BY-2 cells. Journal of Plant Physiology 161: 1143-1156.

Qian, H.; Chen, W.; Li, J.; Wang, J.; Zhou Z.; Liu, W.; Fu, Z. 2009. The effect of exogenous nitric oxide on alleviating herbicide damage in Chlorella vulgaris. Aquatic Toxicology 92: 250-257.

Raven, J.A. 2011. The cost of photoinhibition. Physiologia Plantarum 142: 87-104.

Roleda, Michael Y.; Wiencke, C.; Hanelt, D.; Bischof, K. 2007. Sensitivity of the early life stages of macroalgae from the northern hemisphere to ultraviolet radiation. Photochemistry and Photobiology. 83: 851-862.

Rossel, J.B.; Wilson, I.W.; Pogson, B.J. 2002. Global changes in gene expression in response to high light in Arabidopsis. Plant Physiology 130: 1109-1120.

Rowell, R. M.; Pettersen, R.; Han, J. S.; Rowell, J. S.; Tshabalala, M. A. 2005. Handbook of Wood Chemistry and Wood - Cap. 3 Composites Cell Wall Chemistry. Ed. Roger M. Rowell. CRC Press LLC. pp. 35-76.

Schmidt, E. C.; Santos, R.; Horta, P. A.; Maraschin, M.; Bouzon, Z. L. 2010. Effects of UVB radiation on the agarophyte Gracilaria domingensis (Rhodophyta, Gracilariales): Changes in cell organization, growth and photosynthetic Performance. Micron 41: 919930.

Schmidt, E. C.; Santos, R. W. dos; Faveri, C de; Horta, P. A.; Martins, R. de P.; Latini, A.; Ramlov, F.; Maraschin, M.; Bouzon, Z. L. 2012. Response of the agarophyte 
Gelidium floridanum after in vitro exposure to ultraviolet radiation B: changes in ultrastructure, pigments, and antioxidant systems. J Appl Phycol. DOI 10.1007/s10811012-9786-4. 12 p.

Schubert, N. \& Mendoza-García, E. 2008. Photoinhibition in Red Algal Species With Different Carotenoid Profiles. J. Phycol. 44:1437-1446.

Shi, S.; Wang, G.; Wang, Y.; Zhang, L.; Zhang. L. 2005. Protective effect of nitric oxide against oxidative stress under ultraviolet-B radiation. Nitric Oxide 13: 1-9.

Sinha, R. P.; Klish, M.; Helbling, E. W.; Häder, D.-P. 2001. Induction of mycosporinelike amino acids (MAAs) in cyanobacteria by solar ultraviolet-B radiation. Journal of Photochemistry and Photobiology B: Biology 60: 129-135.

Skriptsova, A.V.; Yakovleva, I.M. 2002. The influence of variations in irradiance upon morphology in an unattached form of Gracilaria gracilis (Stackhouse) Steentoft during field cultivation, South Primorye, Russia. Aquatic Ecology 36: 511-518.

Sonoike, K. 2011. Photoinhibition of photosystem I. Physiologia Plantarum 142: 56-64.

Spath-Wiley, P.; Neefus, C.D.; Jahnke, L.S. 2008. Seasonal effects of sun exposure and emersion on intertidal seaweed physiology: fluctuations in antioxidant contents, photosynthetic pigments and photosynthetic efficiency in the red alga Porphyra umbilicalis Kützing (Rhodophyta, Bangiales). Journal of Experimental Marine Biology and Ecology 361: 83-91

Talarico, L \& Maranzana, G. 2000. Light and adaptive responses in red macroalgae: an overview. Journal of Photochemistry and Photobiology B: Biology 56: 1-11.

Torres, P. 2012. Análise de pigmentos fotossintetizantes e substâncias fenólicas em Gracilariopsis tenuifrons (C. J. Bird \& E. C. Oliveira) Fredericq \& Hommersand em diferentes intensida-des de luz . Dissertação (Mestrado) - Instituto de Biociências da Universidade de São Paulo. Departamento de Botânica. 104 páginas.

Viñegla, B. \& Figueroa, F. L. 2009 Effect of solar and artificial UV radiation on photosynthetic performance and carbonic anhydrase activity in intertidal macroalgae from southern Spain. Ciencias Marinas 35(1): 59-74.

Wanderley, A. 2009. Influência da disponibilidade de nitrato sobre crescimento, atividade da nitrato redutase, composição química e captação de nitrato e fosfato em Gracilariopsis tenuifrons (Gracilariales, Rhodophyta). Universidade de São Paulo. Dissertação de mestrado. 140 p.

Weinberger, F. 2007. Pathogen-Induced Defense and Innate Immunity in Macroalgae. Biological Bulletin, 213 (3): 290-302.

Wijesekara, I.; Pangestutia, R.; Kim, S-K. 2011. Biological activities and potential health benefits of sulfated polysaccharidesderived from marine algae. Carbohydrate Polymers 84: 14-21.

Xu, J. \& Gao, K. 2010. Use of UV-A Energy for Photosynthesis in the Red Macroalga Gracilaria lemaneiformis. Photochemistry and Photobiology 86: 580-585. 
Yakovleva, I. M.; Titlyanov, E. A. 2001. Effect of high visible and UV irradiance on subtidal Chondrus crispus: stress, photoinhibition and protective mechanisms. Aquatic Botany 71: 47-61.

Zar, J.H. 1999. Biostatistical analysis. Prentice Hall, Englewood Cliffs, New Jersey. $471 \mathrm{p}$.

Zeeshan, M. \& Prasad, S.M. 2009. Differential response of growth, photosynthesis, antioxidant enzymes and lipid peroxidation to UV-B radiation in three cyanobacteria. South African Journal of Botany 75:466 - 474. 


\title{
CAPÍtULO II
}

\section{Substâncias fenólicas e atividade antioxidante total de Gracilariopsis tenuifrons (Gracilariales, Rhodophyta) sob alta PAR em laboratório}

\begin{abstract}
Resumo
Algas são seres adaptados às constantes e bruscas mudanças abióticas característica do ambiente marinho, que causam estresse, responsável por alterações fisiológicas capazes de danificar funções básicas nos organismos. Para resistir aos efeitos dessas alterações, acredita-se que esses organismos possuam sistema antioxidante de grande eficiência. Buscando compreender a eficiência da atividade antioxidante apenas em resposta a estímulos luminosos, ápices de $3 \mathrm{~cm}$ da macroalga vermelha Gracilariopsis tenuifrons foram submetidos a dois regimes de irradiância (60 $\mu \mathrm{mol}$ fótons. $\mathrm{m}^{-2} \cdot \mathrm{s}^{-1}$ e $600 \mu \mathrm{mol}$ fótons. $\mathrm{m}^{-2} \cdot \mathrm{s}^{-1}$ ) durante uma semana e coletadas durante o dia e a noite. Assim, de acordo com a comparação entre os tratamentos, foi possível detectar que os ápices submetidos à alta irradiância demonstraram aumento da atividade antioxidante total e, portanto, apresentaram elevação da quantidade de substâncias fenólicas totais provavelmente como estratégia para mitigar os danos causados pela disponibilidade de energia excedente no aparato fotossintetizante e, consequentemente, de espécies reativas de oxigênio.
\end{abstract}

\begin{abstract}
Seaweeds are adapted to abrupt abiotic changes of marine environment that cause stress conditions responsible for physiological alterations able to damage basic functions in the organisms. The efficiency of antioxidant system observed on seaweeds explain the tolerance to environmental changes. Then the purpose of this study was to understanding the antioxidant response to light stimuli through submitting apical tips of $3 \mathrm{~cm}$ of Gracilariopsis tenuifrons to $60 \mu \mathrm{mol}$ fótons. $\mathrm{m}^{-2} \cdot \mathrm{s}^{-1}$ and $600 \mu \mathrm{mol}$ fótons. $\mathrm{m}^{-2} . \mathrm{s}^{-1}$ for a week. Samplings were performed during day and night periods. Apical samples under high light showed increase of total antioxidant activity and high amount of phenolic compounds, probably as a strategy to mitigate damages triggered by excess of energy to the photosynthetic apparatus and ROS production.
\end{abstract}




\section{Introdução}

Macroalgas marinhas são as principais produtoras primárias de uma complexa cadeia alimentar nos costões rochosos, plataforma continental e recifes de coral. Além disso, são locais de recrutamento, fornecem refúgio e abrigo para muitas espécies (Häder et al., 2007).

As algas são adaptadas às constantes e bruscas mudanças abióticas características do ambiente marinho, principalmente nas regiões entremarés. Seres fotossintetizantes bentônicos têm sua sobrevivência diretamente relacionada com a flutuação da radiação fotossinteticamente ativa (PAR) compreendida entre os comprimentos de onda 400 a $750 \mathrm{~nm}$ e da radiação ultravioleta (UVR) que inclui as UVR- A, B e C, compreendidas entre 200 a 400 nm (Shick \& Dunlap, 2002).

Em consequência das mudanças climáticas globais, o efeito dessas radiações nos organismos fotossintetizantes vem sendo alterado em intensidade e frequência. Fenômeno que tem atraído a atenção de muitos pesquisadores que estudam algas marinhas (Karsten et al., 1998; Häder et al., 1998; Karsten \& Wiencke, 1999; Sinha et al., 2001; Korbee et al., 2006; Roleda et al., 2007; Ayres, 2009; Barufi, 2010; Ornelas, 2011; Navarro, 2011; Torres, 2012), pois estes organismos têm demonstrado efetiva resistência a essas alterações (Häder et al., 1998; Häder et al., 2007).

A intensificação da PAR (quantidade e/ou qualidade) promove o aumento da capacidade de transporte de elétrons. Excedendo essa capacidade há elevação da produção de espécies reativas de oxigênio (ROS). As ROS são compostos altamente reativos que causam oxidação às moléculas a que se ligam, são, portanto, um dos principais responsáveis pelo estresse oxidativo. Dessa maneira, as ROS têm sido relacionadas à redução na quantidade de pigmentos, a alterações do PSII (Häder et al., 2007), diminuição e alteração na composição de proteínas (Karsten \& Wiencke, 1999). Ademais, as ROS agem afetando a fluidez e permeabilidade de membranas (Karsten et al., 1998; Sinha et al., 2001; Korbee et al., 2006) e a morfologia (Karsten \& Wiencke, 1999; Navarro et al., 2010; Schimidt et al., 2010). Estes radicais também causam interferências na biologia do organismo (por exemplo, fotossíntese - Häder et al. (2011); assimilação de nutrientes - Xu \& Gao (2010); crescimento - Altamirano et. al. (2000), alterações genéticas e morte - Bischof (2006). Esses efeitos conduzem à redução de crescimento (Aguilera et al., 1999; Altamirano et al., 2000) e perda de 
produtividade e, consequentemente, afetam a estrutura ecológica da comunidade (Karsten \& Wiencke, 1999; Bischof et al., 2006; Korbee et al., 2006).

Em resposta ao aumento das ROS são ativados os mecanismos de defesa antioxidante de ação enzimática como a superóxido dismutase (SOD), glutationa redutase (GR) e ascorbato peroxidase (APX), e de ação não-enzimática, substâncias como carotenoides, glutationa, poliaminas, vitaminas C e E (Scandalios, 2005), substâncias fenólicas, metabólitos derivados de ácidos graxos, terpenoides, compostos halogenados, compostos brominados (Kladi et al., 2004; Cardozo et al., 2007), aminoácidos tipo micosporinas - MAAs (Sinha et al., 2000; Karsten et al., 2005; de la Coba et al., 2009), entre outros. As enzimas antioxidantes atuam neutralizando e/ou transformando as ROS em formas mais inócuas, atrasando ou debelando os efeitos causados pelo estresse oxidativo. Enquanto os antioxidantes não enzimáticos atuam absorvendo UVR e PAR, dissipando calor ou ainda ligando-se às ROS a fim de limitar ou neutralizar sua capacidade reativa (Anh et al., 2010; Carreto \& Carrignan, 2011).

Deste modo, recursos marinhos, principalmente algas, vêm sendo apontados como fonte de potentes antioxidantes naturais, não tóxicos, registrados como eficientes inibidores do estresse oxidativo (Yoon et al., 2011). Em consonância, há uma pressão mundial pela demanda de produtos naturais (Lee et al., 2002; Plaza et al., 2010) e adoção de hábitos mais saudáveis na prevenção de problemas de saúde (Samarakoon \& Jeon, 2012; Wijesekara et al., 2012).

Sendo assim, as substâncias provenientes de algas marinhas poderão ser utilizadas mais amplamente, seja a partir do consumo in natura ou processadas, como ocorre em países asiáticos, ou ainda como conservantes naturais, substituindo os artificiais suspeitos de promover carcinogênese (Yoon et al., 2011; Wijeseskara et al., 2012), e nas indústrias farmacêutica, médica e cosmética, elaborando produtos para tratamento de doenças cardiovasculares, cânceres (Devi et al., 2008; Shalaby, 2011), doenças causadas por vírus e doenças degenerativas (Yangthong et al., 2009; Yoon et al., 2011).

Contudo, há pouca informação sobre a característica fotoprotetora dessas substâncias e sua regulação metabólica (Abdala-Diaz et al., 2006), sobretudo em algas vermelhas. Portanto, usando Gracilariopsis tenuifrons, macroalga vermelha, nativa, que tem potencial para ser produzida em larga escala (Oliveira, 1998) e fonte de ágar de qualidade (Brito, 1999; Brito \& Silva, 2005), buscou-se quantificar a atividade 
antioxidante total e o teor de substâncias fenólicas totais de talos submetidos a dois regimes de irradiância, $60 \mu \mathrm{mol}$ de fótons. $\mathrm{m}^{-2} \cdot \mathrm{s}^{-1}$ e $600 \mu \mathrm{mol}$ de fótons. $\mathrm{m}^{-2} \cdot \mathrm{s}^{-1}$, e coletados em dois períodos do ciclo diário: DIA e NOITE.

\section{Material e Métodos}

\subsection{Delineamento experimental}

Talos de $3 \mathrm{~cm}$ de Gracilariopsis tenuifrons foram submetidos durante uma semana a dois regimes de irradiância: $60 \pm 5 \mu \mathrm{mol}$ de fótons. $\mathrm{m}^{-2} \cdot \mathrm{s}^{-1}$ (controle) e $600 \pm$ $10 \mu \mathrm{mol}$ de fótons. $\mathrm{m}^{-2} \cdot \mathrm{s}^{-1}$, em proporção biomassa/volume de meio de cultura de $1 \mathrm{~g}$ de MF por $1 \mathrm{~L}$ de meio de cultivo. Os ápices foram novamente cortados a $3 \mathrm{~cm}$ antes da coleta das amostras, com o objetivo de padronizá-los e reduzir variações, devido ao tamanho dos ápices. Para não haver limitação nutricional, o meio de cultivo foi trocado $24 \mathrm{~h}$ antes das coletas. As coletas foram realizadas em dois momentos: durante o DIA, em que a alga foi coletada entre 4-6 h após o início do fotoperíodo, e a NOITE, quando a coleta ocorreu entre 2-3 h depois do início do período escuro. As amostras foram congeladas em nitrogênio líquido e acondicionadas em freezer $-80^{\circ} \mathrm{C}$ até sua análise.

As demais condições de cultivo seguiram as especificações descritas no item Material e métodos gerais.

\subsection{Substâncias fenólicas totais}

A análise de substâncias fenólicas totais foi feita usando o método espectrofotométrico de Folin-Ciocalteau baseando-se em Waterman \& Mole (1994), que dosifica fenois totais em vegetais vasculares. Torres (2012) adaptou o processo de extração e quantificação dessas substâncias para Gp. tenuifrons. Deste modo, a quantificação das substâncias fenólicas totais seguiu o procedimento descrito em Torres (2012) após leves modificações.

A extração foi realizada triturando $400 \mathrm{mg}$ MF de Gp. tenuifrons em nitrogênio líquido até obtenção de pó fino. Acrescentou-se $4 \mathrm{~mL}$ de etanol $70 \%$ (v/v) a cada amostra, que seguiram para banho-maria $\left(50^{\circ} \mathrm{C}\right)$ durante $60 \mathrm{~min}$, sendo homogeneizadas com frequência de $15 \mathrm{~min}$. O extrato foi centrifugado durante $10 \mathrm{~min}$ em rotação de $20000 \mathrm{rpm}$, transferido para balão volumétrico de $5 \mathrm{~mL}$ e completado o volume com etanol $70 \%$. 
A reação para análise de substâncias fenólicas foi preparada misturando $500 \mu \mathrm{L}$ do extrato etanólico (amostra), $605 \mu \mathrm{L}$ de água Milli-Q e $30 \mu \mathrm{L}$ de Folin-Ciocalteau (2 $\mathrm{N}$; Sigma-Aldrich, Brasil). Após $3 \mathrm{~min}$ de intervalo, acrescentou-se $300 \mu \mathrm{L}$ de carbonato de sódio $4 \%(\mathrm{w} / \mathrm{v})$ e procedeu-se incubação em temperatura ambiente e penumbra por $2 \mathrm{~h}$. Todas as amostras foram centrifugadas durante $10 \mathrm{~min}$ em 14000 rpm antes da leitura do sobrenadante.

As absorbâncias foram lidas em espectrofotômetro UV-visível (Hewlett Packard modelo 8452A, EUA) em comprimento de onda de $760 \mathrm{~nm}$, usando cubeta de quartzo de $1 \mathrm{~cm}$ de percurso ótico. A curva padrão foi construída com solução de floroglucinol (Sigma-Aldrich, Alemanha) e água (1:1) em concentração de $200 \mu \mathrm{g} \cdot \mathrm{mL}^{-1}$. A calibragem e zeragem do equipamento foram realizadas com etanol 70\%. Os resultados foram expressos em substâncias fenólicas totais floroglucinol equivalentes $\left(\mu \mathrm{g} \cdot \mathrm{gMF}^{-1}\right)$.

\subsection{Atividade antioxidante total}

\subsubsection{Consumo do DPPH (2,2-difenil-1-picril-hidrasil)}

Embora existam diversos métodos (ABTS; FRAP, entre outros) com a mesma finalidade, optou-se pela quantificação da atividade antioxidante total por meio do consumo do DPPH, pois este é um método relativamente barato, de fácil aplicação e é amplamente utilizado em pesquisas de cunho científico.

A atividade antioxidante pelo consumo do radical livre DPPH foi baseada nos trabalhos de Blois (1958), Brand-Williams et al. (1995), Bondet et al. (1997), SanchezMoreno et al. (1998) e Andreguetti (2010).

A extração consistiu em triturar $240 \mathrm{mg}$ MF de Gp. tenuifrons em nitrogênio líquido, adicionar $1 \mathrm{~mL}$ de etanol $70 \%$ às amostras e levá-las ao banho-maria por 60 min sob temperatura de $50^{\circ} \mathrm{C}$, homogeneizando-as a cada $15 \mathrm{~min}$. Depois, o extrato foi centrifugado sob rotação de $14000 \mathrm{rpm}$ durante $10 \mathrm{~min}$.

A análise da atividade antioxidante da alga foi realizada em penumbra misturando $200 \mu \mathrm{L}$ de DPPH (Sigma-Aldrich, Alemanha; $50 \mathrm{mg} . \mathrm{L}^{-1}$ em metanol 70\% (v/v)) a $50 \mu \mathrm{L}$ de extrato etanólico (amostra) em três diferentes concentrações (33\%; $50 \% ; 100 \%)$. As leituras das absorbâncias foram executadas em espectrofotômetro de microplacas UV-visível (Epoch Biotek, EUA) em comprimento de onda de $515 \mathrm{~nm}$, no tempo 0 e a cada 5 min até completar $1 \mathrm{~h}$, utilizando microplacas de Elisa $\left(\right.$ Sarstedt $^{\circ}$, Alemanha) transparentes com 96 poços e de fundo plano. Como controle positivo e 
curva padrão foi usada solução de floroglucinol (Sigma-Aldrich, Alemanha) e água (1:1) em concentração de $0,1 \mu \mathrm{g} \cdot \mu \mathrm{L}^{-1}$ enquanto o metanol $70 \%$ foi empregado como branco.

A fim de compensar a influência da coloração de cada extrato na quantificação da atividade antioxidante pelo consumo do DPPH, foram feitos brancos específicos para cada amostra, sem DPPH, e em cada uma das três concentrações de extrato etanólico (33\%; 50\%; 100\%). A curva padrão foi construída com solução de floroglucinol (Sigma-Aldrich, Alemanha) e água (1:1) em concentração de $0,1 \mu \mathrm{g} \cdot \mathrm{mL}^{-1}$. Os resultados foram expressos em atividade antioxidante floroglucinol equivalente ( $\left.\mu \mathrm{g} . \mathrm{gMF}^{-1}\right)$, usando a porcentagem de $50 \%$ de extrato de alga.

\subsubsection{Sistema antioxidante $\beta$-caroteno/ácido linoleico}

A atividade antioxidante de Gp. tenuifrons foi avaliada de acordo com a capacidade do extrato bruto algáceo em atrasar a peroxidação lipídica mediante o acompanhamento da peroxidação do sistema antioxidante $\beta$-caroteno/ácido linoleico, um ácido graxo insaturado, assim como os que constituem as membranas lipídicas. Este método se fundamenta na medida da degradação do $\beta$-caroteno associado ao ácido linoléico com e sem antioxidante (Marco, 1968; Silva et al., 1999). Assim sendo, é complementar à atividade antioxidante total pelo consumo do DPPH.

Este protocolo foi baseado nos trabalhos de Marco (1968), Miller (1970), Rufino et al. (2006) e Broinizi et al. (2007). O procedimento de extração foi o mesmo utilizado na análise de consumo do DPPH, exceto pela redução da biomassa para $120 \mathrm{mg}$ MF de Gp. tenuifrons. A reação de análise foi preparada em penumbra misturando $400 \mu \mathrm{L}$ de Tween 40 (Sigma-Aldrich, Brasil), $40 \mu \mathrm{L}$ de ácido linoleico (Sigma-Aldrich, Brasil), 45 $\mu \mathrm{L}$ de solução de $\beta$-caroteno (Sigma-Aldrich, Brasil) em concentração de $10 \mu \mathrm{g} . \mu \mathrm{L}^{-1}$ preparada em clorofórmio, $50 \mathrm{~mL}$ de água Milli-Q oxigenada por no mínimo $30 \mathrm{~min}$ e $50 \mu \mathrm{L}$ de extrato etanólico (amostra), avaliados em três diferentes concentrações (33\%; $50 \% ; 100 \%)$.

Procedeu-se as leituras em espectrofotômetro de microplacas UV-visível e comprimento de onda de $458 \mathrm{~nm}$, nos tempos 0 e a cada 15 min por no máximo $2 \mathrm{~h}$, usando microplacas de Elisa (Sarstedt ${ }^{\circ}$, Alemanha) transparentes, de fundo plano e com 96 poços. O hidroxianisol butilado (BHA; Sigma Aldrich, Alemanha) em concentração de $0,02 \mu \mathrm{g} \cdot \mu \mathrm{L}^{-1}$ foi empregado como controle positivo e na confecção da curva padrão. 
Como branco foi usada água Milli-Q oxigenada. Para compensar a influência da coloração de cada extrato algáceo, foram feitos brancos específicos para cada amostra, nas três concentrações analisadas $(33 \% ; 50 \% ; 100 \%)$. Foi construída curva padrão com solução de BHA e metanol em concentração de $0,1 \mu \mathrm{g} \cdot \mu \mathrm{L}^{-1}$. Os resultados foram expressos atividade antioxidante BHA equivalente $\left(\mu \mathrm{g} \cdot \mathrm{gMF}^{-1}\right)$, utilizando a alíquota de $50 \%$ de extrato algal de Gp. tenuifrons.

\subsection{Análise estatística}

O experimento de compostos fenólicos foi feito com três réplicas, enquanto os experimentos de atividade antioxidante foram realizados com cinco réplicas. Os dados foram avaliados a partir de análise de variância ANOVA uni-fatorial. Testes a posteriori de Tukey foram aplicados de acordo com a significância das análises. Antes da execução de cada análise foi avaliada distribuição normal (teste de KolmogorovSmirnov). As análises estatísticas foram avaliadas com o programa STATISTICA v. 6.0, dentro de um intervalo de confiança de $95 \%(\mathrm{p}<0,05)$ e segundo as descrições de Zar (1999).

\section{Resultados}

\subsection{Substâncias fenólicas totais}

Após o período experimental, não foram identificadas diferenças significativas entre as algas coletadas durante o DIA e a NOITE sob a mesma irradiância na avaliação das substâncias fenólicas totais (Figura 9). No entanto, entre os ápices submetidos à irradiância de $60 \mu \mathrm{mol}$ de fótons. $\mathrm{m}^{-2} . \mathrm{s}^{-1}$ e os sob $600 \mu \mathrm{mol}$ de fótons. $\mathrm{m}^{-2} \cdot \mathrm{s}^{-1}$ houve aumento significativo (ANOVA; $\mathrm{p}=0,00002$ ) da produção de substâncias fenólicas em Gracilariopsis tenuifrons.

A variação no teor de substâncias fenólicas totais foi de pouco mais que o dobro para talos submetidos à irradiância de $600 \mu \mathrm{mol}$ de fótons. $\mathrm{m}^{-2} \cdot \mathrm{s}^{-1}$. Amostras expostas a $60 \mu \mathrm{mol}$ de fótons. $\mathrm{m}^{-2} \cdot \mathrm{s}^{-1}$ apresentaram concentrações de substâncias fenólicas de $411 \pm$ $57 \mu \mathrm{g} \cdot \mathrm{gMF}^{-1}$ durante o DIA e $431 \pm 33 \mu \mathrm{g} \cdot \mathrm{gMF}^{-1}$ durante a NOITE. Extratos de talos sob $600 \mu \mathrm{mol}$ de fótons. $\mathrm{m}^{-2} . \mathrm{s}^{-1}$ exibiram teores de $1037 \pm 20 \mu \mathrm{g} \cdot \mathrm{gMF}^{-1}$ para o DIA e 924 $\pm 133 \mu \mathrm{g} \cdot \mathrm{gMF}^{-1}$ para a NOITE (Figura 9). 


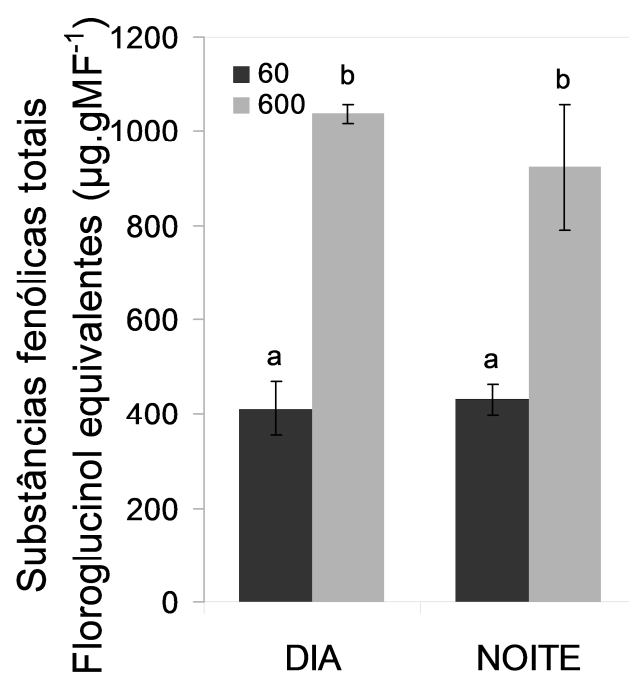

Figura 9: Teor de substâncias fenólicas totais expresso em floroglucinol equivalente e obtido de amostras de Gracilariopsis tenuifrons submetidas a uma semana a $60 \mu \mathrm{mol}$ de fótons. $\mathrm{m}^{-2} \cdot \mathrm{s}^{-1}$ e $600 \mu \mathrm{mol}$ de fótons. $\mathrm{m}^{-2} \cdot \mathrm{s}^{-1}(\mathrm{n}=3)$. Amostras coletadas em dois momentos: DIA e NOITE. Letras diferentes representam diferenças significativas ( $\mathrm{p}<$ $0,05)$.

\subsection{Atividade antioxidante total: consumo do DPPH (2,2-difenil-1-picril-} hidrasil) e sistema $\beta$-caroteno/ácido linoleico

Do mesmo modo que para as substâncias fenólicas totais, estimando a atividade antioxidante (floroglucinol equivalente) pelo método do DPPH, não foram identificadas diferenças significativas entre as algas coletadas durante o DIA e a NOITE sob a mesma irradiância (Figura 10A). Contudo, houve diferença significativa (ANOVA; p =0,000) entre os ápices submetidos à irradiância de $60 \mu \mathrm{mol}$ de fótons. $\mathrm{m}^{-2} \cdot \mathrm{s}^{-1} \mathrm{e}$ os sob $600 \mu \mathrm{mol}$ de fótons.m $\mathrm{m}^{-2} \cdot \mathrm{s}^{-1}$.

A atividade antioxidante pelo método do DPPH para $600 \mathrm{D}$ e $600 \mathrm{~N}$ foi $85 \%$ e $55 \%$ maior do que a atividade antioxidante das amostras na condição de $60 \mu$ mol de fótons. $\mathrm{m}^{-2} \cdot \mathrm{s}^{-1}$ coletadas nos respectivos períodos. Assim as amostras expostas a $60 \mu \mathrm{mol}$ de fótons. $\mathrm{m}^{-2} . \mathrm{s}^{-1}$ apresentaram concentrações de atividades antioxidantes de 91,04 \pm $14,13 \mu \mathrm{g} \cdot \mathrm{gMF}^{-1}$ durante o DIA e $92,77 \pm 4,93 \mu \mathrm{g} \cdot \mathrm{gMF}^{-1}$ durante a NOITE, enquanto os extratos dos talos sob $600 \mu \mathrm{mol}$ de fótons. $\mathrm{m}^{-2} \cdot \mathrm{s}^{-1}$ exibiram atividades de 169,87 $\pm 29,38$ $\mu \mathrm{g} . \mathrm{gMF}^{-1}$ para o DIA e $143,08 \pm 14,12 \mu \mathrm{g} \cdot \mathrm{gMF}^{-1}$ para a NOITE (Figura $10 \mathrm{~A}$ ). 
A

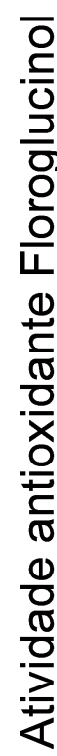

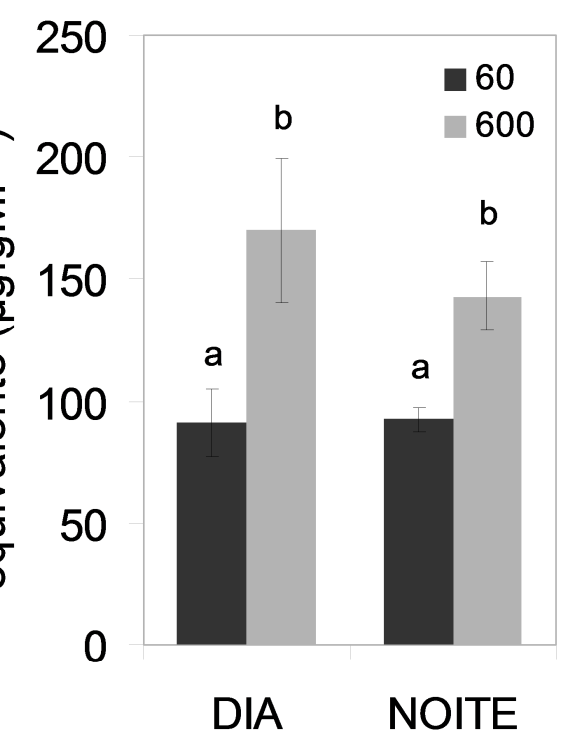

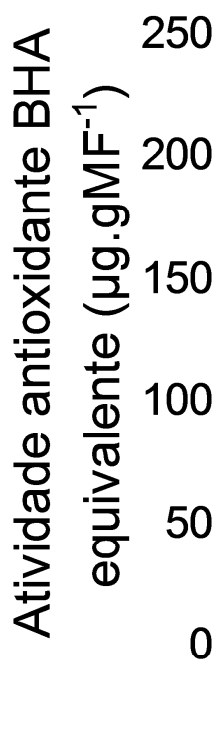

B

Figura 10: Atividade antioxidante de amostras de Gracilariopsis tenuifrons submetidas a uma semana a $60 \mu \mathrm{mol}$ de fótons. $\mathrm{m}^{-2} \cdot \mathrm{s}^{-1}$ e $600 \mu \mathrm{mol}$ de fótons. $\mathrm{m}^{-2} \cdot \mathrm{s}^{-1}(\mathrm{n}=5)$. A: sequestro de DPPH expresso em floroglucinol equivalente. B: sistema do $\beta$ caroteno/ácido linoleico expresso em BHA equivalente. Amostras coletadas em dois momentos: DIA e NOITE. Letras diferentes representam diferenças significativas ( $\mathrm{p}<$ $0,05)$.

Quantificando a atividade antioxidante de $G p$. tenuifrons a partir do sistema $\beta$ caroteno/ácido linoleico, detectou-se diferença significativa apenas entre algas coletadas durante a NOITE e submetidas a irradiância de $600 \mu \mathrm{mol}$ de fótons. $\mathrm{m}^{-2} . \mathrm{s}^{-1}$ (ANOVA; $p=0,000$ ). A atividade antioxidante BHA equivalente foi aproximadamente de $28 \%$ maior para $600 \mathrm{~N}$ em relação aos demais tratamentos (Figura 10B). Ápices expostos a $60 \mu \mathrm{mol}$ de fótons. $\mathrm{m}^{-2} . \mathrm{s}^{-1}$ apresentaram atividade de 76,92 $\pm 2,5 \mu \mathrm{g} \cdot \mathrm{gMF}^{-1}$ durante o DIA e 74,37 $\pm 4,97 \mu \mathrm{g} \cdot \mathrm{gMF}^{-1}$ durante a NOITE, enquanto os extratos provenientes de talos sob $600 \mu \mathrm{mol}$ de fótons. $\mathrm{m}^{-2} \cdot \mathrm{s}^{-1}$ apresentaram 80,13 $\pm 10,88$ $\mu \mathrm{g} . \mathrm{gMF}-1$ para o DIA e $103,29 \pm 7,32 \mu \mathrm{g} \cdot \mathrm{gMF}^{-1}$ para a NOITE.

A porcentagem de inibição do DPPH dos extratos de Gp. tenuifrons submetidos a $60 \mathrm{D}$ e $60 \mathrm{~N}$ foram equivalentes a atividade oxidante das menores quantidades $(0,3 \mu \mathrm{g}$ e $0,5 \mu \mathrm{g}$ ) do floroglucinol (Figura 11A). Entretanto os extratos expostos a 600D e 600N apresentaram a mesma atividade antioxidante que as maiores quantidades de floroglucinol $(1,5 \mu \mathrm{g}$ e $2 \mu \mathrm{g})$. A porcentagem de inibição do DPPH dos talos do 
tratamento de 60 foi cerca de $23,4 \%$ e a dos talos provenientes do tratamento de 600 foi cerca de $48 \%$ (Figura 11A).

A porcentagem de proteção do sistema $\beta$-caroteno/ácido linoleico conferida pela adição dos extratos oriundos dos tratamentos de $60 \mathrm{D}, 60 \mathrm{~N}$ e $600 \mathrm{D}$ foi cerca de $72 \%$ (Figura 11B). Contudo, a porcentagem de proteção fornecida pelo extrato do tratamento $600 \mathrm{~N}$ foi equivalente a porcentagem de proteção da maior quantidade do BHA (64 ng a 512 ng) usada na curva de dosagem, ou seja, cerca de 91\% de proteção lipídica (Figura 11B).

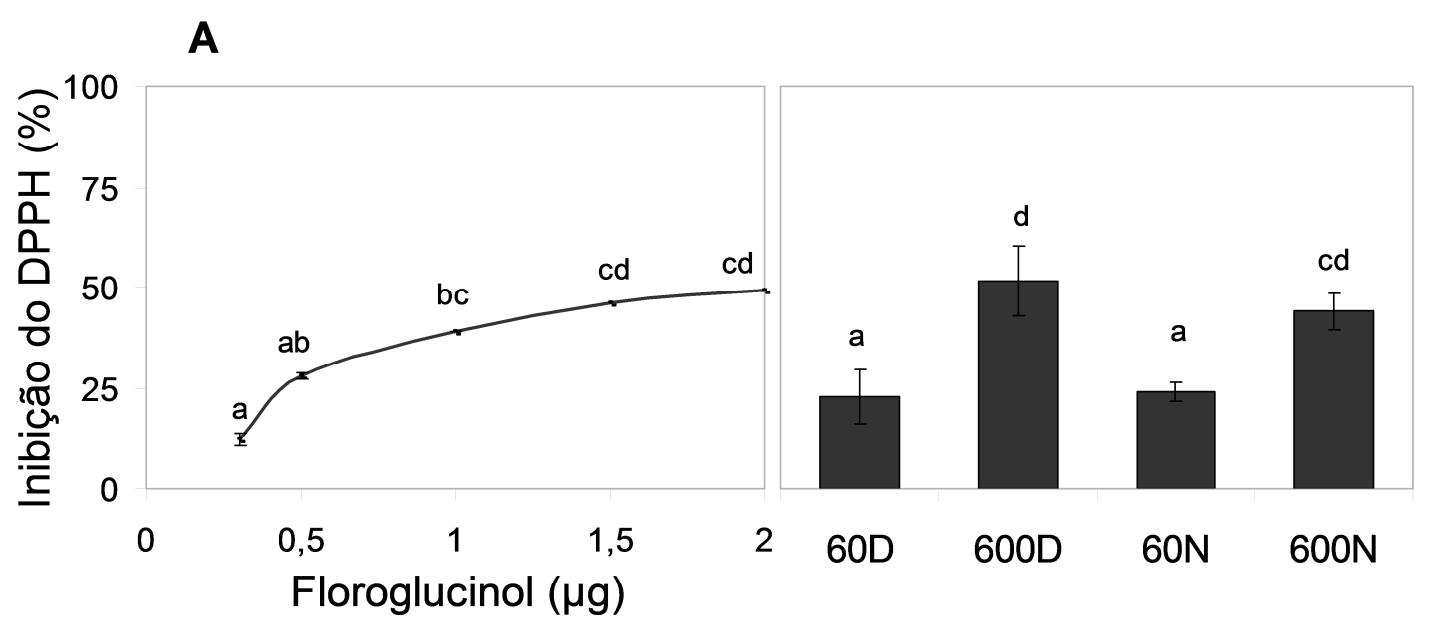

B

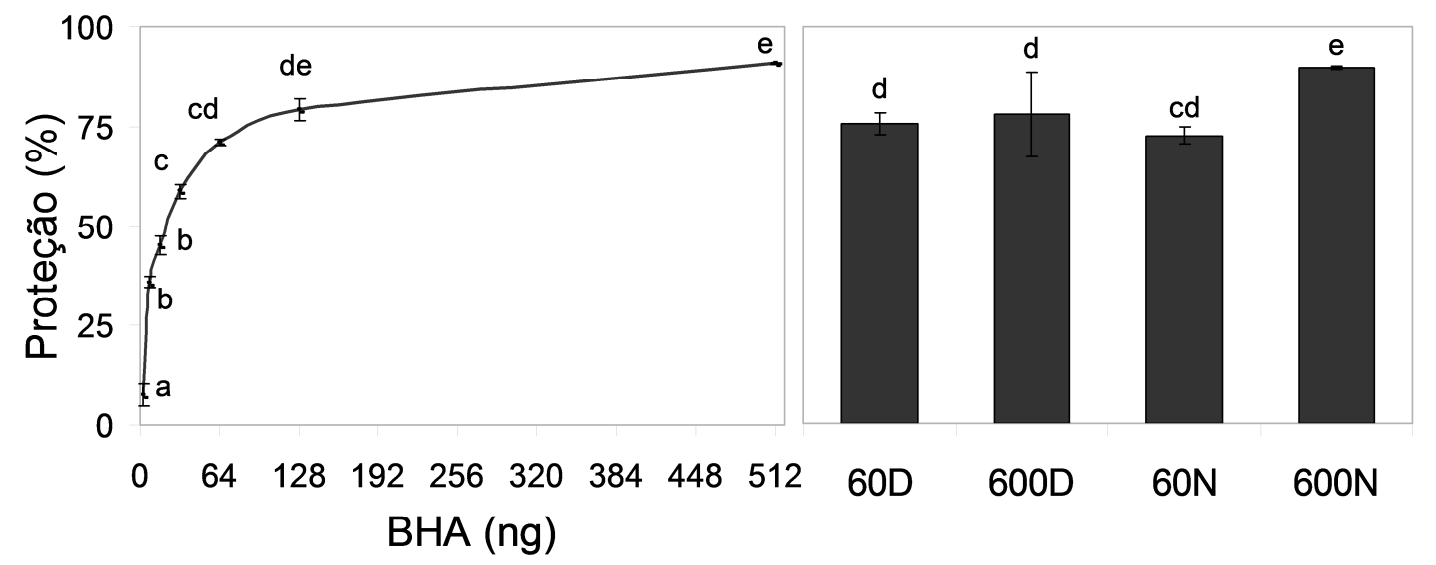

Figura 11: Porcentagens de inibição do DPPH e de proteção do sistema $\beta$ caroteno/ácido linoleico de diferentes concentrações de padrões e de amostras de Gracilariopsis tenuifrons submetidas a uma semana a $60 \mu \mathrm{mol}$ de fótons. $\mathrm{m}^{-2} \cdot \mathrm{s}^{-1}$ e 600 $\mu$ mol de fótons. $m^{-2} \cdot s^{-1}(n=5)$. A: inibição do DPPH $(\%)$ promovida pelo padrão floroglucinol e extratos de $G$ p. tenuifrons, representados pelos respectivos tratamentos 60D; 600D; 60N; 600N. B: proteção do sistema $\beta$-caroteno/ácido linoleico (\%) promovida pelo padrão BHA e extratos de Gp. tenuifrons. Amostras coletadas em dois momentos: DIA e NOITE. Letras diferentes representam diferenças significativas ( $\mathrm{p}<$ $0,05)$. 


\section{Discussão}

As respostas dos seres fotossintetizantes aos estímulos da PAR elevada são semelhantes aos estímulos provocados pela radiação UV (Sinha et al., 2000; Bischof, 2002; Häder et al., 2007; Hanelt \& Roleda, 2009; Raven, 2011; Torres, 2012). Assim a atividade antioxidante é disparada em resposta a diversas situações de estresse (Scandalios, 2005). Em decorrência da exposição a altas intensidades de PAR, produtores primários tendem a produzir espécies reativas de oxigênio (ROS) de forma exagerada, podendo alterar e danificar processos biológicos essenciais no organismo (Bhandari \& Sharma, 2006). A estabilidade das macroalgas marinhas em situação de estresse (principalmente exposição à luminosidade, dessecação e salinidade) permite afirmar que esses organismos possuem eficiente sistema de defesa antioxidante (Matanjun et al., 2008), por isso têm sido extensamente investigados.

\subsection{Substâncias fenólicas totais}

O aumento de substâncias fenólicas em algas sob estímulo luminoso sugere que estas substâncias funcionam como mecanismo de proteção em ecossistemas sujeitos a alta irradiância e que o aumento destes compostos no talo das algas sinaliza altos níveis de PAR (Abdala-Diaz et al., 2006).

Deste modo, Gracilariopsis tenuifrons exposta a alta PAR apresentou produção de substâncias fenólicas em resposta a exposição à irradiância de $600 \mu \mathrm{mol}$ de fótons.m ${ }^{2} . \mathrm{s}^{-1}$ tanto durante o dia quanto durante a noite. Este aumento nos talos de Gp. tenuifrons poderia estar relacionado ao fotoestresse, estado em que estas substâncias agiriam absorvendo o excesso de luminosidade e atrasando a oxidação.

Figueroa et al. (2009) obtiveram resultados parecidos ao estudar os efeitos da radiação UVB na clorófita Zygnemopsis decussata, pois segundo eles, nessa alga, a UVR estimulou o acúmulo de substâncias fenólicas, que consequentemente auxiliaram na redução do estresse.

Torres (2012), também estudando Gp. tenuifrons sob três regimes de irradiância (60; 600 e $1000 \mu \mathrm{mol}$ de fótons. $\mathrm{m}^{-2} \cdot \mathrm{s}^{-1}$ ) em laboratório, utilizando metodologias em espectrofotômetro UV-visível e cromatografia líquida de alta eficiência (CLAE) detectou aumento nas substâncias fenólicas totais em resposta ao aumento de PAR. Além disso, Torres (2012) identificou em CLAE uma substância que demonstrou resposta mais evidente em relação a alta PAR, um aminoácido tipo micosporina 
(MAA), derivado de palitinol, que apresentou aumento de quantidade em resposta a 600 e $1000 \mu \mathrm{mol}$ de fótons. $\mathrm{m}^{-2} \cdot \mathrm{s}^{-1}$. Deste modo, é provável que algumas MAAs tenham sido extraídas e quantificadas junto com as substâncias fenólicas e sejam detectadas em espectro semelhante ao das substâncias fenólicas.

O acúmulo de substâncias fenólicas, como florotaninos (sintetizados a partir da via do acetato-malonato) tem sido amplamente observado em algas pardas e verdes para mitigar os efeitos da alta irradiância (Karsten et al., 1998; Aguirre von Wobeser et al., 2000; Rozema et al., 2002; Han \& Han, 2005; Connan et al., 2007; Oren \& GundeCimerman, 2007; Figueroa et al., 2009; Häder et al., 2011; Poper, 2011; Wang et al., 2012). Contudo, outras substâncias também podem atuar absorvendo ou dissipando o excesso de irradiância, principalmente UVR. Dentre elas, substâncias como ficobiliproteínas (Cabello-Pasini et al., 2011), clorofilas (Gonzalez et al., 2009), carotenoides e MAAS (sintetizados a partir da via do chiquimato) nas algas vermelhas.

Então, Gp. tenuifrons exibe como uma das estratégia de defesa antioxidante em resposta a alta PAR a produção e acúmulo de substâncias fenólicas e MAAs. AbdalaDiaz et al. (2006) afirmam que a luz estimula o aumento das substâncias fenólicas e que nos ápices essas substâncias podem agir diretamente como fotoprotetores contra a alta irradiância por absorver os fótons incidentes ou agir indiretamente como resultado de sua atividade antioxidante. Enquanto Gomez \& Huovinen (2010) afirmam que as substâncias protetoras promovem mecanismos de aclimatação eficientes, que reduzem a inibição da fotossíntese e os danos no DNA. Eles observaram ainda que apenas sob alta PAR as substâncias fenólicas presentes na alga parda Lessonia nigrescens agem junto com a redução da atividade fotossintetizante para liberar o excesso de energia solar absorvida.

É possível que as substâncias fenólicas assim como os MAAs atuem nos talos de Gp. tenuifrons expostos a alta irradiância tanto absorvendo a PAR quanto mitigando seus efeitos intracelularmente se ligando às ROS e dissipando energia em forma de calor. Substâncias fenólicas, assim como MAAs, agem absorvendo e atenuando os efeitos da luz excessiva (Anh et al., 2010; Carreto \& Carrignan, 2011). E uma vez produzidas, podem ser encontradas no citoplasma (Shick \& Dunlap, 2002; Korbee et al., 2006; Roleda et al., 2007) e, principalmente, na parede celular (Abdal-Diaz et al., 2006; Connan et al., 2007; Poper, 2011), localização que parece ser estratégica para interceptação dos raios UV (Gomez \& Huovinen, 2010). 
A condição de $60 \mu \mathrm{mol}$ de fótons. $\mathrm{m}^{-2} \cdot \mathrm{s}^{-1}$ pode representar dias ou estações do ano de menor incidência luminosa para Gp. tenuifrons, enquanto o regime de $600 \mu \mathrm{mol}$ de fótons. $\mathrm{m}^{-2} . \mathrm{s}^{-1}$ representaria períodos de maior intensidade de luz. Sendo assim, tanto as substâncias fenólicas quanto as MAAs aumentam sazonalmente, sendo produzidas em maior quantidade no verão, quando se tem mais luz e calor (Pérez-Rodríguez et al., 2001; Aherne \& Obrien, 2002; Connan, 2004).

Por outro lado, a produção e acúmulo de substâncias fenólicas em $G p$. tenuifrons não exibiram diferenças significativas durante o ciclo diário representado por DIA e NOITE. Entretanto, Abdala-Diaz et al. (2006) que estudaram algas pardas em condições ambientais, com variação natural na luminosidade, observaram significativa flutuação diária de substâncias fenólicas em Cystoseira tamariscifolia. Tendo havido, na alga, decréscimo de 50\% dessas substâncias ao longo da manhã e aumento a partir do meio dia até o fim do dia. Os autores afirmaram que há uma relação de fotorregulação da produção e acumulação de fenois durante a exposição diária à irradiância.

Por outro lado, Connan (2004), ao analisar a variação temporal dos níveis de florotaninos em algumas algas pardas em ambiente natural, afirma que o acúmulo de substâncias fenólicas é estimulado por longos períodos de emersão e exposição à radiação solar direta. A autora registrou nas feofíceas Ascophyllum nodosum e Fucus vesiculosus presença de grande quantidade de compostos fenólicos, duas espécies que ocorrem no mediolitoral, região sujeita a intensa luminosidade e dessecação. Entretanto, para uma terceira espécie de alga parda investigada (Bifurcaria bifurcata), que ocorre na região do infralitoral, não houve variação da quantidade de substâncias fenólicas entre dia e noite.

Os resultados da quantificação de substâncias fenólicas usando Gp. tenuifrons demonstram que esta alga sob exposição a alta irradiância a quantidade de compostos fenólicos tende a aumentar e esta resposta é mantida ainda durante a noite, mesmo após cessar o estímulo luminoso, provavelmente como mecanismo de proteção que pode atuar de forma mais eficiente quando a condição de estresse não está presente.

\subsection{Atividade antioxidante total}

\subsubsection{Consumo do DPPH (2,2-difenil-1-picril-hidrasil)}

Como radical livre, o DPPH estima a capacidade antioxidante de uma substância, como por exemplo, substâncias fenólicas, carotenoides, polissacarídeos 
vitaminas C e E. Por isso o DPPH foi usado para mensurar a aptidão de Gp. tenuifrons em consumir ROS. Assim, em resposta a alta PAR, atividade antioxidante total exibiu aumento, evidenciado pelo maior consumo do DPPH, indicando que essa condição provavelmente promoveu maior produção de ROS nos ápices. Respostas similares foram observadas por Sinha et al. (2000), Adala-Diaz et al. (2006) e Korbe et al. (2006).

Análises complementares, mostraram que alterações em pigmentos fotossintetizantes, proteínas solúveis, conteúdo tissular de carbono, hidrogênio e nitrogênio (capítulo II) e óxido nítrico (NO; capítulo III) também apontaram estresse oxidativo nos ápices de Gp. tenuifrons expostos à irradiância de $600 \mu \mathrm{mol}$ de fótons.m ${ }^{2} \cdot \mathrm{s}^{-1}$. Esses talos apresentaram redução dos pigmentos, principalmente ficobiliproteínas e nitrogênio nos tecidos. Comportamento que pode indicar que a dissociação dos pigmentos (Talarico \& Maranzana, 2000; Muramatsu \& Hihara, 2012; Tamary et al., 2012), junto com o aumento das ROS sejam o sinal (Khan \& Wilson, 1995; Mittler et al., 2011) para o aumento da produção de substâncias absorvedoras de irradiância e antioxidantes, dentre elas substâncias fenólicas e MAAs. Assim, é possível que fontes nitrogenadas provenientes da quebra dos pigmentos sejam utilizadas na síntese de substâncias antioxidantes, como MAAs, e NO, este último radical que desempenha diversas funções, por exemplo, antioxidante.

Além disso, obteve-se equiparada porcentagem de inibição do DPPH entre extratos de talos provenientes dos tratamentos $600 \mathrm{~N}$ e $600 \mathrm{D}$ (cerca de $48 \%$ ) e as maiores quantidades da dosagem de floroglucinol $(1,5 \mu \mathrm{g}$ e $2 \mu \mathrm{g})$, mostrando que a atividade antioxidante do extrato desses ápices de $G p$. tenuifrons é relativamente eficiente. Kumar et al. (2008) estudando Kappaphycus alvarezii obtidas em um cultivo na Índia, região com predomínio de intensa irradiância, encontraram uma atividade antioxidante de cerca de 40\% de inibição do DPPH. Enquanto Lekameera et al. (2008), que estudaram a alga parda Colpomenia sinuosa, coletada no Sul da Índia e sujeita a altas irradiâncias, obtiveram 88,57\% de inibição do DPPH.

No entanto, considerando a atividade antioxidante, em comparação com algas pardas, as algas vermelhas, geralmente, não são grandes produtoras de substâncias fenólicas (Matanjun, 1997; Zubia et al., 2007; Wang et al., 2009). Contudo, Zubia et al. (2007) ao analisar as substâncias fenólicas detectou maior quantidade destas substâncias em Gp. tenuifrons do que em outras algas vermelhas (por exemplo, Chondrophycus papillosus, Digenea simplex, Gracilaria caudata, G. cornea, G. cylindrica, G. 
tikvahiae, Halymenia floresii, Hypnea spinella, Liagora ceranoides) e do que em algumas algas pardas como Sargassum pteropleuron, S. ramifolium e Turbinaria tricostata. Relacionando as ponderações supracitadas, Frikha et al. (2011) afirmam que a taxa da atividade biológica depende da natureza e quantidade de compostos ativos presentes nos extratos.

\subsubsection{Sistema $\beta$-caroteno/ácido linoleico}

A peroxidação lipídica, oxidação dos ácidos graxos, causada pelo acúmulo de ROS modifica a integridade estrutural e funcional das membranas celulares alterando sua fluidez e permeabilidade, afetando funções básicas dos sistemas biológicos (Soares, 2002). Um dos métodos para avaliar a eficiência de um espécime em conservar a integridade de suas membranas, sob condições de estresse, é a determinação de atividade antioxidante pelo sistema do $\beta$-caroteno/ácido linoleico.

Em Gp. tenuifrons foi possível notar que a atividade contra peroxidação lipídica conferida pelo extrato dos talos submetidos à irradiância de $60 \mu \mathrm{mol}$ de fótons. $\mathrm{m}^{-2} . \mathrm{s}^{-1}$ permaneceu constante durante DIA e NOITE. Isso sugere que $60 \mu \mathrm{mol}$ de fótons. $\mathrm{m}^{-2} . \mathrm{s}^{-1}$ pode não ser uma condição que requeira efetivamente a ativação deste mecanismo de proteção. Entretanto, os extratos dos ápices expostos a irradiância de $600 \mu$ mol de fótons. $\mathrm{m}^{-2} \cdot \mathrm{s}^{-1}$ apresentaram maior atividade contra a peroxidação lipídica apenas a NOITE. Esse resultado sugere que durante o DIA há consumo imediato das substâncias antioxidantes protetoras de membranas por causa do estresse oxidativo, promovido pelo excesso de irradiância. Por isso em 600D a capacidade de proteção lipídica foi similar à detectada nos ápices expostos $60 \mu \mathrm{mol}$ de fótons. $\mathrm{m}^{-2} \cdot \mathrm{s}^{-1} \mathrm{em}$ ambos os períodos. Possivelmente, sob elevada irradiância, outros mecanismos de defesa antioxidativos devem ter contribuído para a proteção contra a peroxidação lipídica. Por exemplo, Harada \& Chow (2009), estudando Gp. tenuifrons nas mesmas condições experimentais do presente trabalho detectaram elevação da atividade da enzima ascorbato peroxidase (APX; enzima antioxidante localizada em diversos sistemas de membranas) durante o dia e a noite. $\mathrm{O}$ trabalho desses autores aponta que além das substâncias antioxidantes, a luz também ativa enzimas antioxidantes chave para combater o efeito e dano oxidativo e, por isso, não haveria a necessidade imediata de $G p$. tenuifrons em investir na sintetização de substâncias antioxidates não enzimáticas em grandes quantidades para impedir a peroxidação lipídica durante o dia. 
Além disso, é possível que nos ápices sob $600 \mu \mathrm{mol}$ de fótons. $\mathrm{m}^{-2} \cdot \mathrm{s}^{-1}$, à noite, $\mathrm{o}$ consumo das substâncias que impedem a peroxidação lipídica tenha sido menor, favorecendo seu acúmulo neste período. Esse aspecto pode permitir aos ápices disporem de quantidade extra dessas substâncias para o início do fotoperíodo, período no qual ocorrerá exposição à alta PAR. Desta forma, extratos de Gp. tenuifrons provenientes dos talos expostos a $600 \mu \mathrm{mol}$ de fótons. $\mathrm{m}^{-2} . \mathrm{s}^{-1}$ e coletados a NOITE apresentaram maior proteção contra a peroxidação lipídica, cerca de $91 \%$, semelhante ao grau observado por Amornlerpidson et al. (2007) para a alga parda Padina minor (acerca de $94 \%)$.

Finalmente, considerando os resultados aqui obtidos a partir da avaliação do teor de substâncias fenólicas, atividade antioxidante total e proteção contra peroxidação lipídica de Gp. tenuifrons, pode-se dizer que a condição de alta luminosidade conduziu ao estresse oxidativo, que disparou mecanismos relacionados à síntese e acúmulo de substâncias antioxidantes como compostos fenólicos, promovendo o aumento da atividade antioxidante total e de substâncias contra a peroxidação lipídica.

A evidenciação desses sistemas de proteção antioxidativos em Gp. tenuifrons sugerem que essa alga possui tolerância a condições de elevada irradiância. Por outro lado, a possibilidade de indução dessas substâncias antioxidantes poderia ser aproveitada em abordagens biotecnológicas e elaboração de produtos nutracêuticos com alto teor de antioxidantes.

\section{Referências bibliográficas}

Abdala-Diaz, R.T., Cabello-Pasini, A., Perez-Rodriguez, E.; Conde Alvarez, R.M., Figueroa, F.L., 2006. Daily and seasonal variations of optimum quantum yield and phenolic compounds in Cystoseira tamariscifolia (Phaeophyta). Mar. Biol. 148, 459465 .

Aherne, S. A. \& O’Brien, N. M. 2002. Dietary Flavonols: Chemistry, Food Content, and Metabolism. Nutrition 18:75-81.

Aguilera, J.; Dummermuth A.; Karsten, U.; Schriek, R.; Wiencke1, C. 1999. Enzymatic defences against photooxidative stress induced by ultraviolet radiation in Arctic marine macroalgae. Polar Biol. 25: 432-441.

Aguilera, J.; Karsten, U.; Lippert, H.; Vogele, B.; Philipp, E.; Hanelt, D.; Wiencke, C. 1999. Effects of solar radiation on growth, photosynthesis and respiration of marine macroalgae from the Arctic. Mar Ecol Prog Ser Vol. 191: 109-119. 
Aguirre-von-Wobeser, E; Figueroa, F.L.; Cabello-Pasini, A. 2001. Photosynthesis and growth of red and Green morphotypes of Kappaphycus alvarezii (Rhodophyta) from the Philippines. Marine Biology 138: 679-686.

Altamirano, M.; Flores-Moyaa, A.; Figueroa, F. L. 2000. Long-Term Effects of Natural Sunlight under Various Ultraviolet Radiation Conditions on Growth and Photosynthesis of Intertidal Ulva rigida (Chlorophyceae) Cultivated In Situ. Botanica Marina Vol. 43, pp. 119-126.

Amornlerdpison, D.; Peerapornpisal, Y.; Taesotikul,T.; Jamjai, U.; Nualchareo., M; Duangta Kanjanapothi, D. 2007. Antioxidant activity of Padina minor Yamada. Sci. Tech. J. Vol. 7 No. S1 pp. 7.

Andreguetti, D. 2010. Análogos de micosporinas: síntese e avaliação de parâmetros farmacológicos e toxixológicos. Dissertação de mestrado. 106p.

Ahn, Y. H.; Yoo, J. S.; Kim, S. H. 2010. An antioxidant capacity assay using a polyvinyl alcohol-based DPPH pellet. Bull. Korean Chem. Soc. Vol. 31, No. 9. pp. 2557-2560.

Ayres, L. M. 2009. Efeitos da radiação UV-B em variants cromáticas de Gracilaria birdeae (Gracilariales-Rhodophyta): crescimento, conteúdo pigmentar, fotossíntese e ultra-estrutura. Dissertação de mestrado. Universidade de São Paulo. 45p.

Bhandari, R. \& Sharma, P.K. 2006. High-light-induced changes on photosynthesis, pigments, sugars, lipids and antioxidant enzymes in freshwater (Nostoc spongiaeforme) and marine (Phormidium corium) cyanobacteria. Photochemistry and Photobiology. 82: $702-710$.

Barufi, J. B. 2010. fotoproteção em Gracilaria tenuistipitata (Rhodophyta): uma abordagem fisiológica e molecular. Tese de doutorado. Universidade de São Paulo. $325 \mathrm{p}$.

Barufi, J. B.; Mata, M.T.; Oliveira, M. C.; Figueroa, F. L. 2012. Nitrate reduces the negative effect of UV radiation on photosynthesis and pigmentation in Gracilaria tenuistipitata (Rhodophyta): the photoprotection role of mycosporine-like amino acids. Phycologia. 51 (6), pp. 636-648.

Bischof, K.; Kräbs, G.; Wiencke, C.; Hanelt, D. 2002. Solar ultraviolet radiation affects the activity of ribulose-1,5-bisphosphate carboxylase-oxygenase and the composition of photosynthetic and xanthophyll cycle pigments in the intertidal green alga Ulva lactuca L. Planta. 215: 502-509.

Bischof, K.; Gómez, I.; Molis, M.; Hanelt, D.; Karsten, U.; Lüder, U.; Roleda, M. Y.; Zacher, K.; Wiencke, C. 2006. Ultraviolet radiation shapes seaweed communities. Rev Environ Sci Biotechnol 5:141-166.

Blois, M. S. 1958. Antioxidant determinations by the use of a stable free radical. Nature publishing group 181: 1199-1200. 
V. Bondet, V.; Brand-Williams, W.; Berset, C. 1997. Kinetics and mechanisms of antioxidant activity using the DPPH• free radical method. Lebensm.-Wiss. u.-Technol. 30: 609-615.

Brand-Williams, W.; Cuvelier, M. E.; Berset, C. 1995. Use of a free radical method to evaluate antioxidant activity. Lebensm.-Wiss. u.-Technol. 28:25-30.

Brito, L.L. 1999. Influencia del tratamiento alcalino sobre el agar de Gracilariopsis tenuifrons (Gracilariales: Rhodophyta). Instituto Oceanográfico de Venezuela, Universidad de Oriente, Cumaná, Venezuela. perbrica@telcel.net.ve.67-70.

Brito, L. L. \& Silva, S. 2005. Fenología y ciclo de vida del alga Gracilariopsis tenuifrons (Gracilariaceae) en Sucre, Venezuela. Rev. Biol. Trop. (Int. J. Trop. Biol. ISSN-0034-7744). (www.tropiweb.com). 53: 67-73.

Broinizi, P. R. B.; Andrade-Wartha, E. R. S. de; Silva, A. M. De O. e; Novoa, A. J. V.; Torres, R. P.; Azeredo, H. M. C. Alves, R. E.; Mancini-Filho J. 2007. Avaliação da atividade antioxidante dos compostos fenólicos naturalmente presentes em subprodutos do pseudofruto de caju (Anacardium occidentale L.). Ciênc. Tecnol. Aliment., Campinas, 27: 902-908.

Cabello-Pasini, A.; Macías-Carranza, V.; Abdala, R.; Korbee, N.; Figueroa, F. L. 2011. Effect of nitrate concentration and UVR on photosynthesis, respiration, nitrate reductase activity, and phenolic compounds in Ulva rigida (Chlorophyta). J Appl Phycol 23:363369.

Cardozo, K. H.M.; Guaratini, T.; Barros, M. P.; Falcão, V. R.; Tonon, A. P.; Lopes, N. P.; Campos, S.; Torres, M. A.; Souza, A. O.; Colepicolo, P.; Pinto, E. 2007. Metabolites from algae with economical impact. Comparative Biochemistry and Physiology, Part C. 146: 60-78.

Carreto, J. I. \& Carignan, M. O. 2011. Mycosporine-like amino acids: relevant secondary metabolites. chemical and ecological aspects. Mar. Drugs. 9: 387-446.

Connan, S.; Goulard, F.; Stiger, V.; Deslandes, E.; Gall, E. A. 2004. Interspecific and temporal variation in phlorotannin levels in an assemblage of brown algae. Botanica Marina 47: 410-416.

Connan, S.; Deslandes, E.; Gall, E. A. 2007. Influence of day-night and tidal cycles on phenol content and antioxidant capacity in three temperate intertidal brown seaweeds. Journal of Experimental Marine Biology and Ecology 349: 359-369.

de la Coba, F.; Aguilera, J.; Figueroa, F. L.; de Gálvez, M. V.; Herrera, E. 2009. Antioxidant activity of mycosporine-like amino acids isolated from three red macroalgae and one marine lichen. Appl Phycol. 21:161-169.

Devi, K.P.; Suganthy, N.; Kesika, P.; Pandian, S.K. 2008. Bioprotective properties of seaweeds: In vitro evaluation of antioxidant activity and antimicrobial activity against food borne bacteria in relation to polyphenolic content. Complementary and Alternative Medicine (http://www.biomedcentral.com/1472-6882/8/38) 1-11p. 
Figueroa, F. L.; Korbee, N.; Carrillo; Medina-Sánchez, J. M.; Mata, M.; Bonomi, J.; Sánchez-Castillo, P.M. 2009. The effects of UV radiation on photosynthesis estimated as chlorophyll fluorescence in Zygnemopsis decussata (Chlorophyta) growing in a high mountain lake (Sierra Nevada, Southern Spain). J. Limnol., 68: 206-216.

Frikha, F.; Kammoun, M.; Hammami, N.; Mchirgui, R. A.; Belbahri, L.; Gargouri, Y.; Miled, N.; Ben-Rebah, F. 2009. Chemical composition and some biological activities of marine algae collected in Tunisia. Ciencias Marinas. 37(2): 113-124.

Gómez, I. \& Huovinen, P. 2010. Induction of phlorotannins during UV exposure mitigates inhibition of photosynthesis and DNA Damage in the Kelp Lessonia nigrescens Photochemistry and Photobiology 86: 1056-1063.

González, A. E. B.; Charles, M. B.; Mancini-Filho, J.; Novoa, A. V. 2009. Las algas marinas como fuentes de fitofármacos antioxidants. Revista Cubana de Plantas Medicinales. 14: 1-18.

Häder, D.-P.; Kumar, H.D.; Smith, R. C.; Worrest, R. C. 1998. Effects on aquatic ecosystems. Journal of Photochemistry and Photobiology B: 46:53-68.

Häder, D.-P.; Kumar, H.D.; Smith, R. C.; Worrest, R. C. 2007. Effects of solar UV radiation on aquatic ecosystems and interactions with climate change. Photochem. Photobiol. Sci. 6:267-285.

Häder, D.P.; Helbling, E. W.; Williamson, C. E.; Worrest, R. C. 2011. Effects of UV radiation on aquatic ecosystems and interactions with climate change. Photochem. Photobiol. Sci.10: 242-260.

Han, Y-S \& Han, T. 2005. Uv-b induction of UV-B protection in Ulva pertusa (Chlorophyta). J. Phycol. 41: 523-530.

Hanelt, D. \& Roleda, M. Y. 2009. UVB Radiation may ameliorate photoinhibition in specific shallow-water tropical. Aquat. Bot. (2009), doi:10.1016/j.aquabot.2008.12.005.

Harada, D.; Chow, F. Efeito da luz nos sistemas antioxidantes da alga Gracilariopsis tenuifrons. In: Simpósio Internacional de Iniciação Científica da Universidade de São Paulo (SIICUSP), 17, 2009, Ribeirão Preto. Anais eletrônicos. São Paulo: USP, 2009. Disponível em: < https://uspdigital.usp.br/siicusp/cdOnlineTrabalhoVisualizarResumo

Karsten, U.; Friedl, T.; Schumann, R.; Hoyer, K.; Lembcke, S. 2005. Mycosporine-like amino acids and phylogenies in green algae: Prasiola and its relatives from the trebouxiophyceae (chlorophyta). J. Phycol. 41:557-566.

Karsten, U.; Sawall, T.; Hanelt, D.; Bischof, K.; Figueroa, F. L.; Flores-Moyac, A.; Wiencke, C. 1998. An inventory of UV-absorbing mycosporine-like amino acids in macroalgae from polar to warm-temperate regions. Botanica Marina 41: 443-453. 
Karsten, U. \& Wiencke, C. 1999. Factors controlling the formation of UV-absorbing mycosporine-like amino acids in the marine red alga Palmaria palmata from Spitsbergen (Norway). j. Plant Physiol.155. pp. 407-415.

Khan, A. U. \& Wilson, T. 1995. Reactive oxygen species as cellular messengers. Chemistry \& Biology. 2:437-445.

Kladi, M.; Vagias, C.; Roussis, V. 2004. Volatile halogenated metabolites from marine red algae. Phytochemistry Reviews. 3: 337-366.

Korbee, N.; Figueroa, F. L.; Aguilera, J. 2006. Acumulación de aminoácidos tipo micosporina (MAAs): biosíntesis, fotocontrol y funciones ecofisiológicas. Revista Chilena de Historia Natural 79: 119-132.

Kumar, K. S.; Ganesan, K.; Rao, P.V. S. 2008. Antioxidant potential of solvent extracts of Kappaphycus alvarezii (Doty) Doty - An edible seaweed. Food Chemistry 107: 289295.

Lee, J.-C.; Kim, H-R.; Kim, J.; Jang, Y-S. 2002. Antioxidant Property of an Ethanol Extract of the Stem of Opuntia ficus-indica var. Saboten. J. Agric. Food Chem. 50: 6490-6496.

Lekameera, R.; Vijayabaskar, P.; Somasundaram, S. T. 2008. Evaluating antioxidant property of brown alga Colpomenia sinuosa (DERB. ET SOL). African Journal of Food Science. 2:126-130.

Marco, G.J. 1968. A rapid method of evaluation of antioxidants. The journal of American oil chemists' society. 594-598.

Matanjun, P.; Mohamed, S.; Mustapha, N.M.; Muhammad, K.; Ming, C.H. 2008. Antioxidant activities and phenolics content of eight species of seaweeds from north Borneo. Journal of Applied Phycology 20: 367-373.

Miller, H. E. 1970. A simplified method for the evaluation of antioxidants. Short communication. pp 91.

Mittler, R.;Vanderauwera, S.; Suzuki, N.; Miller, G.; Tognetti, V. B.; Vandepoele, K.; Marty Gollery, M.; Shulaev, V.; Breusegem, F. V. 2011. ROS signaling: the new wave? Trends in Plant Science. 16(6):300-309.

Muramatsu, M. \& Hihara, Y. 2012. Acclimation to high-light conditions in cyanobacteria: from gene expression to physiological responses. J Plant Res. 125:1139.

Navarro, N. P.; Mansilla, A.; Plastino, E. M. 2010. UVB radiation induces changes in the ultra-structure of Iridaea cordata. Micron 41:899-903.

Navarro, N. P. M. 2011. Efeitos da radiação ultravioleta solar em algas de importância econômica da região subantartica do Chile durante a primavera. Tese de doutorado. Universidade de São Paulo. 269 p. 
Oliveira Filho, E. C. 1998. Seaweeds resources of Brazil. In: Critchelly A.T. Ohno M. (eds), seaweeds resources of the world. Japan international Cooperation Agency. 366371.

Ornelas, F. 2011. Efeitos da radiação UVB no crescimento, conteúdo pigmentar e fotossíntese de Gracilaria Caudata (Gracilariales-Rhodophyta). Dissertação de mestrado. Universidade de São Paulo. 96 p.

Oren, A. \& Gunde-Cimerman, N. 2007. Mycosporines and mycosporine-like amino acids: UVprotectants or multipurpose secondary metabolites? FEMS Microbiol Lett 269: $1-10$.

Plaza, M.; Santoyo, S.; Jaime, L.; Garcia-Blairsy, G. R.; Herrero, M.; Señorans,F.J.;Ibañez, E. 2010. Screening for bioactive compounds from algae. Journal of Pharmaceutical and Biomedical Analysis. 51:450-455.

Pérez-Rodriguez, E.; Aguilera, J.; Goméz, I.; Figueroa, F. L. 2001. Excretion of coumarins by the mediterranean green alga Dasycladus vermicularis in responses to environment stress. Marine Biology. 139: 633-639.

Popper, Z. A.; Michel, G.; Hervé, C.; Domozych, D. S.; Willats, W. G. T.; G. Tuohy, M. G.; Kloareg, B.; Stengel, D. B. 2011. Evolution and diversity of plant cell walls: from algae to flowering plants. Annu. Rev. Plant Biol. 62:567-90.

Raven, J. A. 2011. The cost of photoinhibition. Physiologia Plantarum 142: 87-104.

Roleda, Michael Y.; Wiencke, C.; Hanelt, D.; Bischof, K. 2007. Sensitivity of the early life stages of macroalgae from the northern hemisphere to ultraviolet radiation. Photochemistry and Photobiology. 83: 851-862.

Rozema, J.; Bjorn, L.O.; Bornman ,J.F.; Gaberscik, A.; Hader, D.-P.; Trost, T.; Germ, M.; Klisch, M.; Groniger, A.; Sinha, R.P.; Lebert, M.; He, Y.-Y.; Buffoni-Hall, R.; de Bakker, N.V.J.; van de Staaij, J.; Meijkamp, B.B. 2002. The role of UV-B radiation in aquatic and terrestrial ecosystems - an experimental and functional analysis of the evolution of UV-absorbing compounds. Journal of Photochemistry and Photobiology B: Biology 66: 2-12.

Rufino, M. de S. M.; Ricardo Elesbão Alves, R.E.;Brito, E.S. de; Mancini Filho, J.; Moreira, A.V. B. 2006. Metodologia Científica: Determinação da atividade antioxidante total em frutas no sistema $\beta$-caroteno/ácido linoléico. Comunicado técnico on line. ISSN 1679-6535.

Samarakoon, K. \& Jeon,Y-J. 2012. Bio-functionalities of proteins derived from marine algae - A review. Food Research International 48: 948-960.

Sánchez-Moreno, C.; Larrauri, J. A.; Saura-Calixto, F. 1998. A procedure to measure the antiradical efficiency of polyphenols. J Sci Food Agric.76: 270-276.

Scandalios, J.G. 2005. Oxidative stress: molecular perception and transduction of signals triggering antioxidant gene defenses. Braz. J. Med. Biol. Res. 38: 995-1014. 
Schmidt, E. C.; Santos, R.; Horta, P. A.; Maraschin, M.; Bouzon, Z. L. 2010. Effects of UVB radiation on the agarophyte Gracilaria domingensis (Rhodophyta, Gracilariales): Changes in cell organization, growth and photosynthetic Performance. Micron 41: 919930.

Shalaby, E. A. 2011. Algae as promising organisms for environment and health. Plant Signaling \& Behavior 6:9, 1338-1350.

Shick, J. M. \& Dunlap, W.C. 2002. Mycosporine-like amino acids and related gadusols: biosynthesis, accumulation, and UV-protective functions in aquatic organism. Annu. Rev. Physiol. 64:223-62.

Silva, F. A. M.; Borges, M.F.M.; Ferreira, M.A. 1999. Métodos para avaliação do grau de oxidação lipídica e da capacidade antioxidante. Química Nova, 22(1): 94-103.

Sinha, R. P.; Klish, M.;Gröninger, A.; Häder, D-P. 2000. Mycosporine-like amino acids in the marine red alga Gracilaria cornea - effects of UV and heat. Environmental and Experimental Botany. 43:33-43.

Sinha, R.P.; Klish, M.; Helbing, E.W.; Häder, D-P. 2001. Induction of mycosporins like amino acids in cyanobateria by solar radiation. J. Photochem. Photobiol. 60: 129-135.

Soares, S. E. 2002. Ácidos fenólicos como antioxidantes. Rev. Nutr., Campinas. 15(1):71-81.

Talarico, L. \& Maranzana, G. 2000. Light and adaptive responses in red macroalgae: an overview. Journal of Photochemistry and Photobiology B: Biology 56:1-11.

Tamary, E.; Kiss, V.; Nevo, R.; Adam, Z.; Bernát,G. Rexrorth, S.; Rögner, M.; Reich, Z. 2012. Structural and functional alterations of cianobacterial phycobilissomes induced by high light stress. Biochimica et Biophysica Acta. 1817: 319-327.

Torres, P. B. 2012. Análise de pigmentos fotossintetizantes e substâncias fenólicas em Gracilariopsis tenuifrons (C. J. Bird \& E. C. Oliveira) Fredericq \& Hommersand em diferentes intensidades de luz. Dissertação de mestrado. Universidade de São Paulo. $104 p$.

Wang, T.; Jónsdóttir, R.; Ólafsdóttir, G. 2009. Total phenolic compounds, radical scavenging and metal chelation of extracts from Icelandic seaweeds. Food Chemistry. doi:10.1016/j.foodchem.2009.02.041.9p.

Wang, T.; Jónsdóttir, R.; Liu, H.; Gu, L.; Kristinsson, H. G.; Raghavan, S.; Ólafsdóttir, G. 2012. Antioxidant capacities of phlorotannins extracted from the brown algae Fucus vesiculosus. J. Agric. Food Chem. 60: 5874-5883.

Waterman, P. G. \& Mole, S. 1994. Analysis of phenolic plant metabolites. Blackwell scientific publications. 238p. 
Wijesekara, I.; Senevirathne, M.; Li, Y-X; Kim, S-K. 2012. Functional ingredients from marine algae as potential antioxidants in the food industry. Handbook of Marine Macroalgae: Biotechnology and Applied Phycology. pp. 398-402.

Xu, J. \& Gao, K. 2010. Use of UV-A Energy for Photosynthesis in the Red Macroalga Gracilaria lemaneiformis. Photochemistry and Photobiology, 2010, 86: 580-585.

Yangthong, M.; Hutadilok-Towatana, N.; Phromkunthong, W. 2009. Antioxidant activities of four edible seaweeds from the Southern Coast of Thailand. Plant Foods Hum Nutr. DOI 10.1007/s11130-009-0127-y. pp.6.

Yoon, N. Y.; Lee,S-H.; Wijesekara, I.; Kim, S-K. 2011. In vitro and intracellular antioxidant activities of brown alga Eisenia bicyclis. Fish Aquat Sci 14(3), 179-185, 2011.

Zar, J.H. 1999. Biostatistical analysis. Prentice Hall, Englewood Cliffs, New Jersey. 471p.

Zubia, M.; Robledo, D.; Freile-Pelegrin, Y. 2007. Antioxidant activities in tropical marine macroalgae from the Yucatan Peninsula, México. Journal of Applied Phycology 19: 449-458. 


\title{
CAPÍTULO III
}

\section{Espécies reativas de oxigênio (ROS) e óxido nítrico (NO) em Gracilariopsis tenuifrons (Gracilariales, Rhodophyta) sob estímulo de irradiância em laboratório}

\begin{abstract}
Resumo
Durante a fotossíntese a excitação das moléculas pela luz promove a produção de átomos que formam radicais livres (ROS e RNS). Embora elas sejam sintetizadas naturalmente, sua formação é intensificada sob estresse. O papel fisiológico das ROS e sua interação com o NO é pouco conhecido em macroalgas marinhas. O NO ainda é bem pouco entendido em relação à fotossíntese. O objetivo deste trabalho é avaliar a produção de ROS e NO na macroalga vermelha Gracilariopsis tenuifrons submetida a dois regimes de irradiância $\left(60 \mu \mathrm{mol}\right.$ fótons. $\mathrm{m}^{-2} . \mathrm{s}^{-1}$ e $600 \mu \mathrm{mol}$ fótons. $\left.\mathrm{m}^{-2} . \mathrm{s}^{-1}\right)$ durante uma semana e coletadas durante o dia e a noite. Os valores de ROS foram equivalentes entre os tratamentos, enquanto o teor de NO demonstrou aumento significativo em ápices expostos a elevada PAR. Portanto, a condição de elevada irradiância levou $G p$. tenuifrons ao estresse oxidativo. E como resposta a alga produziu NO, que pode ter atuado como sinalizador de mecanismos de defesa e antioxidante.
\end{abstract}

\begin{abstract}
During photosynthesis, the excited molecules by light promotes the generation of free radicals (ROS and RNS). Although these radicals are naturally synthesized, the production of ROS and RNS is intensifying under stress conditions. The physiological role of ROS and the interaction with NO is unknown in marine seaweed. Nitric oxide is still unexplored and understood related to photosynthesis. The objective of this work is to evaluate the production of ROS and NO of Gracilariopsis tenuifrons under $60 \mu \mathrm{mol}$ fótons. $\mathrm{m}^{-2} \cdot \mathrm{s}^{-1}$ and $600 \mu \mathrm{mol}$ fótons. $\mathrm{m}^{-2} \cdot \mathrm{s}^{-1}$ for one week and during day and night periods. Values of ROS were equivalent between the treatments, while NO increased significantly under elevated PAR. Therefore, under stress condition of elevated irradiance Gp. tenuifrons produced NO as response to oxidative stress condition, should this molecule to act as signaling of defense mechanisms.
\end{abstract}




\section{Introdução}

A luz visível, compreendida entre $400 \mathrm{~nm}$ e $700 \mathrm{~nm}$, também chamada de PAR (radiação fotossinteticamente ativa), é indispensável para a fotossíntese. Sendo assim, durante a fotossíntese a ativação das moléculas pigmentares das plantas pela energia promove a produção de átomos que formam radicais livres.

Eletronicamente, um radical livre pode ser definido como qualquer espécie que tem um ou mais elétrons não pareados. Essa definição inclui principalmente o átomo do hidrogênio (com um elétron não pareado), a maioria dos metais de transição e as moléculas de oxigênio sozinhas. $\mathrm{O}_{2}$ tem dois elétrons não pareados, cada um localizado em um orbital diferente. Estes dois elétrons apresentam mesmo número de spin, que conferem efeito de radicais livres, pois quando estes átomos encontram outros átomos conseguem oxidá-lo aceitando um par de elétrons (Halliwell \& Guteridge, 1984; Khan \& Wilson, 1995; Blokhina et al., 2003). Deste modo são radicais altamente reativos e instáveis, existindo por alguns nano ou micro segundos, antes de disparar cadeias de reação que causarão reatividade em cascata provocando danos em componentes da célula (Monaghan et al., 2009), podendo causar alterações genéticas e finalmente a morte.

Embora os radicais livres desencadeiem reações danosas, as espécies reativas de oxigênio (ROS) são produzidas e acumuladas em condições de homeostase e estresse (Dummermuth et al., 2003), e atuam como mensageiros e sinalizadores de respostas fisiológicas do metabolismo (Hayat et al., 2010; Mittler et al., 2011; Hsu \& Lee, 2012). As ROS podem potencialmente reagir com todas as biomoléculas, como pigmentos, proteínas, lipídios e DNA e quase qualquer componente da célula. Desde que uma planta não possa consumir as ROS, sua produção excessiva causará a morte celular (Karuppanapadian et al., 2011).

Em homeostase, sob aclimatação ou estresse, as ROS são consumidas por vários sistemas de defesa antioxidante. A modulação entre a produção e o consumo das ROS confere a estes radicais uma dualidade de funções conduzida por uma grande rede de genes (Karuppanapadian et al., 2011). Em contrapartida, quando a produção das ROS ocorre limitada a regiões particulares da célula, como parte de algumas membranas ou uma organela, o controle e acúmulo dessas substâncias são altamente específicos (Mittler et al., 2011).

A produção e acúmulo das ROS tende a aumentar sob elevada PAR e UVR, promovendo alterações na cadeia de transporte de elétrons, devido às reações de 
transferência de energia do $\mathrm{O}_{2}$. A partir de reações exotérmicas, a radiação atua elevando os níveis de moléculas excitadas afetando a fotossíntese e provocando a produção de radicais livres (Aguilera et al., 2002; Carvalho et al., 2004; Karuppanapadian et al., 2011). Por isso, cloroplastos estão sujeitos a exibir aumento constante e exacerbado de ROS, produzidas pelo excesso de energia luminosa adicionada à clorofila e ao oxigênio molecular (Halliwell \& Gutteridge, 1984; Mallick et al., 2002). Assim, sob alta luminosidade os componentes da cadeia de transporte de elétrons tendem a ser relativamente reduzidos. Contudo, os efeitos danosos das ROS são consideravelmente variáveis de acordo com o tipo de organismo, a idade e o estado metabólico (Halliwell \& Guteridge, 1984).

Por outro lado, as espécies reativas de nitrogênio (RNS) embora possam causar os mesmos efeitos das ROS, são menos conhecidas (Monaghan et al., 2009). As ROS são representadas principalmente pelo radical superóxido $\left(\mathrm{O}_{2}{ }^{*}\right)$, peróxido de hidrogênio $\left(\mathrm{H}_{2} \mathrm{O}_{2}\right)$, oxigênio singlete $\left({ }^{1} \mathrm{O}_{2}\right)$, radical hidroxil $\left(\mathrm{OH}^{*}\right)$, radical hidroperoxil $\left(\mathrm{HO}_{2}\right.$. radical peroxil (ROO.), carbonil (CO*). As RNS estão representadas pelos radicais NO*, $\mathrm{NO}^{+}$e $\mathrm{NO}^{-}$, peroxinitrito $\left(\mathrm{ONOO}^{-}\right)$, dióxido de nitrogênio $\left(\mathrm{N}_{2} \mathrm{O}\right)$ e dinitrogênio trioxido $\left(\mathrm{N}_{2} \mathrm{O}_{3}\right)$. Essas espécies reativas tendem a ocorrer a partir de alterações ambientais bruscas (Neill, et al., 2002; Dummermuth et al., 2003; Scandalios, 2005; KriegerLiszkay et al., 2008; Vass, 2011), patógenos e alterações de estresse em decorrência de ações antrópicas (Collén et al., 2006).

Assim como as ROS, o óxido nítrico (NO), que faz parte das RNS, também é produzido naturalmente pelas células e age como sinalizador associado a diversos processos bioquímicos e fisiológicos, como regulador do crescimento (He et al., 2004; Hayat et al., 2010), respostas de defesa (Zeidler et al., 2004; Hayat et al., 2010), apoptose (Shi et al., 2005) e resposta imune (Delledone et al., 2001; Mackerness et al., 2001). Além disso, sua produção é induzida por estímulos abióticos como estresse hídrico (Sang et al., 2008), osmótico (He et al., 2004) e luminoso (He et al., 2004; Hsu \& Lee, 2010), além de metais pesados (Xu et al., 2010). O NO pode agir como modulador do potencial tóxico das ROS, transformando e neutralizando as ROS e estimulando o surgimento de novos compostos menos reativos, deste modo reduz o estresse e age como molécula antioxidante (Mallick et al., 1999; Delledone et al., 2001; Hua et al., 2003; Shi et al., 2005; De Michele et al., 2009; Xu \& Wang et al., 2010; Hsu \& Lee, 2012). 
O papel fisiológico das ROS e sua interação com o NO é pouco conhecida em macroalgas marinhas. Sendo o NO ainda bem pouco entendido em relação à fotossíntese (Wodala, 2006) e efeitos da PAR. A atuação do NO tem sido estudada em algas pardas: Laminaria digitata em reação a um patógeno (Küpper et al., 2006) enfatizando a produção de lipopolissacarídeos e ácidos graxos em cascata; em algas verdes: Dasycladus vermicularis em resposta a ROS (Ross et al., 2006) causadas por dano mecânico, D. vermicularis e Acetabularia acetabulum respondendo a dano mecânico e adição de ATP (Torres et al., 2008), Ulva fasciata ante estímulos luminosos (Hsu \& Lee, 2012) e Ulva compressa exposta ao cobre em excesso (González et al., 2012); e em algas vermelhas: Gracilaria chilensis respondendo a doadores e sequestradores de NO (Chow et al., 2013).

Portanto, para compreender a produção de ROS e o NO ante estímulos luminosos elegeu-se a macroalga vermelha Gracilariopsis tenuifrons, alga nativa, amplamente distribuída no Brasil desde o estado de Alagoas até São Paulo (Bird \& Oliveira, 1986; Plastino, 1991), com potencial para produção em larga escala (Oliveira, 1998) e fonte de ágar de qualidade (Brito 1999; Brito \& Silva, 2005), buscou-se quantificar as ROS e o NO de ápices submetidos a dois regimes de irradiância, $60 \mu \mathrm{mol}$ de fótons. $\mathrm{m}^{-2} . \mathrm{s}^{-1}$ e $600 \mu \mathrm{mol}$ de fótons. $\mathrm{m}^{-2} . \mathrm{s}^{-1}$, e coletados em um único período do ciclo diário: DIA.

\section{Material e métodos}

Estimou-se a quantidade de ROS e NO a partir de amostras de 0,5 $\mathrm{cm}$ de ápices de Gracilariopsis tenuifrons submetidos às condições de $60 \pm 5 \mu \mathrm{mol}$ de fótons. $\mathrm{m}^{-2} . \mathrm{s}^{-1}$ (controle) e $600 \pm 10 \mu \mathrm{mol}$ de fótons. $\mathrm{m}^{-2} \cdot \mathrm{s}^{-1}$ (tratamento). Os ápices foram cortados a 0,5 cm e supridos com meio VS 50\%, $24 \mathrm{~h}$ antes dos testes para evitar o estresse mecânico gerado pelo corte e limitação de nutrientes que poderiam interferir na interpretação dos resultados. As amostras foram coletadas apenas durante o período diurno. As análises foram executadas no Laboratório de Biologia Celular de Plantas (BioCEL) do Instituto de Biociências da USP, em colaboração com a Profa. Dra. Eny Floh.

\subsection{Espécies reativas de oxigênio (ROS)}

A quantificação desses radicais foi baseada em Laxalt et al. (2007), metodologia usada no BioCEL. O reagente usado para mensuração das ROS foi $\mathrm{H}_{2}$ DCF-DA (2', 7' - 
diclorodihidrofluoresceína diacetato). $\mathrm{O} \quad \mathrm{H}_{2}$ DCF-DA é permeável à membrana plasmática, uma fluoresceína reduzida quimicamente e indicadora de ROS. Portanto, as análises foram realizadas in vivo.

A produção das ROS foi estimada adicionando-se $0,5 \mu \mathrm{L}$ do fluorocromo $\mathrm{H}_{2}$ DCF-DA $(25 \mu \mathrm{M})$ a 99,5 $\mu \mathrm{L}$ de água do mar filtrada e esterilizada e imergindo nessa solução um ápice de $0,5 \mathrm{~cm}$ de $G p$. tenuifrons submetido ao respectivo regime de irradiância. As mensurações para cada condição foram realizadas em 5 réplicas.

Como controles, foram feitas amostras de água do mar sem fluoróforo e sem alga, água do mar com fluoróforo e sem alga e água do mar sem fluoróforo e com a alga. A montagem das amostras foi realizada em penumbra em virtude da sensibilidade do fluorocromo à luz e em microplaca branca com 96 poços de fundo plano. As leituras foram efetuadas após 30 min de incubação em penumbra usando o Fluorômetro Victor ${ }^{3}$ Perkin Elmer (EUA) em excitação de 502 nm e emissão de $523 \mathrm{~nm}$ durante $1 \mathrm{~h}$ em intervalos de $15 \mathrm{~min}$.

\section{2. Óxido nítrico (NO)}

Para a mensuração do NO foi usado o fluoróforo DAF-FM-DA (4-amino-5metilamino-2',7'-difluorofluoresceina diacetato), substância não fluorescente até reagir com o NO. Este fluoróforo permeia células passivamente através das membranas para detectar NO, portanto, as análises foram realizadas in vivo.

O protocolo foi baseado em Kupper et al. (2006), Torres et al. (2008) e Tossi et al. (2011) com modificações. O NO foi estimado imergindo ápices de 0,5 cm de $G p$. tenuifrons em $1 \mu \mathrm{L}$ do fluorocromo DAF-FM-DA $(20 \mu \mathrm{M})$ adicionado a $99 \mu \mathrm{L}$ de água do mar filtrada e esterilizada.

As amostras foram montadas em microplaca branca com 96 poços de fundo plano. Essa montagem ocorreu em penumbra devido à suscetibilidade do fluorocromo à luz. Como controles, foram feitas amostras com água do mar sem fluoróforo e sem alga, água do mar com fluoróforo e sem alga e água do mar sem fluoróforo e com a alga. Foram feitas sucessivas leituras após 30 min de incubação em Fluorômetro Victor ${ }^{3}$ Perkin Elmer (EUA) em excitação de 492 nm e 520 nm de emissão durante 1 h com alternância de 15 min. 


\subsection{Análise estatística}

Tanto para a análise de ROS quanto de NO foram realizadas 5 replicagens para cada tratamento e brancos ou controles. Os resultados foram avaliados com teste $\mathrm{t}$ de Student e antes da execução de cada análise foi avaliada a distribuição normal dos dados gerados. As análises estatísticas foram avaliadas com o programa STATISTICA v. 6.0, com confiança de 95\% ( $\mathrm{p}<0,05$ ), segundo descrições de Zar (1999).

\section{Resultados}

Os resultados de ROS e NO foram expressos em unidade de fluorescência relativa (ufr). A ufr representa valores fornecidos diretamente do fluorômetro, apenas com padronização realizada a partir de brancos.

\subsection{Espécies reativas de oxigênio (ROS)}

Os resultados de determinação das ROS não exibiram variação significativa entre os tratamentos $(\mathrm{p}=0,09)$. O teor de ROS em Gp. tenuifrons foi de $16.676 \pm 4.909$ ufr para $60 \mu \mathrm{mol}$ de fótons. $\mathrm{m}^{-2} . \mathrm{s}^{-1}$ e de $22.674 \pm 9.623$ ufr para $600 \mu \mathrm{mol}$ de fótons. $\mathrm{m}^{-}$ ${ }^{2} \cdot \mathrm{s}^{-1}$ (Figura 12)

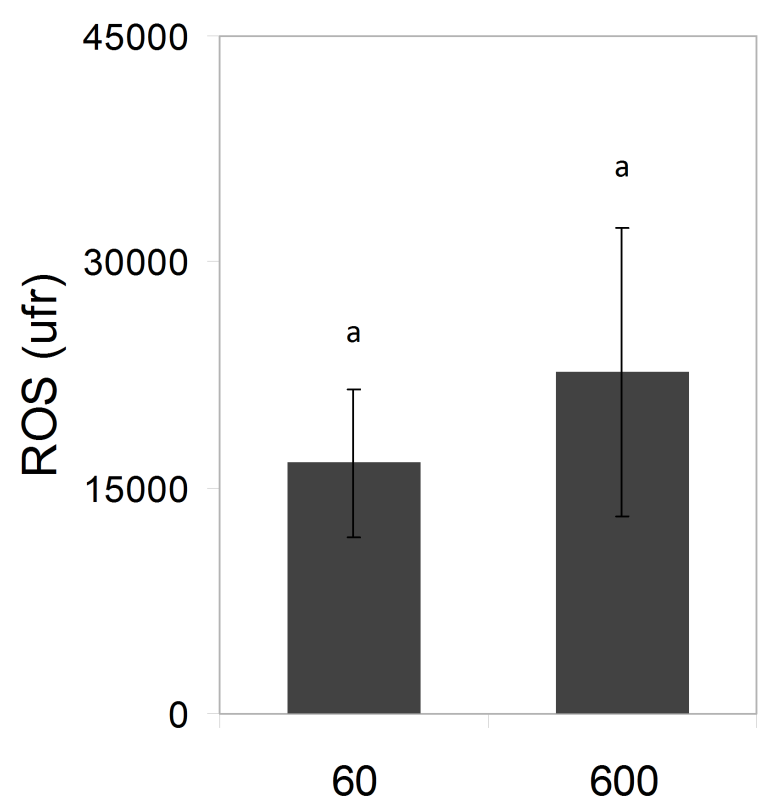

Figura 12: Fluorescência relativa de espécies reativas de oxigênio (ROS) de amostras de Gracilariopsis tenuifrons após uma semana sob $60 \mu \mathrm{mol}$ de fótons. $\mathrm{m}^{-2} . \mathrm{s}^{-1}$ e 600 $\mu$ mol de fótons. $\mathrm{m}^{-2} \cdot \mathrm{s}^{-1}(\mathrm{n}=5)$. Letras distintas representam diferenças significativas $(\mathrm{p}<$ 0,05). ufr: unidade de fluorescência relativa. 


\section{2. Óxido Nítrico (NO)}

Ao quantificar o NO detectou-se diferença significativa entre os tratamentos $(\mathrm{p}=$ $0,0008)$ tendo as algas submetidas a $60 \mu \mathrm{mol}$ de fótons. $\mathrm{m}^{-2} \cdot \mathrm{s}^{-1}$ apresentado $63 \%$ menos NO do que ápices submetidos a $600 \mu \mathrm{mol}$ de fótons. $\mathrm{m}^{-2} \cdot \mathrm{s}^{-1}$. O conteúdo de NO em $G p$. tenuifrons foi de $28.338 \pm 4.168$ ufr para $60 \mu \mathrm{mol}$ de fótons. $\mathrm{m}^{-2} \cdot \mathrm{s}^{-1}$ e de $44.574 \pm 5.642$ ufr para $600 \mu \mathrm{mol}$ de fótons. $\mathrm{m}^{-2} \cdot \mathrm{s}^{-1}$ (Figura 13).

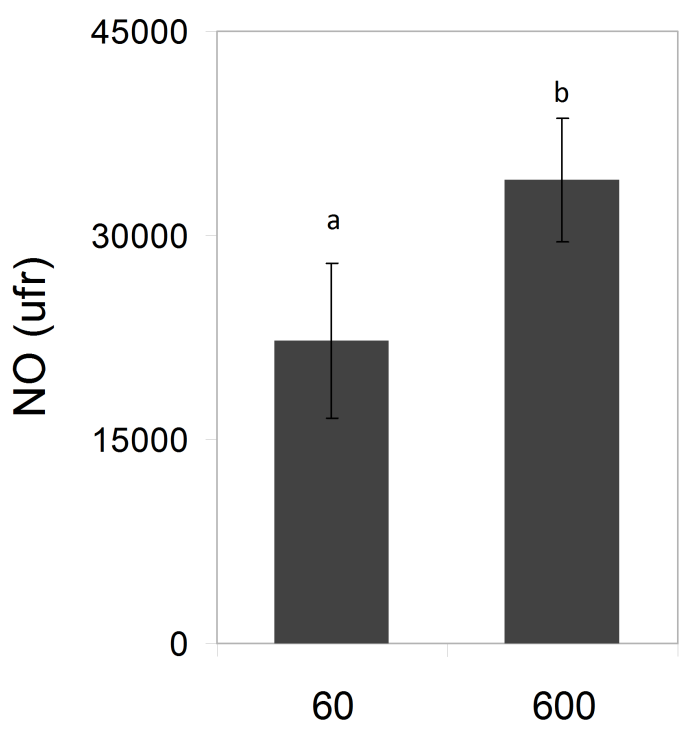

Figura 13: Fluorescência relativa de oxido nítrico (NO) de amostras de Gracilariopsis tenuifrons após uma semana sob $60 \mu \mathrm{mol}$ de fótons. $\mathrm{m}^{-2} . \mathrm{s}^{-1}$ e $600 \mu \mathrm{mol}$ de fótons. $\mathrm{m}^{-2} . \mathrm{s}^{-1}$ $(n=5)$. Letras distintas representam diferenças significativas $(p<0,05)$. ufr: unidade de fluorescência relativa.

\section{Discussão}

\subsection{Espécies reativas de oxigênio (ROS)}

As ROS são compostos com característica de alta reatividade e podem causar danos permanentes, por redução, na maior parte das biomoléculas (Mallick et al., 2002). Entretanto, em ambos os tratamentos, o nível de ROS foi similar nos ápices de $G p$. tenuifrons. Assim, não houve diferença significativa entre os tratamentos de $60 \mu$ mol de fótons. $\mathrm{m}^{-2} \cdot \mathrm{s}^{-1}$ e $600 \mu \mathrm{mol}$ de fótons. $\mathrm{m}^{-2} \cdot \mathrm{s}^{-1}$. Contudo, foi possível perceber que a quantidade de ROS no tratamento de elevada irradiância tende a ser maior.

Avaliando e comparando os resultados deste estudo de teor de pigmentos, atividade antioxidante total, substâncias fenólicas e quantidade de NO de ápices de $G p$. tenuifrons submetidos a elevada luminosidade, todos indicam situação de estresse oxidativo e ativação de mecanismos de proteção. No entanto, esse padrão não foi 
observado para as ROS. Entretanto, a semelhança do teor de ROS entre os tratamentos pode ser justificada pelas estratégias da alga para mitigar o estresse, dentre elas a eficiência dos sistemas de defesa antioxidante de Gp. tenuifrons, que sob alta PAR supostamente agiram de forma a minimizar a quantidade e os efeitos das ROS. Também é provável que o NO tenha agido como antioxidante, bem como sinalizador de reações para aumentar o consumo e de mitigar o efeito das ROS.

É bem conhecido que a exposição a elevada UVR e PAR induz a geração de radicais livres (Steinhoff et al., 2012) e outros oxidantes a partir de múltiplas fontes (Mackerness et al., 2001), especialmente nos cloroplastos, resultando em estresse oxidativo (Mano, 2002), causado pela geração das ROS. Em Gp. tenuifrons a alta PAR provocou redução de pigmentos fotossintetizantes como a clorofila e a deterioração de regiões dos ápices. Assim, Beligni \& Lamatina (1999) dizem que existe uma delicada dinâmica de equilíbrio entre a formação e redução das ROS, e esta dinâmica pode ser alterada a partir da superprodução de ROS causada por estresses, e resultando em fotooxidação da clorofila, destruição de cloroplastos e morte abrupta de células. Corroborando, Mallick et al. (2002), após simular condição de estresse submetendo células de Scenedesmus obliquus (microalga verde) a $\mathrm{H}_{2} \mathrm{O}_{2}$, relataram diminuição da quantidade de clorofila.

A ação das ROS depende da concentração: a) em baixas concentrações, esses oxidantes induzem genes de defesa e respostas de aclimatação, enquanto b) em altas concentrações promove a morte celular (Mallick et al., 2002; Neil et al., 2002). Ademais, concentrações quase letais de ROS promovem a aclimatação à condição de estresse, reduzindo o crescimento do organismo como parte do mecanismo de aclimatação (Karuppanapadian et al., 2011). Neste contexto, Mackerness et al. (2001) afirmam que as ROS, agem como moléculas sinalizadoras em plantas, sendo componentes centrais da resposta contra o estresse e regulam a expressão de genes em resposta a radiação UVB.

Outros parâmetros que permitem crer que sob intensa irradiância houve maior produção das ROS em Gp. tenuifrons foi a elevada atividade antioxidante e os altos níveis de NO. A alta atividade antioxidante obtida pelo teste de consumo do DPPH indica que os talos de Gp. tenuifrons foram estimulados a produzir maior quantidade de substâncias neutralizadoras das ROS. Enquanto os elevados níveis de NO, composto que atua também como antioxidante (Hua et al., 2003; Quian et al., 2009) e como modulador da atividade antioxidante (Shi et al., 2005; Quian et al., 2009; Xu \& Wang et 
al., 2010; Wimalasekera et al., 2011), costumam ser disparados por agentes estressores, que também elevam a produção de ROS (Neill et al., 2002; 2003; Dummermuth et al., 2003; Bhandari \& Sharma et al., 2006; Ross et al., 2006; Torres et al., 2008; Foyer et al., 2010; Nishiyama et al., 2011).

Assim a equivalência da quantidade de ROS nos dois tratamentos, permite supor que Gp.tenuifrons exposta a alta PAR produz e acumula substâncias capazes de mitigar o efeito das ROS, evidenciada na equivalência desses compostos em ambos os tratamentos de irradiância. Portanto, mesmo sob alta PAR, provavelmente a atividade antioxidante de $G p$. tenuifrons foi eficiente contra o estresse oxidativo gerado a partir do excesso de irradiância.

\section{2. Óxido Nítrico (NO)}

O NO interage com as ROS de várias maneiras. Além disso, atua como modulador da formação de enzimas e substâncias antioxidantes e age como antioxidante, inibindo a peroxidação lipídica, mantendo a homeostase da célula e regulando a toxicidade das ROS (Boveris et al., 2000).

Neste ínterim, os ápices de Gp. tenuifrons submetidos a altos níveis de PAR apresentaram maior quantidade de NO do que os ápices expostos à menor irradiância. Possivelmente, a intensa irradiância causou estresse oxidativo e estimulou a síntese de NO, evidenciando que a irradiância causa desequilíbrio sinalizado pelas ROS e então são disparadas reações para amenizar os efeitos danosos provocados pelo estresse.

Deste modo, relacionando os resultados de NO aos resultados das análises de pigmentos e proteínas solúveis, CHN, substâncias fenólicas, atividade antioxidante, ROS e NO dos ápices de Gp. tenuifrons expostos a 60 e $600 \mu \mathrm{mol}$ de fótons. $\mathrm{m}^{-2} \cdot \mathrm{s}^{-1}$, e aliando-os a informações bibliográficas, propôs-se um modelo esquemático do metabolismo do NO. Nesse modelo (Figura 14) encontra-se representado o suposto processo de formação do NO relacionado à irradiância numa célula em homeostase, em que o processo ocorre quase simultaneamente. Contudo, presume-se que expondo a célula a súbito estresse luminoso, como ocorreu no tratamento de $600 \mu \mathrm{mol}$ de fótons.m ${ }^{-}$ ${ }^{2} \cdot \mathrm{s}^{-1}$, a velocidade do processo é intensificada assim como as respostas de aclimatação e tolerância, que conduzirão à recuperação ou a morte de células e posteriormente do organismo.

Então, supõe-se que nos ápices de Gp. tenuifrons expostos a alta PAR, a luminosidade estimulou a cadeia transportadora de elétrons, provocando a dissociação 
de pigmentos fotossintetizantes e proteínas e, causando aumento da produção de ROS, de carotenoides e polissacarídeos (Passo 1, Figura 14). Neste contexto, Talarico \& Maranzana (2000) afirmam que sob irradiância em excesso pigmentos sofrem dissociação. Ademais, sob alta irradiância o NO influencia diretamente a cadeia de transporte de elétrons, principalmente no PSII (Wodala et al., 2006). Ainda, atua inibindo, geralmente de forma reversível, a fosforilação nas membranas do tilacoide, causando fotoinibição, fotooxidações da clorofila (Mallick et al., 2002), de ficobiliproteínas e de proteínas, resultando em inibição da fotossíntese (Mallick et al., 2002; Takahashi \& Yamasaki, 2002; Bouchard et al., 2008; Wodala et al., 2006 ) e, consequentemente, há diminuição na taxa de síntese de ATP (Takahashi \& Yamasaki, 2002). Em corroboração, Bruggink et al. (1988) estudando Lycopersicon lycopersicum (tomate) e Abat et al. (2008) investigando Kalanchoe pinnata (planta medicinal) mencionaram que durante a exposição ao NO a fotossíntese foi inicialmente inibida e reestabilizada algum tempo após a submissão. Isso permitiu à planta um intervalo de aclimatação à nova condição. Por sua vez, Shi et al. (2005) estudando sementes de feijão sujeitadas a forte radiação UVB, perceberam que o NO atenuou o efeito da radiação através da diminuição do conteúdo de clorofila e em consequência mitigou o dano oxidativo na membrana do tilacoide. Do mesmo modo, Xu et al. (2010) analisando a produção de NO e ROS de folhas da gramínea Festuca arundinaceae estimuladas por luz e Hsu \& Lee (2012) avaliando as respostas da alga verde Ulva fasciata a estímulos luminosos (300 e $1200 \mu \mathrm{mol}$ de fótons. $\mathrm{m}^{-2} . \mathrm{s}^{-1}$ ) perceberam que o NO reduziu o dano oxidativo, pois atuou regulando a tolerância ao estresse luminoso, tendo sido um fator de proteção e recuperação do estresse. Além disso, Torres (2012) fazendo análises diárias de Gp. tenuifrons sob elevada PAR por uma semana, observou que a quantidade de carotenoides exibiu incremento nos quatro primeiros dias de teste e Coueé et al. (2006) relataram que os mecanismos de defesa antioxidante por açúcares estão relacionados a flutuações de intensidade de luz, que estimulam o acúmulo de açúcares pela fotossíntese.

Em Gp. tenuifrons presume-se ainda que após dissociados os pigmentos foram quebrados, originando proteínas e compostos nitrogenados (Passo 2, Figura 14). Neste contexto, Stieger \& Fuller (1997) investigando o efeito da luz em uma espécie de ervilha (Pisum sativum), observaram que a irradiância causou a degradação de uma série de proteínas. Já Shi et al. (2005) observaram que a irradiação UVB, que provoca efeitos semelhantes ao da alta PAR (Hanelt \& Roleda, 2009; Raven, 2011), promoveu a 
intensificação das ROS. Esses oxidantes conduziram a oxidação de grupos tiol (que compõem o aminoácido cisteína) resultando em decréscimo nas proteínas, posteriormente mitigado em presença de NO.

Deste modo, possivelmente parte desses compostos provenientes da quebra dos pigmentos de $G p$. tenuifrons foram direcionados para suprir despesas energéticas imediatas do talo (Passo 3, Figura 14) e para substâncias com capacidade antioxidante como os aminoácidos tipo micosporinas (MAAs; Passo 4, Figura 14). Outra parte dos compostos nitrogenados e aminados provavelmente sofreu oxidação e resultaram em substâncias como nitrito, nitrato e aminoácidos (como poliaminas, L-arginina e Lcitrulina) (Passo 5, Figura 14). Assim, as ficobiliproteínas podem seguir a mesma rota que a bilirrubina, um composto animal com características semelhantes às ficobiliproteínas (O’Carra \& Colleran, 1970; Schluchter \& Glazer, 1999). Então, sob ação de radicais peroxil (ROO), a bilirrubina $\left(\mathrm{C}_{33} \mathrm{H}_{36} \mathrm{O}_{6} \mathrm{~N}_{4}\right)$ doa um hidrogênio e forma um composto $\mathrm{N}^{*}$ (Foti \& Amorati, 2010) que pode ser oxidado novamente para originar compostos nitrogenados inorgânicos $\left(\mathrm{NO}_{3}{ }^{-}, \mathrm{NO}_{2}{ }^{-}, \mathrm{NH}_{4}{ }^{+}\right)$. Corroborando, Barufi et al. (2012) ao estudar Gracilaria tenuistipitata observaram que sob UVR, os pigmentos desta alga foram quebrados, deixando disponíveis compostos nitrogenados para a formação de substâncias antioxidantes, como os MAAs.

Supõe-se que os compostos nitrogenados (nitrito, nitrato, poliaminas, L-arginina e L-citrulina) nos ápices de Gp. tenuifrons sofreram a ação de enzimas como nitrato redutase (NR) e óxido nítrico sintase (NOS) e formaram NO (Passo 6, Figura 14). Dependendo das condições celulares, $\mathrm{o} \mathrm{NO}_{3}{ }^{-}$e o $\mathrm{NO}_{2}{ }^{-}$podem facilmente ser convertidos em NO (Bouchard et al., 2008). Adicionalmente, é de importante consideração as observações de alguns autores (Takahashi \& Yamasaki, 2002; Cohen \& Yamasaki, 2003; Morris, 2004; Bouchard et al., 2008) que registraram que o NO é produzido pela NOS a partir da oxidação dos aminoácidos L-arginina e L-citrulina e de poliaminas (Tun et al., 2006; Wimalasekera et al., 2011). Ademais, Tian et al. (2007) estudando o efeito do estresse por alumínio $\left(\mathrm{Al}^{+3}\right)$ e do $\mathrm{NO}$ no crescimento de raízes de Hibiscus moscheutos e Wanderley (2009) que estudou a influência da disponibilidade de nitrato sobre crescimento, atividade da NR, composição química e captação de nitrato e fosfato em Gp. tenuifrons afirmaram que a NR é uma enzima chave para assimilação de nitrato em plantas e algas, respectivamente, e que essa enzima usa o $\mathrm{NAD}(\mathrm{P}) \mathrm{H}$ como fonte de elétrons para a conversão de nitrato em nitrito, que são capazes de gerar NO tanto in vitro quanto in vivo. 


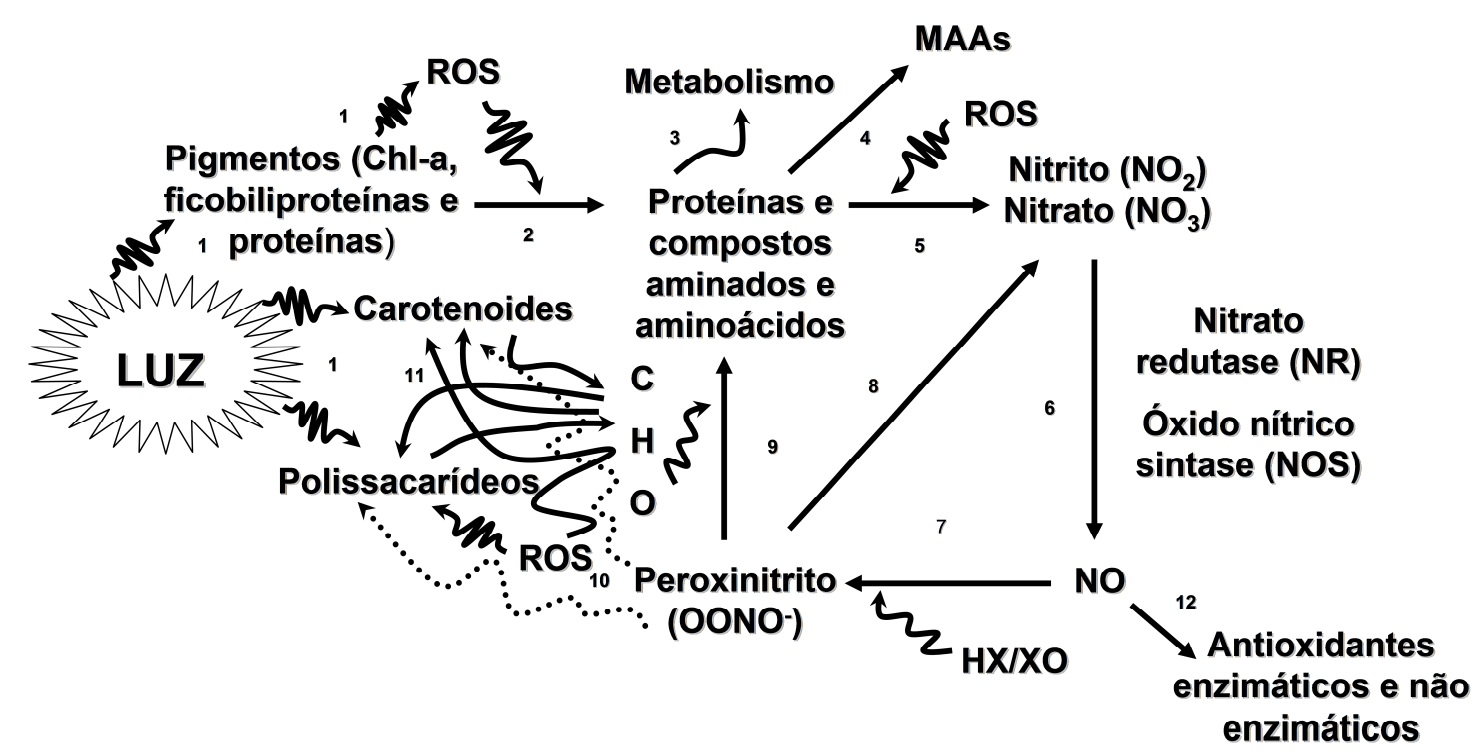

Figura 14: Representação esquemática de modelo proposto para ilustrar o efeito da alta luminosade no metabolismo de Gracilariopsis tenuifrons e sua relação com o aumento de NO. (1) o excesso de energia, produto do estímulo da luz na cadeia de transporte de elétrons, dissocia pigmentos, proteínas e estimula a produção de ROS, polissacarídeos e carotenoides. (2) As ROS iniciam o processo de oxidação de biomoléculas. (3) A oxidação causada pelas ROS age convertendo compostos nitrogenados em substâncias nitrogenadas menos complexas. Parte dos compostos provenientes da conversão é empregada no metabolismo. (4) Parte dos compostos obtidos no passo 3 são direcionados para a produção de MAAs. (5) Outra parte dos compostos sofre novas oxidações das ROS e são convertidos em nitrato, nitrito, poliaminas, L-arginina e Lcitrulina. (6) As enzimas NR e NOS atuam no $\mathrm{NO}_{2}{ }^{-}$e $\mathrm{NO}_{3}{ }^{-}$dissociando-os para formar NO. (7) As ROS reagem com o NO para formar o peroxinitrito. (8) $\mathrm{O}$ peroxinitrito em pH fisiológico pode ser diretamente convertido a nitrato. (9) O peroxinitrito é reduzido por átomos de carbono, nitrogênio e hidrogênio, que em parte são translocados para a manutenção do metabolismo, MAAs e $\mathrm{NO}_{2}{ }^{-}$e $\mathrm{NO}_{3}{ }^{-}$. (10 e 11) Polissacarídeos e carotenoides são oxidados pelo peroxinitrito e são recompostos pela doação de átomos de carbono, hidrogênio e oxigênio. (12) $\mathrm{O}$ aumento das ROS acelera o ciclo e, portanto, os níveis de NO se elevam, conduzindo a maior ativação da atividade antioxidante.

Sendo assim, em Gp. tenuifrons, possivelmente o NO pôde interagir com as ROS e formar peroxinitrito (OONO; Passo 7, Figura 14). Essa reação ocorre para amenizar os efeitos do estresse oxidativo, porque embora o peroxinitrito seja um composto de alta reatividade, as ROS são ainda mais reativas (Wink et al., 1993; Hsu \& Lee, 2012).

Além de reagir com o NO, supostamente o peroxinitrito em $G p$. tenuifrons pode ter sido modificado de diversas formas: (1) convertido a nitrato em $\mathrm{pH}$ fisiológico (Passo 8, Figura 14), (2) reduzido por átomos de carbono, hidrogênio e oxigênio (este em abundância devido às ROS) (Passo 9, Figura 14) e (3) ter oxidado polissacarídeos e carotenoides (setas pontilhadas, Passo 10, Figura 14), que também podem ter sido 
oxidados pela ação das ROS, promovendo a doação de átomos de carbono e hidrogênio (Passo 11. Figura 14). Deste modo, o $\mathrm{pH}$ do meio pode interferir diretamente na produção de NO, causando a redução de peroxinitrito (Wink et al., 1993) em nitrato ou indiretamente na redução de compostos nitrogenados inorgânicos em presença de substâncias antioxidantes, como o ácido ascórbico (Crawford, 2006; Popova \& Tuan, 2010).

A doação de átomos de carbono e hidrogênio em Gp. tenuifrons supostamente promoveu a manutenção de proteínas, compostos aminados (Passo 3, Figura 14), carotenoides e açúcares (Passo 11. Figura 14). Substâncias importantes para a mitigação do estresse oxidativo, pois também atuam como reservas energéticas. Cohen \& Yamasaki (2003) notaram que tanto o NO quanto a NOS estão envolvidos com o aumento de sacarose e a tolerância ao $\mathrm{H}_{2} \mathrm{O}_{2}$. Qu et al. (2006) investigando o efeito da radiação UVB e do NO no crescimento do caule de Pisum sativum, detectaram que a radiação UVB causou a degradação de xiloglicanos, componente chave da matriz de polissacarídeos na parede de dicotiledônias. Entretanto, em raízes de vegetais vasculares, o NO inibiu fortemente a atividade de degradação dos xiloglicanos da parede celular (Beligni \& Lamatina, 2000). Açúcares que causam espessamento na parede das células corticais podem atuar na atenuação física da irradiância em excesso em algas vermelhas, pois há aumento na reflexão de ondas curtas (Raven, 2011). Adicionalmente, Chen \& Yan (2005) estudando a atividade antioxidante de polissacarídeos de algas, demonstraram que estes compostos conferem bom potencial de proteção para as células, pois promoveram a diminuição de peróxido de hidrogênio. Além disso, essas substâncias apresentaram facilidade em difundir através de membranas. Assim, a adição de agaro-polissacarídeos em células vivas conduziu a elevação do crescimento e sobrevivência dessas mesmas células.

Ademais, presume-se que em Gp. tenuifrons, a dissociação/seção dos pigmentos e a ação das ROS sinaliza rápida elevação dos níveis de NO, que além de atuar como antioxidante, dispara respostas antioxidantes, desencadeando a elevação de enzimas antioxidantes como a ascorbato peroxidase (APX) e a produção de antioxidantes como os compostos fenólicos (Passo 12, Figura 14). A habilidade do NO em exercer função de proteção contra o estresse oxidativo se deve a fatores como: (1) reação com radicais lipídicos em que causa a mitigação da oxidação lipídica (Wimalasekera et al., 2011); (2) consumo do ânion superóxido; (3) ativação de enzimas antioxidantes (Beligni \& Lamatina, 1999; Quian et al., 2009) e substâncias antioxidantes (Blokina \& Fargerstedt, 
2010; Xu \& Wang et al, 2010). Assim, o NO age como mensageiro secundário em plantas, em resposta a estresses bióticos e abióticos e encontra-se envolvido em diversos processos, sendo uma das mais intrigantes questões na biologia do NO: sua dupla função de potente oxidante e antioxidante efetivo. Esse duplo papel do NO pode depender da concentração e de como se encontra o ambiente. O estresse oxidativo é um resultado comum da ação de muitos fatores ambientais que se manifestam na célula por aumento da quantidade de ROS, enquanto o papel citoprotetor do NO se baseia na habilidade de manter a homeostase da redução e regular o nível de toxicidade das ROS (Boveris et al., 2000; Mackerness et al., 2001; Quian et al., 2009; Wimalasekera et al., 2011 e Hsu \& Lee, 2012)

Portanto, considerando a quantidade de NO produzida nos talos de Gp. tenuifrons na condição de $600 \mu \mathrm{mol}$ de fótons. $\mathrm{m}^{-2} . \mathrm{s}^{-1}$ (uma vez e meia a mais do que o obtido na irradiância de $60 \mu \mathrm{mol}$ de fótons. $\mathrm{m}^{-2} \cdot \mathrm{s}^{-1}$ ) e o que foi explanado anteriormente, pode-se propor que o NO agiu como sinalizador e/ou antioxidante, pois, supõe-se que em Gp. tenuifrons o NO atua sinalizando a resposta antioxidante, seja como mensageiro, coordenando a atividade de compostos antioxidantes, seja ele próprio atuando nesta função.

\section{Referências bibliográficas}

Abat, J. K.; Matoo, A. K.; Deswal, R. 2008. S-nitrosylated proteins of a medicinal CAM plant Kalanchoe pinnata- ribulose-1,5-bisphosphate carboxylase/oxygenase activity targeted for inhibition. FEBS Journal. 275: 2862-2872.

Aguilera, J.; Bischof,K.; Karsten, U.; Hanelt, D.; Wiencke, C. 2002. Seasonal variation in ecophysiological patterns in macroalgae from an Arctic fjord. II. Pigment accumulation and biochemical defence systems against high light stress. Marine Biology. 140: 1087-1095.

Barufi, J. B.; Mata, M. T.; Oliveira, M. C.; Figueroa, F. L. 2012. Nitrate reduces the negative effect of UV radiation on photosynthesis and pigmentation in Gracilaria tenuistipitata (Rhodophyta): the photoprotection role of mycosporine-like amino acids. Phycologia 51: 636-648.

Beligni, MV. \& Lamatina, L. 1999. NO protects against cellular damage produced by methilviologes hebicides in potato plants. NO: Biology and Chemistry. 3: 199-208.

Bhandari, R. \& Sharma, P.K. 2006. High-light-induced changes on photosynthesis, pigments, sugars, lipids and antioxidant enzymes in freshwater (Nostoc spongiaeforme) and marine (Phormidium corium) cyanobacteria. Photochemistry and Photobiology. 82: 702-710. 
Blokhina, O; Virolainen, E.; Fargestedt, K.V. 2003. Antioxidants, oxidative damage and oxygen deprivation stress: a review. Annals of Botany 91: 179-194.

Blokhina, O; \& Fagerstedt, K.V. 2010. Reactive oxygen species and nitric oxide in plant mitochondria: origin and redundant regulatory systems. Physiologia Plantarum 138: 447-462.

Bird, C.J. \& Oliveira, E.C. 1986. Gracilaria tenuifrons sp. nov. (Gigartinales, Rhodophyta), a species from the tropical western Atlantic with superficial spermatangia. Phycologia 25: 313-320.

Boveris, A. D.; Galatro, A.; Puntarulo, S. 2000. Effect of nitric oxide and plants antioxidants on microsomal content lipids radicals. Biol. Res. 33(2): 5p. doi: 104067/S0716-97602000000200016.

Bouchard, J. N. \& Yamasaki, H. 2008. Heat Stress Stimulates Nitric Oxide Production in Symbiodinium microadriaticum: A Possible Linkage between Nitric Oxide and the Coral Bleaching. Phenomenon Plant Cell Physiol. 49(4): 641-652.

Brito, L.L. 1999. Influencia del tratamiento alcalino sobre el agar de Gracilariopsis tenuifrons (Gracilariales: Rhodophyta). Instituto Oceanográfico de Venezuela, Universidad de Oriente, Cumaná, Venezuela. perbrica@telcel.net.ve.67-70.

Brito, L. L. \& Silva, S. 2005. Fenología y ciclo de vida del alga Gracilariopsis tenuifrons (Gracilariaceae) en Sucre, Venezuela. Rev. Biol. Trop. (Int. J. Trop. Biol. ISSN-0034-7744). (www.tropiweb.com). 53: 67-73.

Brugggink, G. T.; Wolting, H. G.; J.; Dasen, H. A.; Bus, GM. 1988. The effect of nitric oxide fumigation at two $\mathrm{CO} 2$ concentrations on net photosynthesis and stomatal resistance of tomato (Lycopersicon lycopersicum L. cv. Abunda). New Phytol. 110: 185-191.

Carvalho, A.M.; Neto, Ana MP.; Tonon, A P.; Pinto, E.Cardozo, K. H.M; Brigagão, M. RPL; Barros, MP; Torres, MA; Magalhães, P;Campos, S. CG; Guaratini, T; SigaudKutner; Falcão, VR; Colepicolo, P. 2004. circadian protection against oxidative stress in marine algae. Hypnos. 1: 142-157.

Chen, H-M \& Yan, X-J. 2005. Antioxidant activities of agaro-oligossacharides with differents degrees of polymerization in cell-based system. Biochimica et Byophysica Acta. 1722. 103-111.

Chow, F.; Pedersén, M.; Oliveira, M.C. 2013. Modulation of nitrate reductase activity by photosynthetic eléctron transport chain and nitric oxide balance on the red macroalga Gracilaria chilensis (Gracilariales, Rhodophyta). Journal of Applied Phycology DOI 10.1007/s10811-013-0005-8.

Cohen, M. F. \& Yamasaki, H. 2003. Involvement of nitric oxide synthase in sucroseenhanced hydrogen peroxide tolerance of Rhodococcus sp. strain APG1, a plantcolonizing bacterium. Nitric Oxide 9: 1-9. 
Collén, J.; Pinto, E.; Pedersén, M.; Colepicolo, P. 2003. Induction of oxidative stress in the red macroalga Gracilaria tenuistipitata by pollutant metals. Archives of Environmental Contamination and Toxicology 45: 337-342.

Couée, I.; Sulmon, C.; Gouesbet, G.; El Amrani, A. 2006. Involvement of soluble sugars in reactive oxygen species balance and responses to oxidative stress in plants. Journal of Experimental Botany 57: 449-459.

Crawford. N. M. 2006. Mechanisms for nitric oxide synthesis in plants. Journal of Experimental Botany.57(3) pp. 471-478.

Delledonne, M.; Zeier, J.; Marocco, A.; Lamb, C. 2001. Signal interactions between nitric oxide and reactive oxygen intermediates in the plant hypersensitive disease resistance response. Proceedings of the National Academy of Sciences, USA 98: 13454-13459.

De Michele, R.; Vurro, E; Rigo, C; Costa,A; Elviri, L; Di Valentin,M; Careri, M; Zottini,M; di Toppi,L. S.; Lo Schiavo, F. 2009. Nitric Oxide Is Involved in CadmiumInduced Programmed Cell Death in Arabidopsis Suspension Cultures. Plant Physiology.150: pp. 217-228.

Dummermuth, A.L.; Karsten, U.; Fisch, K.M.; König, G.M.; Wiencke, C. 2003. Responses of marine macroalgae to hydrogen-peroxide stress. Journal of Experimental Marine Biology and Ecology 289: 103-121.

Foti, MC \& Amorati, R. 2010. Non-phenolic radical-trapping antioxidants. Journal of Pharmacy and Pharmacology. 61:1435-1448.

Foyer, C.H. \& Shigeoka, S. 2011. Understanding oxidative stress and antioxidant functions to enhance photosynthesis. Plant Physiology 155: 93-100.

González, A; Cabrera, M. de los A.; Henríquez, M. J; Contreras, RA; Morales, B; Moenne, A. Cross Talk among Calcium, Hydrogen Peroxide, and Nitric Oxide and Activation of Gene Expression Involving Calmodulins and Calcium-Dependent Protein Kinases inUlva compressa Exposed to Copper Excess. Plant Physiology. 158: pp. 1451-1462.

Halliwell, B. \& Gutteridge, J. M. C.. 1984. Oxygen toxicity, oxygen radicals, transition metals and diseaseBiochem. J. 219, 1-14

Hanelt, D. \& Roleda, M. Y. 2009. UVB Radiation may ameliorate photoinhibition in specific shallow-water tropical. Aquat. Bot. (2009), doi:10.1016/j.aquabot.2008.12.005.

Hayat, S.; Hasan, S.A.; Mori, M.; Fariduddin, Q.; Ahmad, A. 2010. Nitric Oxide: Chemistry, Biosynthesis and Physiological role. Chapter 1. pp. 115-137. In: NO on plant Physiology. Edited by Hayat, S. Mori, M.; Pitchel, J.; Ahmad, A. Wiley-VCH Verlag GmbH \& Co. KGaA, Weinheim.

He, Y; Tang, R-H; Hao, Y; Stevens, RD; Cook, CW; Ahn, SM; Jing, L; Yang, Z.; Chen, L; Guo, F; Fiorani, F; Jackson, B; Crawford, MN; Pei, Z-M. 2004. Nitric Oxide Represses the Arabidopsis Floral Transition. Science: 305:1968-1971. 
Hsu Y-T \& Lee, T-M. 2012. Nitric Oxide up-regulates the expression of methionine sulfoxide reductase genes in the intertidal macroalga Ulva fasciata for high light acclimation. Plant Cell Physiol. 53(2): 445-456.

Hua, Z.; Wen-Biao, S. Lang-Lai, X. 2003. Effects of Nitric Oxide on the Germination of Wheat Seeds and It's Reactive Oxygen Species Metabolisms Under Osmotic Stress. Acta Botanica Sinica 45 (8): 901-905.

Khan, A. U. \& Wilson, T. 1995. Reactive oxygen species as cellular messengers. Chemistry \& Biology. 2:437-445.

Krieger-Liszkay, A; B. Kós, P. B. and Hideg, E. 2011. Superoxide anion radicals generated by methylviologen in photosystem I damage photosystem II. Physiologia Plantarum 142: 17-25.

Karuppanapandian T, Cheol Moon J, Kim C, Manoharan k, Kim W. 2011. Reactive oxygen species in plants: their generation, signal transduction and scavenging mechanisms. Australian Journal of Crop Science. AJCS 5(6): 709-725.

Küpper, F C; Gaquerel, E; Boneberg, E-M; Morath, S; Salaün, J-P; Potin, P. 2006. Early events in the perception of lipopolysaccharides in the brown alga Laminaria digitatainclude an oxidative burst and activation of fatty acid oxidation cascades. Journal of Experimental Botany. 57 (9): pp. 1991-1999.

Laxalt, AM; Raho, N; Have, A.; Lamattina, L. 2007. NO is critical for inducing phosphatidic, acid accumulation in xylanase-elicited tomato cells. Journal of Biological Chemistry. 282: 21160-21168.

Mackerness, SAH; John, CF; Jordan, B.; Thomas, B. 2001. Early signaling components in ultraviolet-B responses: distinct roles for diferent reactive oxygen species and nitric oxide. FEBS . 489: 237-242.

Mallick, N.; Rai, LC; Mohn, F. H.; Soeder, C. J. 1999. Studies on nitric oxide (no) formation by the green alga Scenedesmus obliquus and the diazotrophic cyanobacterium Anabaena doliolum. Chemosphere. 39(10): pp. 1601-1610.

Mallick, N.; Mohn, F. H.; Soeder, C. J.; Grobbelaar, J. U. 2002. Ameliorative role of nitric oxide on $\mathrm{H} 2 \mathrm{O} 2$ toxicity to a chlorophycean alga Scenedesmus obliquus. J. Gen. Appl. Microbiol., 48: 1-7.

Mittler, R.; Vanderauwera, S.; Suzuki, N.; Miller, G.; Tognetti, V.B.; Vandepoele, K.; Gollery, M.; Shulaev, V.; Breusegem, F.V. 2011. ROS signaling: the new wave? Trends in Plant Science.16(6): 300-309.

Monaghan, P.; Metcalfe, N. B.; Torres, R. 2009. Oxidative stress as a mediator of life history trade-offs: mechanisms, measurements and interpretation. Ecology Letters, 12: 75-92.

Morris, S.M.Jr. 2004. Enzymes of Arginine Metabolism. American Society for Nutritional Sciences. 2743-2747. 
Neill, S.J.; Desikan, R.; Clark, A.; Hurst, R.D.; Hancock, J.T. 2002. Hydrogen peroxide and oxide nitric as signalling molecules in plants. Journal of Experimental Botany. 53: $1237-1247$.

Nishiyama, Y; Allakhverdiev,SI; Murata, N. 2011. Protein synthesis is the primary target of reactive oxygen species in the photoinhibition of photosystem II. Physiologia Plantarum 142: 35-46.

O'Cara P. \& Colleran, E. 1970. Separation and identification of Biliverdin, isomers and isomer analysis of phycobilins and bilirubin. Journal of Cromatography. 50: 458-468.

Oliveira Filho, E. C. 1998. Seaweeds resources of Brazil. In: Critchelly A.T. Ohno M. (eds), seaweeds resources of the world. Japan international Cooperation Agency. 366371.

Plastino, E.M. 1991. Cultivo in vitro, estudos reprodutivos e biossistemática de algas gracilarióides (Rhodophyta, Gracilariales) de talo cilíndrico. Universidade de São Paulo. Tese de doutorado.

Qian, H.; Chen, W.; Li, J.; Wang, J.; Zhou Z.; Liu, W.; Fu, Z. 2009. The effect of exogenous nitric oxide on alleviating herbicide damage in Chlorella vulgaris. Aquatic Toxicology 92: 250-257.

Qu, Y; Feng, H; Wang, Y; Zhang,M; Cheng, J; Wang, X; An, L. 2006. NO Functions as a signal in UVB induced inhibition of pea stem elongation. Plant Science. 170: 9941000 .

Raven, J.A. 2011. The cost of photoinhibition. Physiologia Plantarum 142: 87-104.

Rockel, P.; Strube, F.; Rockel, A.; Wildt, J.; Kaiser, W. M. 2002. Regulation of nitric oxide (NO) production by plant nitrate reductase in vivo and in vitro. Journal of Experimental Botany, Vol. 53, No 366, pp. 103-110.

Ross, C; Küpper, FC; Jacobs, RS. 2006. Involvement of Reactive Oxygen Species and Reactive Nitrogen Species in the Wound Response of Dasycladus vermicularis. Chemistry \& Biology.13: 353-364.

Sakihama, Y. Nakamura, S. Yamasaki, H. 2002. NO production mediated by nitrate reductase in green alga Chlamydomonas reinhardtii: na alternative NO production pathway in photosynthetic organisms. Plant Cell Physiology. 43: 290-297.

Sang, J; Jiang, M; Lin, F; Xu, S; Zhang,A; Tan,M. 2008. Nitric Oxide Reduces Hydrogen Peroxide Accumulation Involved in Water Stress-induced Subcellular Antioxidant Defense in Maize Plants. Journal of Integrative Plant Biology. 50(2): 231-243.

Scandalios, J.G. 2005. Oxidative stress: molecular perception and transduction of signals triggering antioxidant gene defenses. Braz. J. Med. Biol. Res. 38: 995-1014.

Schluchter, W.M. \& Glazer, A.N. 1999. Biosynthesis of phycobiliproteins in cyanobacteria. In: The Phototrophyc Prokaryotes. Ed. By Peschek et al. Plenum Plubshers, New York. http://books.google.com.br/books. 
Shi, S.; Wang, G.; Wang, Y.; Zhang, L.; Zhang. L. 2005. Protective effect of nitric oxide against oxidative stress under ultraviolet-B radiation. Nitric Oxide 13: 1-9.

Steinhoff, S.F; Graeve, M; Bartoszek, K.; Bischof, K.; Wiencke, C. 2012. Phlorotannin Production and Lipid Oxidation as a Potential Protective Function Against High Photosynthetically Active and UV Radiation in Gametophytes ofAlaria esculenta(Alariales, Phaeophyceae). Photochemistry and Photobiology. 88: 46-57.

Stieger, P.A. \& Feller, U. 1997. Requirements for the light-stimulated degradation of stromal proteins in isolated pea (Pisum sativum L. ) chloroplasts. Journal of Experimental Botany. 48(314): pp.1639-164.

Talarico, L \& Maranzana, G. 2000. Light and adaptive responses in red macroalgae: an overview. Journal of Photochemistry and Photobiology B: Biology 56: 1-11.

Takahashi, S. \& Yamasaki, H. 2002. Reversible inhibition of photophosphorilation in chloroplasts by NO. FEBS Letters.512: 145-148.

Tian, Q-Y. Sun,D-H; Zhao, M-G; Zhang, W-H. 2007. Inhibition of nitric oxide synthase (NOS) underlies aluminum-induced inhibition of root elongation in Hibiscus moscheutos. New Phytologist. 174: 322-331.

Torres, P. 2012. Análise de pigmentos fotossintetizantes e substâncias fenólicas em Gracilariopsis tenuifrons (C. J. Bird \& E. C. Oliveira) Fredericq \& Hommersand em diferentes intensida-des de luz . Dissertação (Mestrado) - Instituto de Biociências da Universidade de São Paulo. Departamento de Botânica. 104 páginas.

Torres, J.; Rivera, A; Clark, G; Roux, S.J. 2008. Participation of extra cellular nucleotides in the wound response of Dasycladus vermicularis and Acetabularia acetabulum (DASYCLADALES, CHLOROPHYTA). J. Phycol. 44:1504-1511.

Tun, N.N.; Holk, A.; Scherer, G.F.E. 2001. Rapid increase of NO release in plant cell cultures induced by cytokinin. FEBS Lett. 509: 174-176.

Tossi, V; Amenta, M; Lamattina,L; Cassia; R. 2011. Nitric oxide enhances plant ultraviolet-B protection up-regulating gene expression of the phenylpropanoid biosynthetic pathway. Plant, Cell and Environment.34: 909-921.

Vass, I. 2011. Role of charge recombination processes in photodamage and photoprotection of the photosystem II complex. Physiologia Plantarum 142: 6-16.

Wodala, B. Combined effects of nitric oxide and cyanide on the photosynthetic electron transport of intact leaves. Acta Biologica Szegediensis. 50(3-4):185.

Wanderley, A. 2009. Influência da disponibilidade de nitrato sobre crescimento, atividade da nitrato redutase, composição química e captação de nitrato e fosfato em Gracilariopsis tenuifrons (Gracilariales, Rhodophyta). Universidade de São Paulo. Dissertação de mestrado. 140 p.

Wimalasekera, R.; Tebartz, F.; Scherer, G. F.E. 2011. Polyamines, polyamine oxidases and NO in development, abiotic and biotic stress.Plant Science. 181: 593-603. 
Wink, D A; Hanbauer,I; Krishna, Mc; Degraff, W; Gamson, J; Mitchell, J.B. 1993. Nitric oxide protects against cellular damage and cytotoxicity from reactive oxygen species. Proc. Natl. Acad. Sci. USA. 90: pp. 9813-9817.

Xu, Y; Sun, X; Jin,J; Zhou, H. 2010. Protective effect of NO on light-induced oxidative damage in leaves of tall fescue. Journal of Plant Physiology. 167: 512-518.

Xu, J.; Wang, W; Yin, H; Liu, X; Sun, H; Mi, Q. 2010. Exogenous nitric oxide improves antioxidative capacity and reduces auxin degradation in roots of Medicago truncatula seedlings under cadmium stress. Plant Soil. 326:321-330.

Zar, J.H. 1999. Biostatistical analysis. Prentice Hall, Englewood Cliffs, New Jersey. 471p.

Zeidler, D; Zarhringer, U; Gerber, I; Dubery, I; Hartung, T; Bors, W; Hutzeler, P; Durner, J. 2004. Innate immunity in Arabidopsis thaliana: Lipopolysaccharides activate nitric oxide synthase (NOS) and induce defense genes. PNAS. 101 (44):15811-15816. 


\section{Discussão geral}

O presente trabalho contribui para projeto de pesquisa da Dra. Fungyi Chow intitulado "Fisiologia integrativa de macroalgas: estudo exploratório da biodiversidade química" (FAPESP 10/02948-3). Os resultados se integram a outros trabalhos de iniciação científica, mestrado e doutorado orientados pela Dra. Fungyi focados em estudos das respostas fisiológicas de macroalgas em condições de estresse e caracterização de perfil químico.

Com o objetivo de caracterizar em laboratório o padrão fisiológico de Gracilariopsis tenuifrons referente a atividade oxidante e antioxidante, as algas foram expostas a luminosidade normal de $60 \mu \mathrm{mol}$ de fótons. $\mathrm{m}^{-2} \cdot \mathrm{s}^{-1}$ e elevada de $600 \mu \mathrm{mol}$ de fótons. $\mathrm{m}^{-2} \cdot \mathrm{s}^{-1}$, tendo alcançado os objetivos de estabelecimento de protocolos $\mathrm{e}$ avaliação das respostas de taxa de crescimento, teor de pigmentos fotossintetizantes e de proteínas solúveis totais, atividade antioxidante, quantidade de compostos fenólicos totais e produção de NO. Além disso, avaliações excedentes (conteúdo tecidual de carbono, hidrogênio e nitrogênio e quantificação das ROS) foram realizadas e permitiram maiores inferências acerca das respostas de Gp. tenuifrons à alta PAR

Assim sendo, foi observado que o excesso de irradiância nos ápices de $G p$. tenuifrons provocou respostas de aclimatação que conduzem à ativação de diversos mecanismos de proteção contra estresse oxidativo. $\mathrm{O}$ estresse oxidativo foi denunciado pela redução de pigmentos fotossintetizantes, proteínas e nitrogênio tissular, elevação do carbono e hidrogênio tissulares, das substâncias fenólicas, da atividade antioxidante total e da quantidade produzida de NO. Por outro lado, os mecanismos de defesa antioxidativo pareceram atuar na proteção e manutenção da alga, porque aparentemente, esses mecanismos junto com outros sistemas de defesa não avaliados no trabalho atuaram de forma eficiente para reduzir a quantidade de ROS, tendo em vista a similaridade entre os tratamentos, aspecto que se refletiu na resposta da taxa de crescimento, que também não sofreu alteração entre os tratamentos.

Dentro da dinâmica relacionada ao estresse luminoso, o NO se destaca, pois este composto tem por característica interagir de várias maneiras na célula, age diretamente como antioxidante, modulador da formação de enzimas e substâncias antioxidantes, inibidor da peroxidação lipídica, regulando a toxicidade das ROS, permitindo assim a manutenção da homeostase da célula (Boveris et al., 2000). Além disso, alguns autores (Bruggink et al., 1988; Mallick et al., 2002; Takahashi \& Yamasaki, 2002; Bouchard et al., 2008; Wodala 2006; Abat et al., 2008) concordam que o NO em resposta a alta 
irradiância mitiga os efeitos do excesso de irradiância no sistema fotossintetizante, estimulando a degradação de pigmentos fotossintetizantes como ficobiliproteínas, clorofila e carotenoides.

Os resultados mostraram que Gp. tenuifrons sob alta irradiância teve decréscimo dos pigmentos fotossintetizantes. Esses pigmentos sofreram degradação, podendo disponibilizar suas fontes nitrogenadas para alocação e síntese de substâncias de natureza antioxidante, como aminoácidos tipo micosporinas (MAAs) e NO. Essas fontes nitrogenadas podem seguir a mesma rota que a bilirrubina, um composto animal com características semelhantes às ficobiliproteínas (O'Carra \& Colleran, 1970; Schluchter \& Glazer, 1999). Assim, sob ação de radicais peroxil, a bilirrubina $\left(\mathrm{C}_{33} \mathrm{H}_{36} \mathrm{O}_{6} \mathrm{~N}_{4}\right)$ doa um hidrogênio e forma um composto $\mathrm{N}^{*}$ (Foti \& Amorati, 2010), que pode ser oxidado novamente para originar compostos nitrogenados inorgânicos $\left(\mathrm{NO}_{3}{ }^{-}\right.$, $\mathrm{NO}_{2}{ }^{-}, \mathrm{NH}_{4}{ }^{+}$), que dependendo das condições celulares podem facilmente ser convertidos em NO. Este último poderia atuar como mensageiro e sinalizador para ativar os mecanismos de defesa antioxidante (Bouchard et al., 2008). Situação semelhante foi observada por Barufi et al. (2012) estudando o efeito da limitação de nitrogênio, UVR e PAR em Gracilaria tenuistipitata, propuseram que a disponibilidade total de nitrogênio, em situação de escassez de nitrogênio e presença de UVR, é mobilizada para a síntese de compostos absorvedores de UVR, como os MAAs. Além disso, Huovinen et al. (2006) estudando Grateloupia lanceola e Shanab et al. (2012) estudando cianobactérias, perceberam que ao adicionar maior quantidade de nitrato e compostos nitrogenados no meio de cultura, ocorreu incremento de ficobiliproteínas e elevação na atividade antioxidante.

A clorofila também sofre com o excesso de luz, que conduz a um "branqueamento"(desgaste) da clorofila e/ou degradação de proteínas dos centros de reação dos fotossistemas PSI e PSII. Essa degradação dos pigmentos ocasiona redução da absorção de fótons (700 nm) (Sonoike, 2010; Keren \& Krieger-Liszkay, 2011). Este comportamento pode indicar que a dissociação dos pigmentos (Talarico \& Maranzana, 2000; Muramatsu \& Hihara, 2012; Tamary et al., 2012), como um mecanismo de proteção do aparelho fotossintetizante, junto com o aumento das ROS sejam o primeiro sinal para o disparo de respostas contra o estresse oxidativo (Khan \& Wilson, 1995; Mittler et al., 2011).

Relacionando os carotenoides aos estímulos da luz, estes pigmentos parecem ser substâncias mais estáveis que os outros pigmentos, pois comparativamente com 
ficobiliproteínas e clorofila, apresentou as menores perdas de conteúdo. Os carotenoides apresentam papel regulatório da atividade de fotossíntese sob estresse luminoso, dissipando excesso de energia através de fluorescência; e sua livre localização na membrana lipídica dos cloroplastos pode facilitar seu desempenho na extinção das ROS (Schubert \& Mendoza-García, 2008).

Ademais, o espessamento da parede de células de Gp tenuifrons e o aumento de carbono e hidrogênio nos ápices apontaram possível acúmulo de açúcares, que provavelmente funcionaram como barreira física contra a irradiância e/ou estoque energético, e ainda como antioxidantes. Adicionalmente, Chen \& Yan (2005) demonstraram que os polissacarídeos de algas conferem bom potencial de proteção para as células, pois promoveram a diminuição de $\mathrm{H}_{2} \mathrm{O}_{2}$.

Assim, embora as macroalgas vermelhas não sejam consideradas boas produtoras de substâncias antioxidantes, Gp. tenuifrons exposta a alta PAR apresentou aumento na sua capacidade antioxidante, com elevado teor de compostos fenólicos. Deste modo, os ápices de Gp tenuifrons expostos à condição de $600 \mu \mathrm{mol}$ fótons. $\mathrm{m}^{-2} . \mathrm{s}^{-1}$ pelo período de uma semana, embora tenha configurado estresse, não confirmou fotoinibição devido aos diversos mecanismos envolvidos com a resposta a intensa irradiância, como absorção e dissipação de energia, estoque e rápida disponibilização de macronutrientes e a capacidade de produzir substâncias capazes de atrasar as reações de oxidação.

Portanto o trabalho buscou contribuir com a adição de conhecimento para a fisiologia do estresse, principalmente sobre atividade antioxidante em macroalgas que são escassos no litoral brasileiro e em ambientes tropicais e subtropicais. Do ponto de vista fisiológico, esses resultados são valiosos para a compreensão do metabolismo da alga e podem ser relacionados à alterações de cunho climático. Além de fornecer dados inéditos sobre produção de NO em macroalgas em condições de alta irradiância. E avaliar e estabelecer vários protocolos metodológicos para Gp. tenuifrons e para uso geral de abordagens fisiológicas no Laboratório de Algas Marinhas "Édison José de Paula", dentre eles metodologias de atividade antioxidante total pelo método do sequestro do radical DPPH, atividade antioxidante pelo sistema $\beta$-caroteno/ácido linoleico, compostos fenólicos totais pelo método do Folin-Ciocalteau, detecção intracelular por fluoróforo de ROS e NO. Do ponto de vista prático, os resultados deste trabalho demonstraram que Gp. tenuifrons tem habilidade para alterar sua capacidade antioxidante sob condições de estresse e elevada luminosidade. Dessa forma, é possível 
que o conhecimento produzido auxilie na produção da alga, bem como para sua utilização na indústria alimentícia, medica, farmacêutica e cosmética.

\section{Referências Bibliográficas (parte II)}

Abat, J. K.; Matoo, A. K.; Deswal, R. 2008. S-nitrosylated proteins of a medicinal CAM plant Kalanchoe pinnata- ribulose-1,5-bisphosphate carboxylase/oxygenase activity targeted for inhibition. FEBS Journal. 275: 2862-2872.

Barufi, J. B.; Mata, M. T.; Oliveira, M. C.; Figueroa, F. L. 2012. Nitrate reduces the negative effect of UV radiation on photosynthesis and pigmentation in Gracilaria tenuistipitata (Rhodophyta): the photoprotection role of mycosporine-like amino acids. Phycologia 51: 636-648.

Bouchard, J. N. \& Yamasaki, H. 2008. Heat Stress Stimulates Nitric Oxide Production in Symbiodinium microadriaticum: A Possible Linkage between Nitric Oxide and the Coral Bleaching. Phenomenon Plant Cell Physiol. 49(4): 641-652.

Boveris, A. D.; Galatro, A.; Puntarulo, S. 2000. Effect of nitric oxide and plants antioxidants on microsomal content lipids radicals. Biol. Res. 33(2): 5p. doi: 104067/S0716-97602000000200016.

Bruggink, G. T.; Wolting, H. G.; Dassen, J. H. A.; Bus, V. G. M. 1988. The Effect of Nitric Oxide Fumigation at Two CO2 Concentrations on Net Photosynthesis and Stomatal Resistance of Tomato (Lycopersicon lycopersicum L. cv. Abunda). New Phytologist, 110 (2): 185-191.

Chen, H-M. \& Yan, X-J. 2005 Antioxidant activities of agaro-oligosaccharides with different degrees of polymerization in cell-based system. Biochimica et Biophysica Acta 1722: 103-111.

Foti, M. C. \& Amorati, R. 2009. Non-phenolic radical-trapping antioxidants. Journal of Pharmacy and Pharmacology 61: 1435-1448.

Huovinen, P. Matos, J.; Pinto, I. S.; Figueroa, F. L. 2006. The role of ammonium in photoprotection against high irradiance in the red alga Grateloupia lanceola. Aquatic Botany 84: 308-316.

Keren, N.; Krieger-Liszkay, A. 2011. Photoinhibition: molecular mechanisms and physiological significance Physiologia Plantarum 142: 1-5.

Khan, A. U. \& Wilson, T. 1995. Reactive oxygen species as cellular messengers. Chemistry \& Biology. 2:437-445.

Mallick, N.; Mohn, F. H.; Soeder, C. J.; Grobbelaar, J. U. 2002. Ameliorative role of nitric oxide on $\mathrm{H} 2 \mathrm{O} 2$ toxicity to a chlorophycean alga Scenedesmus obliquus. J. Gen. Appl. Microbiol., 48: 1-7.

Mittler, R.;Vanderauwera, S.; Suzuki, N.; Miller, G.; Tognetti, V. B.; Vandepoele, K.; Marty Gollery, M.; Shulaev, V.; Breusegem, F. V. 2011. ROS signaling: the new wave? Trends in Plant Science. 16(6):300-309. 
Muramatsu, M. \& Hihara, Y. 2012. Acclimation to high-light conditions in cyanobacteria: from gene expression to physiological responses. J Plant Res. 125:1139.

Schubert, N. \& Mendoza-García, E. 2008. Photoinhibition in Red Algal Species With Different Carotenoid Profiles. J. Phycol. 44:1437-1446.

Shanab, S. M.M.; Mostafa, S. S. M.; Shalaby, E. A.; Mahmoud, G. I. 2012. Aqueous extracts of microalgae exhibit antioxidant and anticancer activities. Asian Pacific Journal of Tropical Biomedicine 608-615.

Sonoike, K. 2011. Photoinhibition of photosystem I. Physiologia Plantarum 142: 56-64.

Takahashi, S. \& Yamasaki, H. 2002. Reversible inhibition of photophosphorilation in cloroplasts by nitric oxide. FEBS Letters 512: 145-148.

Talarico, L \& Maranzana, G. 2000. Light and adaptive responses in red macroalgae: an overview. Journal of Photochemistry and Photobiology B: Biology 56: 1-11.

Tamary, E.; Kiss, V.; Nevo, R.; Adam, Z.; Bernát,G. Rexrorth, S.; Rögner, M.; Reich, Z. 2012. Structural and functional alterations of cianobacterial phycobilissomes induced by high light stress. Biochimica et Biophysica Acta. 1817: 319-327.

Wodala, B. 2006. Combined effects of nitric oxide and cyanide on the photosynthetic electron transport of intact leaves. Acta Biologica Szegediensis 50 (3-4):185. 